MAYNARA LUCCA ANDRADE

mTORC1 é um importante mediador do aumento de adiponectina sérica e do metabolismo de BCAA no tecido adiposo induzido pela rosiglitazona

São Paulo

2019 


\section{MAYNARA LUCCA ANDRADE}

mTORC1 é um importante mediador do aumento de adiponectina sérica e do metabolismo de aminoácidos de cadeia ramificada no tecido adiposo induzidos pela rosiglitazona

Tese apresentada ao Programa de PósGraduação em Fisiologia e Biofísica do Instituto de Ciências Biomédicas da Universidade de São Paulo, para obtenção do título de Doutor em Ciências.

Orientador: Prof. Dr William Tadeu Lara

Festuccia

Versão Corrigida

São Paulo 


\section{CATALOGAÇÃO NA PUBLICAÇÃO (CIP) Serviço de Biblioteca e informação Biomédica do Instituto de Ciências Biomédicas da Universidade de São Paulo}

Ficha Catalográfica elaborada pelo(a) autor(a)

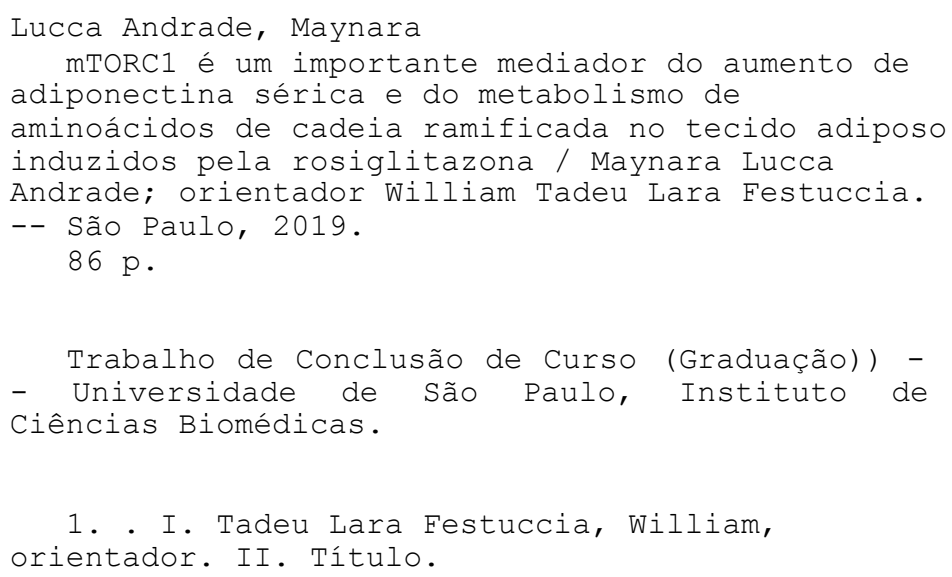


Candidato(a): Maynara Lucca Andrade

Titulo da Dissertação/Tese: mTORC1 é um importante mediador do aumento de adiponectina sérica e do metabolismo de aminoácidos de cadeia ramificada no tecido adiposo induzidos pela rosiglitazona

Orientador: William Tadeu Lara Festuccia

A Comissão Julgadora dos trabalhos de Defesa da Dissertação de Mestrado/Tese de Doutorado, em sessão publica realizada a ..........................., considerou o(a) candidato(a):

\section{( ) Aprovado(a) ( ) Reprovado(a)}

Examinador(a):

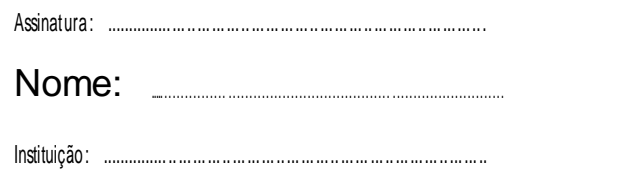

Examinador(a):

Assinatura:

Nome:

Insititução:

Examinador(a):

Assinatura:

Nome:

Insitiuição:

Presidente:

Assinatura:

Nome:

Insitiuição: 


\section{CERTIFICADO}

Certificamos que o projeto intitulado "Caracterização do envolvimento do sensor de nutrientes mTOR no desenvolvimento de doenças metabólicas crônicas associadas a obesidade", registrado sob o protocolo ne 115/2016, que envolve à produçầo, manutençăo e/ou utilizaçằo de ànimais pertencentes ao filo chordata, subfilo Vertebrata (exceto o homem), para fins de Pesquisa Cientifico, encontra-se de acordo com os preceitos da Lei ñ 11.794 , de 8 de outubro de 2008, do Decreto $n^{2} 6.899$, de 15 de julho de 2009 , e com as normas editadas pelo Conselho Nacional de Controle e Experimentaçăo Animal (CONCEA). Ante esta conformidade, o referido projeto foi avaliado e aprovado em 24/09/2016 pela COMISSÄO DE ÉTICA NO USO DE ANIMAIS do Instituto de Ciências Biomédicas da Universidade de São Paulo (CEUA-ICB/USP), outorgando esta licença de uso de animais com validade de 4 ano(s) a partir da data de aprovação.

- Investigador Principal: Dr.(a.) William Tadeu Lara Festuccia

- Departamento: Fisiologia e Biofisica

- Membros da Equipe: Thiago Belchior (Pós doutorando), Fernanda Janku Cabral (Pós doutorando), Alex Shimura Yamashita (Pós-doutorando), Juliana Magdalon (Pós graduando), Maynara Lucca Andrade (Pós-graduando), Rafael Junges Moreira (Pós graduando). Tiago Eugénio de Oliveira da Silva (Pós-graduando), Erique de Castro (Pósgraduando), Milene Ortiz silva (Pós-graduando). Thayna dos Santos Vieira (Treinamento técnico), Carlos Mario Donado Pestana (Pós-doutorando)

Ao final do período outorgado por esta licença, o pesquisador responsável deverá encaminhar a esta comissão, atế o ủltimo dia de validade da atual propostā, relatôrio final de acordo com a Resolução Normativa CONCEA n 30/2016 - Diretriz Brasileira para o Cuidado e a Utilização de Animais em Atividades de Ensino ou de Pesquisa Cientifica (DBCA), conforme modelo constante no endereço eletrônico wwwicb usp.br/ceua. Havendo interesse na renovação do projeto, a solicitação devera ser protocolada pela Secretaria da CEUA-ICB/USP atê o



\section{CERTIFICATE}

We hereby certify that the project entitled "Involvement of the nutrient sensor mTOR in the development of obesity associated chronic metabolic diseases", protocol ne 115/2016, which involves the production, maintenance and/or use of animals belonging to the phylum Chordata, subphylum Vertebrata (except human), for Scientific Research Purposes, is in accordance with the provisions of the Law $\mathrm{n} 211.794$ passed on October $8^{\text {th }}, 2008$, Decree $n$ ㅇ 6899 passed on July $15^{t *}, 2009$, and the rules issued by the National Council for Control and Animal Experimentation (CONCEA). According to this legislation, the project was evaluated and approved on 9/24/2016 by the ETHICS COMMITTEE ON ANIMAL. USE, Institute of Biomedical Sciences, University of Sao Paulo (CEUA-ICB/USP), and the license for animal use is valid for 4 year(s) from the date of approval.

- Principal Investigator: Dr.(a.) William Tadeu Lara Festuccia

- Team members: Thiago Belchior (Postdoctoral Researcher), Fernando Janku Cabral (Postdoctoral Researcher), Alex Shimura Yamashita (Postdactoral Researcher), Juliana Magdalon (Graduate Student), Maynara Lucca Andrade (Graduate Student), Rafael Junges Moreira (Groduate Student), Tiago Eugênio de Oliveira da Silva (Graduate Student), Erique de Castro (Graduate Student), Milene Ortiz Silva (Graduate Student), Thayna dos Santos Vieira (Technical Trainee), Carlos Mario Donado Pestana (Postdoctoral Researcher).

At the end of the period granted by this license, the Principal Investigator must submit a final report of the project to this committee, according to the Rule n 30 and the Diretriz Brasileira para o Cuidado e a Utilizaçăo de Animais em Atividades de Ensino ou de Pesquisa Cientifica (DBCA) issued by the CONCEA. If a renewal of the project is intended, the request must be submitted to the CEUA-ICB/USP secretary before the expiration of the current proposal: After this date, a new proposal must be prepared.

\begin{tabular}{|c|c|c|c|c|}
\hline $\begin{array}{l}\text { Espécie/ } \\
\text { Species }\end{array}$ & Linhagem/Strain & Sexo/Gender & $\begin{array}{l}\text { Idade-Peso/ } \\
\text { Age-Weight }\end{array}$ & Total \\
\hline $\begin{array}{l}\text { Mus } \\
\text { musculus }\end{array}$ & 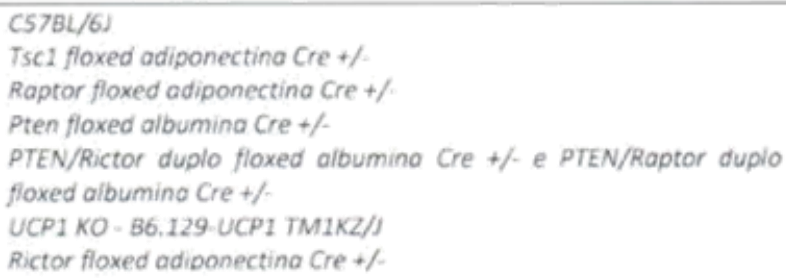 & $\begin{array}{l}\text { Mocho/Male } \\
\text { Mocho/Male } \\
\text { Macho/Male } \\
\text { Macho/Male } \\
\text { Mocho/Male } \\
\text { Mocho/Male } \\
\text { Mocho/Male }\end{array}$ & $\begin{array}{l}8 \text { semonas/weeks } \\
8 \text { semonas/weeks } \\
8 \text { semanas/weeks } \\
8 \text { semonas/weeks } \\
8 \text { semonas/weeks } \\
8 \text { semonas/weeks } \\
8 \text { semonos/weeks }\end{array}$ & $\begin{array}{l}230 \\
140 \\
80 \\
80 \\
90 \\
160 \\
40\end{array}$ \\
\hline
\end{tabular}




\section{COMISSAO DE ETICA NO USO DE ANIMAIS \\ INSTITUTO DE CIENCIAS BIOMEDICAS \\ UNIVERSIDADE DE SÄO PAULO}

Av. Professoritineu Prestes 2415 . CB iill 05508000 CEUA-ICBIUSP Telefone (1,1) 3091,7333 e-mail cep (q)



São Paulo, 26 de setembro de 2016.

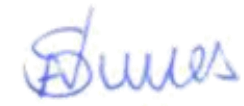

Prof: Dr, Anderson de Sá Nunes Coordenador CEUA-ICB/USP

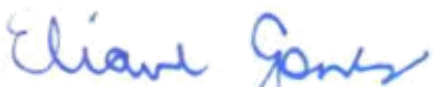
Eliane Aparecida Gomes de M. Nascimento Secretária CEUA-ICB/USP 
Às duas mulheres da minha vida, Vó Zalina (in memoriam) e Rosária 


\section{AGRADECIMENTOS}

A jornada percorrida durante um Doutorado só se torna possível porque existem pessoas nos dando suporte (orientador, família e amigos), e sem os quais qualquer jornada se tornaria ineficiente e vazia de propósito. Acredito que o mais importante não é o término da jornada, mas a maneira de que ela foi conduzida e o quanto isso contribui ao nosso redor. Minha jornada foi repleta de pessoas especiais com quem aprendi e ensinei que o que mais importa são as pessoas e o bem-estar de cada um. Logo, o sentimento de gratidão ao fim desse ciclo é verdadeiro!!

Em primeiro lugar, e mais importante, deixo aqui meu eterno e imensurável agradecimento aos meus pais (Rosária e Talmor) por contribuírem com o meu desenvolvimento desde meus primeiros passos até hoje, e por serem compreensivos nos meus inúmeros momentos ausentes da família em virtude do meu objetivo. Em especial minha mãe, que sempre incentivou e acreditou na minha jornada rumo aos meus so nhos, mesmo que isso significasse a minha distância cada vez maior, além de ser meu maior exemplo de amor que tive na vida!!! Aos meus irmãos, Tharyan e Thayane, que sempre se fazem presentes e conectados independente da distância que nos separa. Amo todos vocês!

Agradeço imensamente ao professor William Festuccia, por quem tenho uma enorme admiração quanto ao seu trabalho desenvolvido junto à Ciência. Obrigada por permitir juntarme à sua equipe de maneira tão receptiva, por me ensinar a fazer uma pesquisa séria e comprometida, por me dar suporte ao longo dessa trajetória e contribuir com meu crescimento científico. Por ter paciência comigo também!!! Muito obrigada!!!

Aos meus colegas de laboratório: Alex Shimura, Fernanda Janku, Vivian Paschoal, Patrícia Chimin, Rafael Junges, Érique Castro, Tiago Eugênio -Chicoll, Milene Ortiz, Mayara Moreno, Gustavo Gilio, Albert Souza, Adriano Brito, Carol Tomazelli, Thayná Vieira. Em especial aos colegas que se tornaram ami gos de coração pra vida: Thiago Belchior e Juliana Magdalon. Todos vocês contribuíram para momentos inesquecíveis e muito felizes, tornando-se uma família científica. Muito obrigada a todos vocês, por tornarem o caminho mais leve e rico de aprendizado! Vocês são pesquisadores brilhantes!

Aos membros do laboratório da professora Sayuri, bem como a própria professora Sayuri Myamoto, onde tive a felicidade e oportunidade única de aprender mais sobre o universo dos lipídeos. Obrigada Isa, Alex, Dri, Lucas... Em especial, ao Marcos Yoshinaga, por me ensinar mais do que análise de lipídeos, ser sempre tão solícito e por não me deixar desanimar perante as dificuldades do caminho. Muito Obrigada!!!! 
Aos meus amigos da vida, que ajudam a nos manter firmes perante todas as dificuldades e quem nos faz lembrar de onde viemos e pra onde devemos ir. João Esteves, Ana Cláudia Pelissari, Débora Guariglia, Gi Bueno, Nayara Caruzzo, Solange Franzói e Sidney Peres. Em especial à Janayna Dias Lima, com quem vivi e aprendi lições que transcendem qualquer Doutorado. Muito obrigada a todos, vocês são muito importantes pra $\operatorname{mim} ! ! !$

Ao Rafael Prado, por me apoiar e ensinar a ser uma pessoa melhor! Obrigada.

Aos professores Evan Rosen e Linus Tsai (Harvard Medical School- Boston) que me deram a oportunidade ímpar de aprender e conviver com cientistas dedicados dos mais diferentes lugares do mundo. Aos membros do laboratório do Rosen/Tsailab: Deepti, Luhong, Anlu, Shuai, Suraj, Frankie, Margot, Hyun, Jin, Erwei, Tyler, Adam, Nufar, Chris e Rachel. Além dos membros do laboratório do professor Alex Banks: Deepti, Yuchen, Jessy e June. Obrigada a todos pela oportunidade de aprender muito!

Agradeço também aos funcionários do ICB-USP que nos dão suporte durante todo o processo na pós-graduação: Zé Maria, Paloma, Leila, Tarcísio, Bob, Seu Pena, Renata. Muito obrigada!

Por fim, gostaria de registrar um agradecimento póstumo, à minha vó Zalina, que sem dúvida foi grande responsável pela minha caminhada até aqui. Sua profissão de educadora me norteou ao caminho escolhido bem como a forma de trilhar esse caminho. Quem me ensinou a ler antes de todos, pacientemente treinando ditado de palavras e leitura. Além de me permitir ter um ensino de qualidade durante todo meu período escolar. Seu legado jamais será esquecido! Muito obrigada! Te amo. 


\section{APOIO FINANCEIRO}

O presente trabalho teve apoio do CNPQ (processo 166034/2014-2) e FAPESP (processo 2015/13508-8). 
"O essencial é invisível aos olhos."

Antoine de Saint-Exupéry 
ANDRADE, M.L. mTORC1 é um importante mediador do aumento de adiponectina sérica e do metabolismo de BCAA no tecido adiposo induzido pela rosiglitazona.[tese]São Paulo. Instituto de Ciências Biomédicas, 2019.

\section{Resumo}

As tiazolidinedionas (TZDs), ligantes sintéticos dos receptores nucleares PPAR $\gamma$, têm sido amplamente utilizadas no tratamento da resistência à insulina, dislipidemias e síndrome metabólica. Estas drogas melhoram a homeostase da glicose promovendo redistribuição de gordura dos estoques viscerais para o subcutâneos, aumento da secreção de adiponectina, redução da lipemia, lipotoxicidade e da inflamação do tecido adiposo. Um estudo recente mostrou que o tratamento de ratos com a TZD rosiglitazona (RSG) aumenta a atividade dos complexos 1 e 2 da mTOR, que desempenham função importante no controle do metabolismo lipídico, adiposidade e função endócrina do tecido adiposo. Assim, o presente estudo teve como objetivo central elucidar o envolvimento especificamente do complexo 1 da mTOR de adipócitos nas alterações morfológicas, metabólicas e secretórias do tecido adiposo branco e marrom induzidas pela ativação farmacológica de PPAR $\gamma$ em camundongos. Para isto, camundongos com deleção de raptor (mTORC1) exclusivamente em adipócitos alimentados com dieta hiperlipídica foram tratados ou não com RSG (30 mg/kg/dia) por 8 semanas. Nossos dados mostraram que tanto o mTORC1 quanto o agonista de PPAR $\gamma$ são importantes reguladores da adiposidade. A deficiência de mTORC1 em adipócitos reduziu as massas de todos os tecidos adiposos investigados, enquanto o tratamento com RSG reduziu a massa somente dos depósitos de gordura viscerais retroperitoneal a epididimal e aumentou significativamente a massa do tecido adiposo marrom, efeito esse que foi completamente abolido pela deficiência do complexo 1 da mTOR. Deficiência de mTORC1 em adipócitos promoveu aumento no conteúdo de UCP1 (expressão gênica e proteica), efeito este que não foi alterado pelo tratamento com RSG. Outros efeitos de RSG mostraram-se dependentes de mTORC1 como o aumento de porcentagem de adipócitos de área média, aumento dos níveis de adiponectina e redução dos níveis de aminoácidos de cadeia ramificada (BCAA) séricos, bem como o aumento da expressão gênica de CD36 e PEPCK e do conteúdo de cardiolipinas e ceramidas de cadeia longa, lipídeos que constituem a membrana mitocondrial interna e atuam como mediadores inflamatórios, respectivamente. Por outro lado encontramos efeitos de RSG independentes de mTORC1, como a redução nos níveis séricos de triacilglicerol, redução da expressão gênica de fatores inflamatórios, como IL1 $\beta$ e TNF $\alpha$, NLRP3, DUSP6, além de PGC1 $\alpha$ e FAS, insulina plasmática e melhora na homeostase glicêmica. Concluímos 
assim que mTORC1 em adipócitos é importante mediador de algumas ações específicas induzidas pela ativação farmacológica de PPAR $\gamma$ com RSG como a secreção de adiponectina e o aumento do metabolismo oxidativo de BCAA no tecido adiposo.

Palavras-chave: mTOR; PPAR $\gamma$; rosiglitazona; adiposidade; mitocôndria; lipídeos; inflamação 
ANDRADE, M.L. mTORC1 is an important mediator of the increase in serum adiponectin and BCAA metabolism in adipose tissue induced by rosiglitazone.[thesis]São Paulo.Biomedical Sciences Institute -USP, 2019.

\section{Abstract}

Thiazolidinediones (TZDs), synthetic ligands of nuclear receptors PPAR $\gamma$, have been widely used in the treatment of insulin resistance, dyslipidemia and metabolic syndrome. These drugs improve glucose homeostasis by promoting redistribution of fat from visceral to subcutaneous depots, by increasing adiponectin secretion and reducing lipemia, lipotoxicity, and adipose tissue inflammation. A recent study showed that treatment of rats with TZD rosiglitazone (RSG) increases the activity of mTOR complexes 1 and 2, which play an important role in the control of lipid metabolism, adiposity and endocrine function of adipose tissue. Thus, we investigated herein the specific involvement of adipocyte mTOR complex 1 in the morphological, metabolic and secretory alterations of white and brown adipose tissue induced by pharmacological activation of PPAR $\gamma$ in mice. For this, mice with raptor deletion (mTORC1) exclusively in adipocytes and littermate controls were fed a hyperlipidic diet and treated or not with RSG (30 mg/ kg/ day) for 8 weeks. Our data showed that both mTORC1 and PPAR $\gamma$ agonist are important adiposity regulators. Indeed, mTORC1 deficiency in adipocytes reduced the mass of all adipose depots investigated, while RSG reduced the masses of visceral fat depots retroperitoneal and epididymal only and markedly increased brown adipose tissue mass, such an effect that was blocked by mTOR 1 complex deficiency. mTORC1 deficiency in adipocytes increased UCP1 content (gene and protein expression). Interesting, RSG lost its ability to reduce the percentage of smaller adipocytes, to increase serum levels of adiponectin and reduce those of branched chain amino acids (BCAA), as well as to increase mRNA levels of CD36 and PEPCK, mitochondrial lipids such as cardiolipin and lipid mediators as long chain ceramides in white adipose tissue in the absence of mTORC1 activity. Other effects of RSG such as reducing serum triacylglycerol (TAG) and insulin levels, adipose tissue inflammation and IL1 $\beta$ and TNF $\alpha$ content, and improving glucose homeostasis were not affected by mTORC1 deficiency. We conclude that mTORC1 is important mediator of some specific actions of pharmacological PPAR $\gamma$ activation with RSG such as adiponectin secretion and BCAA oxidation at adipose tissue. 
Key-words: mTOR, PPAR $\gamma$, rosiglitazone, adiposity; mitochondria; lipids; inflammation 


\section{Lista de figuras}

Figura 1: Captação de glicose e ácidos graxos pelos adipócitos, mediada pela ação da insulina.

Figura 2: Representação esquemática das ações das TZDs em adipócitos, fígado e músculo esquelético.

Figura 3: Vias de sinalização da mTOR 31

Figura 4: Desenho experimental 36

Figura 5: Padrão de bandas dos géis de genotipagem para adiponectina-cre (A), Raptor Lox (B).

Figura 6: Peso corporal (A), ganho de peso (B), e pesos do tecido adiposo inguinal (C), tecido adiposo retroperitoneal (D), tecido adiposo epididimal (E) e tecido adiposo marrom (G) de camundongos C57BL6J alimentados com dieta controle ou dieta hiperlipídica (HFD) associada à diferentes doses de rosiglitazona $(0,5,15,30 \mathrm{mg} / \mathrm{kg}$ de peso corporal por dia) .48 Figura 7: Ganho de peso (A), consumo alimentar (B), peso dos tecidos adiposos inguinal (C), retroperitoneal (D), marrom (E), epididimal $(F)$, fígado $(G)$ e coração $(H)$ e expressão de proteínas relacionadas a via da mTOR no tecido adiposo inguinal (I) em camundongos ARapWT e ARapKO alimentados com dieta hiperlipídica tratados ou não com rosiglitazona (RSG) na dose de $30 \mathrm{mg} / \mathrm{kg} /$ dia durante 8 semanas

Figura 8: Análise morfológica do tecido adiposo inguinal. .50

Figura 9: Imagens fotográficas e histológica do tecido adiposo marrom .51

Figura 10: Histologia de fígado. .52

Figura 11: Teste de tolerância à glicose (GTT, A), área sob a curva GTT (B), teste de tolerância à insulina (ITT, C) e velocidade de decaimento da glicemia (kITT) (D), glicemia (E) e insulinemia (F) de jejum em camundongos ARapWT e ARapKO alimentados com dieta hiperlipídica tratados ou não com rosiglitazona na dose de $30 \mathrm{mg} / \mathrm{kg} /$ dia durante 8 semanas 53 
Figura 12: Níveis séricos de leptina (A) e triacilglicerol (B) de camundongos ARapWT e ARapKO alimentados com dieta hiperlipídica tratados ou não com rosiglitazona na dose de 30 $\mathrm{mg} / \mathrm{kg} /$ dia durante 8 semanas . .54

Figura 13: Perfil inflamatório do tecido adiposo epididimal .55

Figura 14: Expressão gênica de marcadores inflamatórios. .56

Figura 15: Níveis séricos de adiponectina (A), conteúdo de mRNA de adiponectina (B e C) e Dsba-1 (D e E) nos tecidos adiposos inguinal e marrom, respectivamente, de camundongos ARapWT e ARapKO alimentados com dieta hiperlipídica tratados ou não com rosiglitazona na dose de $30 \mathrm{mg} / \mathrm{kg} /$ dia durante 8 semanas .57

Figura 16: Metabolismo de BCAA .58

Figura 17: Consumo de $\mathrm{O} 2$. .59

Figura 18: Conteúdo de proteína UCP-1 (A). Conteúdo de mRNA de UCP-1 (B), PGC1 $\alpha$, NDUFB5 (D), CPT1 $\alpha$ (E), SDHB (F), MFN2 (G), F1F0-ATPase (H) no tecido adiposo inguinal de camundongos ARapWT e ARapKO alimentados com dieta hiperlipídica tratados ou não com rosiglitazona na dose de $30 \mathrm{mg} / \mathrm{kg} /$ dia durante 8 semanas.. 60

Figura 19: Expressão gênica no tecido adiposo inguinal 62

Figura 20: Análise de PCA de amostras de tecido adiposo epididimal de camundongos ARapWT e ARapKO alimentados com dieta hiperlipídica tratados ou não com rosiglitazona na dose de $30 \mathrm{mg} / \mathrm{kg} / \mathrm{dia}$ durante 8 semanas. .64

Figura 21: Lipídeos (A), cardiolipina (B), PE (C), ceramidas (D), \% ceramidas de cadeia longa (E) e \% ceramidas de cadeia muito longa (F) identificados no tecido adiposo de camundongos ARapWT e ARapKO alimentados com dieta hiperlipídica tratados ou não com rosiglitazona na dose de $30 \mathrm{mg} / \mathrm{kg} /$ dia durante 8 semanas. .65

Figura 22: Heatmap dos 50 lipídeos mais alterados significativamente identificados no tecido 
adiposo epididimal de camundongos ARapWT e ARapKO alimentados com dieta hiperlipídica tratados ou não com rosiglitazona na dose de $30 \mathrm{mg} / \mathrm{kg} / \mathrm{dia}$ durante 8 semanas. 66 


\section{LISTA DE ABREVIATURAS E SIGLAS}

4E-BP: proteínas de ligação ao fator de iniciação eucariótico 4E

AG: ácido(s) graxo(s)

AGPAT: acil-CoA:1-acilglicerol-3-fosfato aciltransferase

AMPc: monofosfato cíclido de adenosina

ANOVA: análise de variância

ATGL: lipase de TAG do tecido adiposo

ATP: adenosina trifosfato

BCAA: branched chain amino acids, i.e., aminoácidos de cadeia ramificada

BCKDHA: branched-chain alpha-keto acid dehydrogenase subunit alpha

BCKDK: branched-chain alpha-keto acid dehydrogenase kinase

BSA: albumina sérica bovina

CD36: cluster of differentiation 36, i.e., agrupamento de diferenciação 36

C/EBP: proteína estimuladora de ligação a CCAAT

$\mathrm{CO}_{2}$ : gás carbônico

CPT I: carnitina-acil transferase I

DAG: diacilglicerol

DBT: Lipoamide acyltransferase component of branched-chain alpha-keto acid dehydrogenase complex

Deptor: proteína de interação a mTOR contendo o domínio DEP

DGAT: diacilglicerol aciltransferase

DLD: Dihydrolipoyl dehydrogenase

DMSO: dimetilsulfóxido

DTNB: 5,5'-ditiobis(2-ácido nitrobenzoico)

ER: receptor de estrógeno

ERK: quinase regulada por sinal extracelular

ERR: receptor relacionado a estrógeno

FABP4: proteína ligante de ácido graxo 4

FAS: ácido graxo sintase

FATP: proteína transportadora de ácidos graxos

FKBP12: proteína ligante de FK506 de $12 \mathrm{kDa}$

GAP: proteína ativadora de GTPase

GPAT: glicerol-3-fosfato aciltransferase

GTP: trifosfato de guanosina

GTT: Glucose Tolerance Test, Teste de Tolerância à Glicose

GyK: Glicerol Quinase

GLUT4: transportador de glicose 4

HFD: high-fat diet, i.e., dieta hiperlipídica

HSL: lipase hormônio-sensível

IGF1: Insulin-like growth factor 1

IL-10 - Interleucina 10

IL-6 - Interleucina 6

IL-1 $\beta$ - Interleucina $1 \beta$

IRS1: substrato do receptor de insulina 1

ITT: Insulin Tolerance Test, i.e., Teste de tolerância à insulina

KO: knockout, i.e., nocaute 
LPL: lipase de lipoproteína

MAPK: proteína quinase ativada por mitógeno

MCP-1 - Proteína Quimiotática De Monócitos-1

mLST8: proteína 8 letal em mamíferos com Sec13

mSIN1: proteína de interação a proteína quinase ativada por estresse de mamíferos

mTOR: proteína alvo mecanístico da rapamicina

mTORC: complexo da mTOR

NADH: nicotinamida adenina dinucleotídeo

NDUFB: NADH desidrogenase [ubiquinona] $1 \beta$

PAK: quinase ativada por $\mathrm{p} 21$

PBS: tampão fosfato-salino

PCA: Principal Component Analysis, i.e., análise de component principal

PCR: reação em cadeia da polimerase

PDK1: proteína quinase dependente de 3'-fosfatidilinositol 1

PEPCK: fosfoenolpiruvato carboxiquinase

PGC-1 $\alpha$ : coativador de PPAR $\gamma$

PI3K: fosfatidilinositol-3-quinase

$\mathrm{PIP}_{3}$ : fosfatidilinositol $(3,4,5)$-trifosfato

PKA: proteína quinase $\mathrm{A}$

PKC: proteína quinase $\mathrm{C}$

PPAR: receptor ativado por proliferadores de peroxissoma

PRAS40: substrato rico em prolina da Akt de $40 \mathrm{kDa}$

PRDM16: domínio de PR contendo 16

Protor-1: proteína observada com Rictor-1

Raptor: proteína reguladora associada a mTOR

RHEB: homóloga de Ras enriquecida no cérebro

Rictor: companheiro da mTOR não-sensível a rapamicina

RSG: rosiglitazona

S6K: quinases de S6

SCD-1 - Estearoil-CoA Dessaturase 1

SDHB: complexo da succinato desidrogenase, subunidade B

SESN: SESTRIN 1/2/3

SGK1: proteína quinase induzida por soro e glicocorticoides

SREBP: proteína ligante aos elementos reguladores de esteroides

TAG: triacilglicerol

TAG-AG: ácidos graxos provenientes de triacilglicerol

TGF: fator de crescimento transformador

$\mathrm{TNF} \alpha$ - fator de necrose tumoral

TSC: complexo da esclerose tuberosa

TZD: Tiazolidinedionas

U.A.: unidades arbitrárias

UCP-1: proteína desacopladora 1

VLDL: lipoproteína de densidade muito baixa

WT: wild type, i.e., selvagem 


\section{Lista de tabelas}

Tabela 1: Sequência de primers utilizados na genotipagem.................................................................37

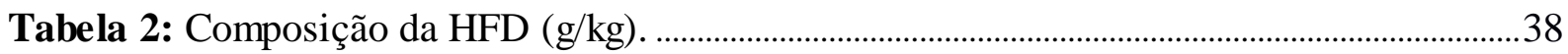

Tabela 3: Primers utilizados no PCR em tempo real .........................................................................42

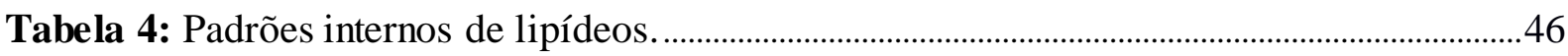




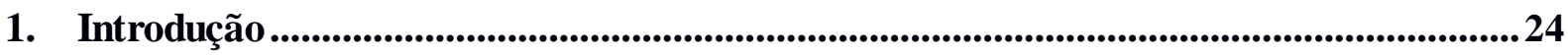

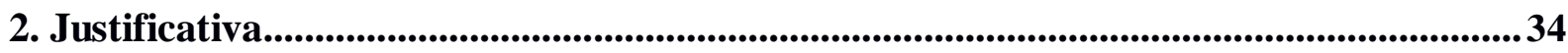

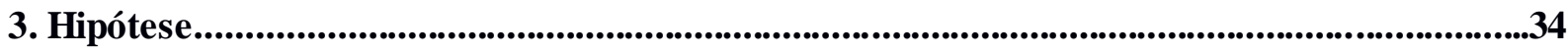

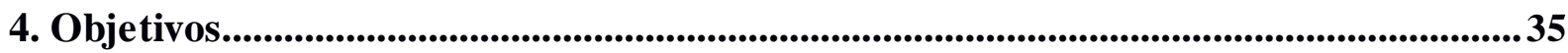

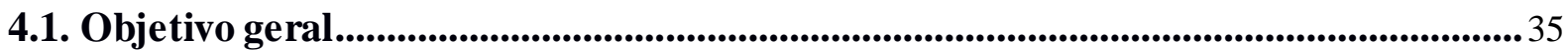

4.2. Objetivo específicos ............................................................................................................................. 35

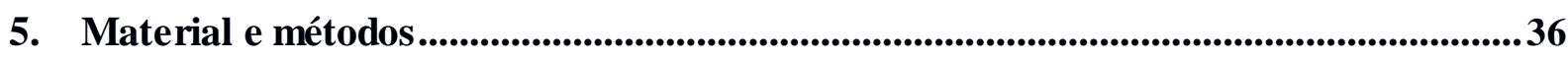

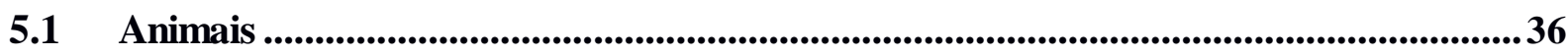



5.3 Condições ambientais, dieta, peso corporal e consumo alimentar............................38

5.4 Dosagem de rosiglitazona e eutanásia ....................................................................................38

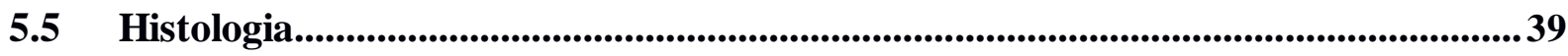

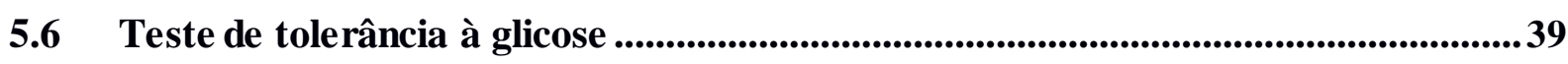

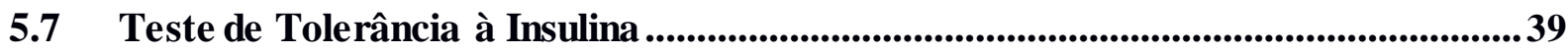

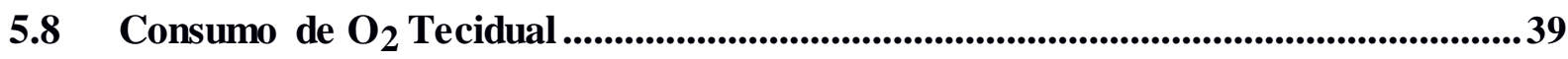

5.9 Extração de RNA e transcrição reversa...............................................................................40

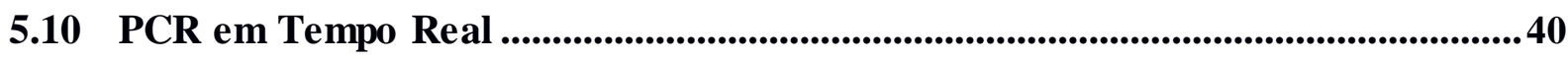

5.11. Western Blot .........................................................................................................................41

5.12 Células Imunes Residentes No Tecido Adiposo ................................................................43

5.13 Marcação Celular Para Análise em Citometria De Fluxo ...........................................43

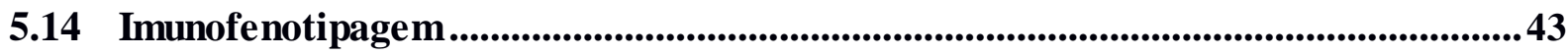

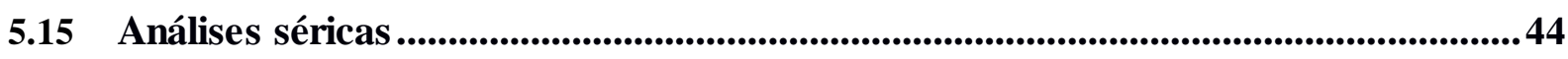

5.16 Análise lipidômica por cromatografia líquida reversa (RPLC), ionização por eletropray (ESI) e tempo de espectrometria de massa de vôo (TOFMS) .............................44

5.17 Extração de lipídeos ......................................................................................................44 
5.18 Aquisição e análise de lipídeos ..............................................................................................45

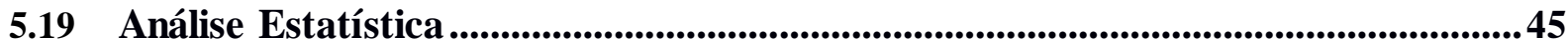

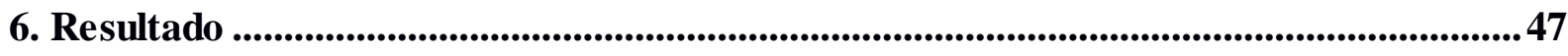



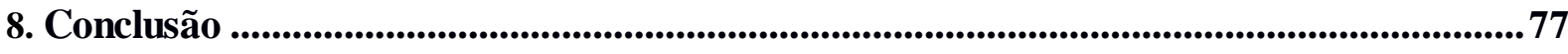

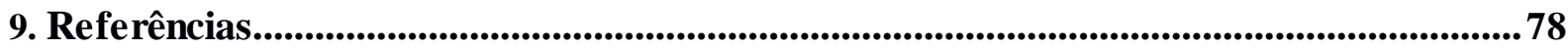




\section{Introdução}

O tecido adiposo é um órgão complexo envolvido no controle do metabolismo, sendo o principal reservatório energético do nosso organismo, responsável por estocar ou liberar substratos energéticos de acordo com o estado nutricional. Além de atuar como depósito, tem fundamental participação na homeostase corporal como um órgão endócrino, secretando adipocinas (proteínas) e lipocinas (lipídeos) que controlam diversos processos. Entre as principais adipocinas temos a adiponectina, que possui ações antiinflamatórias, a leptina, que está relacionada ao controle do apetite, além de citocinas proinflamatórias como TNF $\alpha$ e resistina. O tecido adiposo é um órgão heterogêneo constituído por fibras colágenas, tecido nervoso, células endoteliais e tronco-mesenquimais, neutrófilos, macrófagos, fibroblastos, pré-adipócitos e adipócitos (SARANTOPOULOS, 2018). A célula principal que define o tecido adiposo é o adipócito. Esta possui a maquinaria enzimática necessária para sintetizar e armazenar lipídeos na forma de triacilglicerol em situações de equilibrio energético positivo (ingestão maior que gasto calórico), bem como, de hidrolisar estas moléculas liberando seus constituintes ácidos graxos e glicerol para a circulação em situações de equilíbrio energético negativo (gasto maior que ingestão calórica). Estes processos denominados de lipogênese e lipólise, respectivamente, são regulados finamente por mecanismos neurais, hormonais e nutricionais (FONSECA-ALANIZ,2006). A insulina, por exemplo, é um importante ativador do processo de lipogênese em adipócitos por mecanismo que envolve maior captação de glicose e ácidos graxos via proteínas transportadoras e ativação de diversas enzimas envolvidas na síntese de triacilglicerol. A insulina estimula a captação de glicose em adipócitos induzindo a translocação de vesículas contendo o transportador específico desta hexose GLUT4 para a membrana celular. Depois de captada, a glicose é convertida principalmente em glicerol 3-fosfato pela via glicolítica servindo então como substrato para a síntese de triacilglicerol. Já o transporte de ácidos graxos ocorre por ação predominante do transportador CD36, que também é estimulado pela insulina (Fig. 1) (HACZEYNI, 2018). 


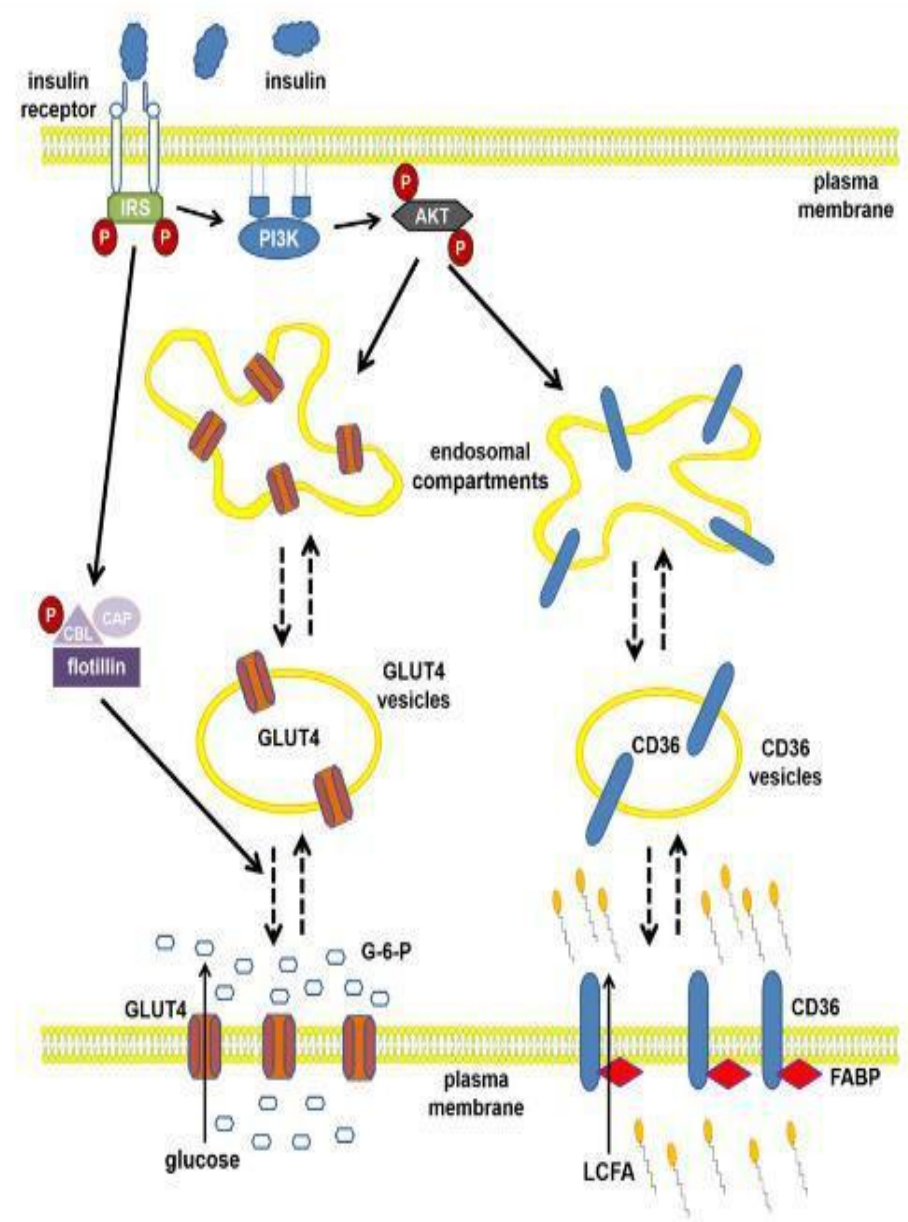

Figura 1 . Captação de glicose e ácidos graxos pelos adipócitos, mediada pela ação da insulina. Extraído de HACZEYNI, 2018.

Os adipócitos podem ser classificados em três tipos de acordo com suas características: branco, marrom e bege. O adipócito branco apresenta gota unilocular de lipídeos, possui poucas mitocôndrias, e tem como função principal o armazenamento de lipídeos e a secreção de adipocinas. O segundo tipo de adipócito encontrado é o marrom, multilocular, rico em mitocôndrias e tem como principal função a produção de calor. Esse processo é catalisado pela proteína desacopladora mitocondrial 1 (UCP-1), que após ativação alostérica por ácidos graxos provenientes da lipólise dos estoques intracelulares de triacilglicerol, promove desacoplamento mitocondrial, dissipando na forma de calor, o gradiente de prótons produzido pela cadeia transportadora de elétrons, processo esse denominado de termogênese livre de tremor muscular (RICQUIER, 2011;WU, 2012). O terceiro tipo de adipócito é o bege, que apresenta características mistas e, dependendo do estímulo vigente pode se comportar funcionalmente como um adipócito branco clássico ou 
adipócito marrom. O recrutamento desses adipócitos para fenótipo termogênico, processo este denominado browning, ocorre principalmente por estímulo $\beta$-adrenérgico como exposição ao frio e tratamento com agonistas adrenérgicos $\beta 1$ e 3, como também pela ativação farmacológica de PPAR $\gamma$, e envolve a multilocularidade, o aumento da massa mitocondrial e do conteúdo de UCP-1 (SPONTON, 2018).

A formação de novos adipócitos envolve três processos distintos: 1- a proliferação de células-tronco mesenquimais presentes na fração estroma-vascular do tecido adiposo; 2término da proliferação e conversão das células tronco mesenquimais em pré-adipócitos; e 3) diferenciação terminal de pré-adipócitos em adipócitos maduros, processo este denominado de adipogênese. A progressão de células-tronco mesenquimais à pré-adipócitos e posteriormente, à adipócitos maduro é caracterizados por alterações na expressão de diversos antígenos de superfície celular (SARANTOPOULOS, 2018). Entre eles podemos destacar o CD34 e a Sca-1 que são utilizados como marcadores de pré-adipócitos. O CD34 é uma glicoproteína transmembrana que promove adesão celular, migração e diferenciação, enquanto o Sca-1 (stem cell antigen 1) é um marcador de superfície celular amplamente expresso em células-tronco mesenqui mais (ROSEN,2006; SARANTOPOULOS, 2018). Outro importate marcador de superfície de pré-adipócito é o Pref-1, cuja expressão se extingue durante o processo de diferenciação. A deleção de Pref-1 reduz significativamente a quantidade de tecido adiposo em camundongos (HUDAK, 2013).

Entre os diversos fatores que controlam a adipogênese, os receptores nucleares PPAR $\gamma$ (receptor ativador da proliferação de peroxissomos) são componentes essenciais, já que sua deleção impede a diferenciação de pré-adipócitos em adipócitos maduros (ROSEN,2006). Os PPAR $\gamma$ são encontrados em duas isoformas distintas (PPAR $\gamma 1$ e PPAR $\gamma 2)$, sendo a isoforma 1 altamente expressa em adipócitos maduros e em menor proporção em macrófagos, neurônios e cardiomiócitos, enquanto a isoforma 2 é expressa exclusivamente em adipócitos maduros (GESTA,2006). Além da adipogênese, os PPAR $\gamma$ são também essenciais para a manutenção do fenótipo dos adipócitos maduros por meio do controle da expressão de várias proteínas envolvidas em diversos aspectos do metabolismo de lipídeos incluindo captação, esterificação, lipólise, reciclagem e oxidação dos ácidos graxos à triacilglicerol (FESTUCCIA,2006; FESTUCCIA,2009a; FESTUCCIA; 2009b), bem como, de aspectos do metabolismo de carboidratos incluindo a captação e conversão da glicose em glicerol 3 fosfato (FESTUCCIA,2009a). Além do metabolismo de lipídios, os PPAR $\gamma$ modulam também a função endócrina do tecido adiposo, inibindo a expressão e secreção de leptina, TNF $\alpha$ e IL-6 
e outras moléculas pró-inflamatórias (DE VOS, 1996; SPIEGELMAN , 2008) aumentando a secreção de adiponectina e CRTP1 (BERG, 2002; WONG,2008). A deleção parcial ou sistêmica de PPAR $\gamma$ causa severos danos metabólicos (HE,2003; IMAI,2004; GRAY,2005). Estudo recente em camundongos com deficiência desse receptor nuclear encontraram severa lipodistrofia, hepatomegalia, hiperfagia, diabetes tipo 2 caracterizada por hiperinsulinemia, hiperglicemia, poliúria, além de um intrigante aumento na massa magra (GILARDI, 2019).

Os PPAR $\gamma$ podem ser ativados tanto por ácidos graxos poliinsaturados de cadeia longa, atuando como um sensor intracelular de lipídios (EVANS,2004), quanto por uma família de ligantes sintéticos denominados de tiazolidinedionas (TZDs) que incluem a rosiglitazona e a pioglitazona. As TZDs possuem grande especificidade de interação e potência de ativação de PPAR $\gamma$, sendo largamente utilizadas no tratamento da resistência à insulina, síndrome metabólica e dislipidemias (EVANS,2004). A administração de TZDs em humanos e roedores induz melhora na tolerância à glicose, na sensibilidade à insulina e no perfil plasmático de lipídios. Apesar destes efeitos benéficos, o uso clínico das TZDs, especialmente a rosiglitazona, têm sido limitado devido aos diversos efeitos colaterais associados a estas drogas que incluem o aumento na adiposidade, retenção de líquido e insuficiência cardíaca, que acometem aproximadamente 15\% dos pacientes (LARSEN, 2003; SEMPLE, 2006). Entre os diversos mecanismos envolvidos na melhora da homeostase da glicose induzida pelo tratamento com TZDs, podemos citar a redistribuição de gordura dos estoques viscerais para o subcutâneos, o aumento da secreção e níveis circulantes de adiponectina e a redução da lipemia, lipotoxicidade e inflamação do tecido adiposo (MIYAZAKI, 2002; YANG,2007).

Estudos indicam a existência de relação direta entre variações regionais no acúmulo de gordura e desenvolvimento de doenças metabólicas (DESPRES, 2006). Mais especificamente, a deposição de gordura nos estoques intra-abdominais ou viscerais está diretamente relacionada com uma maior susceptibilidade para o desenvolvimento de distúrbios metabólicos, como a intolerância à glicose, hiperinsulinemia, dislipidemia e hipertensão. Assim, a redistribuição de gordura dos estoques viscerais para os subcutâneos induzida pelas TZDs atenua os efeitos maléficos da excessiva deposição de gordura visceral na homeostase metabólica. Os mecanismos pelos quais as TZDs promovem redistribuição de gordura ainda não foram completamente elucidados, mas parecem envolver um aumento nos depósitos subcutâneos da atividade da lipase lipoproteica (LPL), e assim do clearance e deposição de lipídios circulantes, bem como do conteúdo de DNA e número de adipócitos, indicando uma possível participação dos processos de proliferação e/ou apoptose (LAPLANTE,2003). 


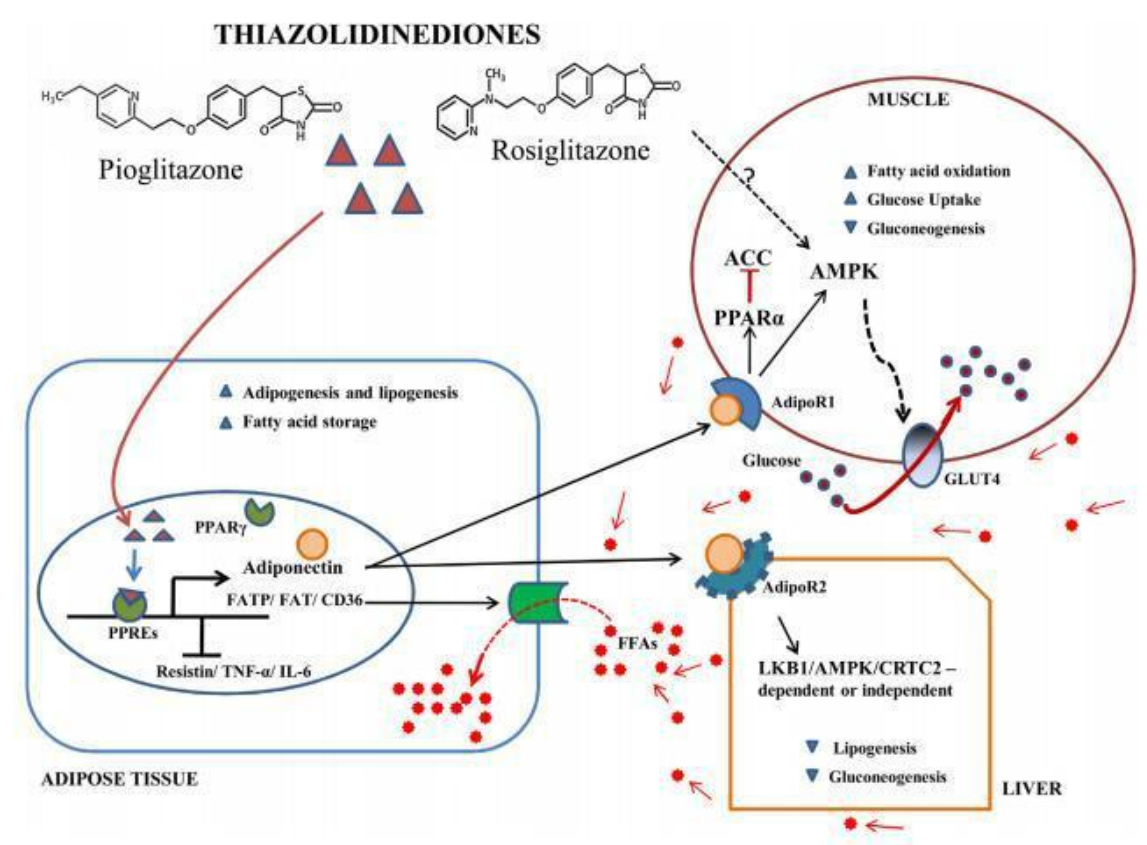

Figura 2. Representação esquemática das ações das TZDs em adipócitos, fígado e músculo esquelético. (GUPTA,2016)

Além dos efeitos citados acima, a ativação dos PPAR $\gamma$ com TZDs promove a biogênese mitocondrial, a expressão da proteína desacopladora UCP1 e o recrutamento de adipócitos bege no tecido adiposo branco (WILSON-FRITCH,2003; PETROVIC,2008; LAPLANTE,2006; OHNO,2012), aumentando a capacidade oxidativa e termogênica deste tecido. Este efeito, entretanto, não está associado ao aumento proporcional no gasto energético corporal. Importante, a indução de genes termogênicos pela rosiglitazona parece ser mais expressiva nos depósitos subcutâneos e depender do corregulador PRDM16 (OHNO,2012).

Similarmente ao tecido adiposo branco subcutâneo, a ativação farmacológica de PPAR $\gamma$ aumenta também a massa do tecido adiposo marrom, através do aumento do número de adipócitos marrons, bem como, da expressão de genes relacionados à captação e esterificação de ácidos graxos em triacilglicerol como a LPL, PEPCK (fosfoenolpiruvato carboxiquinase) e GyK (gliceroquinase), entre outros (FESTUCCIA,2009a). O tecido adiposo marrom é especializado na termogênese (produção de calor), devido a presença da UCP1 na membrana mitocondrial interna (CANNON, 2004; SPONTON, 2018). Interessantemente, o aumento da massa do tecido adiposo marrom pela rosiglitazona ocorre concomitantemente com um aumento do conteúdo de UCP1 e outras proteínas termogênicas, efeito este que não está associado a um aumento da termogênese e gasto calórico devido a inibição da atividade 
simpática e dos hormônios tireoideanos pelas TZDs (FESTUCCIA,2008).

Apesar destes estudos, os mecanismos moleculares pelos quais TZDs exercem suas ações no tecido adiposo branco e marrom ainda não foram completamente determinados. Neste sentido, estudo conduzido por Blanchard (BLANCHARD,2012) encontrou que o tratamento de ratos com rosiglitazona induz um aumento no tecido adiposo da atividade do complexo 1 da mTOR, um sensor de nutrientes que desempenha função importante no controle do metabolismo lipídico e adiposidade.

A mTOR (proteína alvo mecanístico da rapamicina) é uma serina-treonina quinase extremamente conservada, membro da família da fosfoinositol 3-quinase (PI3K) que controla a síntese protéica e lipídica, o crescimento e a proliferação celular de acordo com os níveis de fatores de crescimento e nutrientes e o estado energético da célula. mTOR é o centro catalítico de dois complexos multiprotéicos distintos, complexo 1 e 2 da mTOR (mTORC1 e mTORC2, respectivamente), que possuem funções biológicas e substratos distintos, além de diferente sensibilidade a inibição pela rapamicina.

O mTORC1 é o principal regulador do crescimento e proliferação celular. É ati vado principalmente por aminoácidos, além de fatores de crescimento como a insulina e IGF1, e sua atividade visa regular os processos anabólicos e catabólicos nas células. (LEE, 2017). Além da quinase mTOR, o complexo 1 da mTOR é composto por quatro proteínas RAPTOR, mLST8, PRAS40 e DEPTOR. A proteína RAPTOR (proteína reguladora associada à mTOR), bem como a mLST8 (proteína letal em mamíferos com Sec13) são essenciais para o funcionamento de mTORC1, enquanto a PRAS40 (substrato rico em prolina de AKT de 40 kDa) e a DEPTOR (proteína de interação à mTOR contendo o domínio DEP) atuam inibindo a atividade do complexo.

Mecanisticamente, a ativação de mTORC1 por fatores de crescimento, como a insulina, envolve a interação e ativação de receptor localizado na membrana celular. A interação da insulina com seu receptor promove alteração em sua conformação, aumentando a atividade tirosina quinase intrínseca do mesmo, sua autofosforilação, bem como, a fosforilação do substrato do receptor de insulina 1 (IRS1). O IRS1 por sua vez, ativa alostericamente a fosfatidilinositol 3-quinase (PI3K) e a produção de fosfatidilinositol $(3,4,5)$ trifosfato (PIP3). Esse aumento do conteúdo de PIP3 promove o recrutamento e ativação da proteína quinase dependente de 3 '-fosfatidilinositol 1 (PDK1) e do complexo 2 da mTOR, os quais recrutam e ativam a Akt através da sua fosforilação em resíduos de Thr308 e Ser473, respectivamente. A ativação da Akt fosforila e inibe TSC2, que em conjunto com TSC1 e 
TBC1D7 formam o complexo da esclerose tuberosa (TSC1/2). Além dessa via, a insulina também pode estimular mTORC1 ativando a via da MAPK/ERK (quinase regulada por sinal extracelular), que também fosforila e inibe o complexo TSC1/2. (LAPLANTE,2009). Ambas as vias ativam mTORC1 pela fosforilação e inibição do complexo TSC1/2, que deixa de exercer sua atividade inibitória em mTORC1 (EFEYAN, 2013).

Ao contrário dos fatores de crescimento, os mecanismos envolvidos na ativação de mTORC1 por aminoácidos são bastante complexos e não totalmente compreendidos. Estudos conduzidos pelo laboratório do professor David Sabatini (SHEN, 2019; SHEN, 2018; SHEN, 2017; EFEYAN, 2013; SANCAK 2010) tem buscado entender melhor a interação entre os aminoácidos e mTORC1. Um regulador importante da sinalização de mTORC1 na presença de aminoácidos é o complexo RAG GTPase, que se localiza na membrana dos lisossomos ancorado a outro complexo, o RAGULATOR, que ao ser ativado, recruta mTORC1, resultando em sua translocação do citoplasma para os lisossomos (SANCAK,2010). Esse complexo (RAG GTPase), é um heterodímero composto por RAGA/B ou RAGC/D que encontram-se ligados ao GDP, apresentando sua forma ativa quando o RAGA/B está ligado ao GTP enquanto que o RAGC/D está ligado ao GDP (BAR-PELED, 2014). O complexo RAGULATOR, na presença de aminoácidos, interage com a v-ATPase do lisossomo atuando como o catalisador da troca de RAGA/B-GDP para RAGA/B-GTP. O RAG GTPase também é regulado por outros complexos e proteínas importantes, como o GATOR1 e GATOR2. Na presença de aminoácidos, o GATOR2 está em sua forma ativa inibindo o GATOR1, inativando a ação do complexo RAG GTPase. Na ausência de aminoácidos, SESTRIN 1/2/3 (SESN) e CASTOR1 atuam na inibição de GATOR2, processo esse interrompido quando SESN se liga à leucina e CASTOR1 à arginina, conforme ilustrado na Figura 2 (LEE, 2017). Em estudo recente conduzido por Castellano (2017), descobriu-se que a mTORC1 detecta também o colesterol, através de mecanismo que também envolve a translocação para os lisossomos. Quando ativa, mTORC1 exerce suas ações principalmente pela fosforilação de diversas proteínas como a S6K, 4E-BP e a ULK-1.

Já o complexo 2 da mTOR é menos compreendido quando comparado ao 1 e está envolvido no controle do anabolismo e sobrevivência celular. Assim como o complexo 1, é também formado pela mTOR, mLST8 e DEPTOR, que associam-se a outras três proteínas, a RICTOR, mSIN1 (proteína não-sensível à rapamicina) e PROTOR-1. O mTORC2 é regulado por fatores de crescimento e mediado pela PI3K(SAXTON,2017). Além da Akt, mTORC2 fosforila e ativa a SGK1 (proteína quinase induzida por soro e glicocorticóides) e a PKC 
(proteína quinase C)(LAMMING,2014).

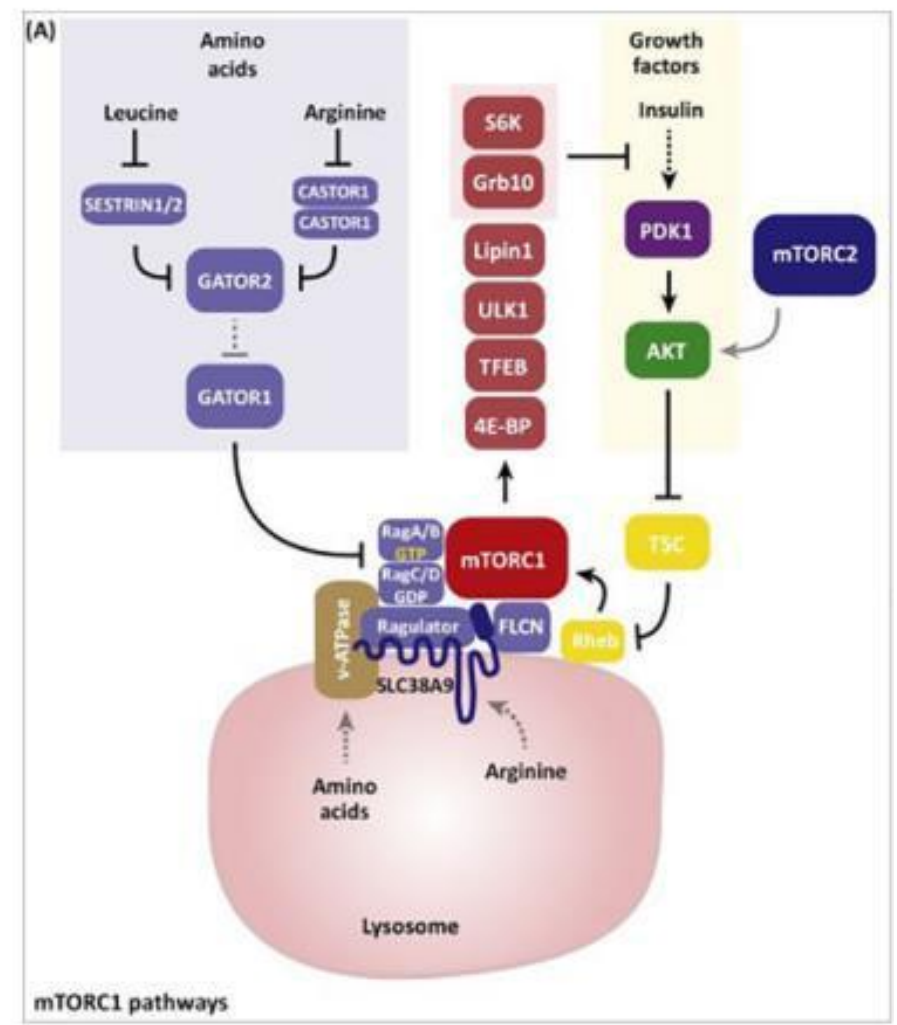

Figura 3.Vias de sinalização da mTOR. Extraído e adaptado do artigo The Complex Roles of mTOR in Adipocytes and Beyond (LEE et al., 2017)

Como detalhado abaixo, diversos estudos tem mostrado a fundamental participação de mTOR no desenvolvimento e manutenção do tecido adiposo (SHAN,2016;CAI,2016). A inibição farmacológica de mTORC1 em pré-adipócitos com rapamicina bloqueou completamente a diferenciação de pré-adipócitos em adipócitos maduros através da inibição de PPAR $\gamma$ (KIM, 2004). Corroborando com o envolvimento de mTORC1 no controle da adiposidade, tanto o tratamento com rapamicina, quanto a deleção de S6K1, uma proteína que é diretamente fosforilada e ativada por mTORC1, protegem contra o aumento de adiposidade e obesidade induzida por dieta rica em lipídios (HOUDE,2010; POLAK,2008; UM,2004). Neste sentido, camundongos com deleção de RAPTOR e assim deficiência de mTORC1 exclusivamente em adipócitos, apresentam deficiência na captação e estoque de lipídeos nos adipócitos e reduzida adiposidade associada à esteatose hepática e resistência à insulina (LEE, 2017). Em conjunto estes estudos sugerem que a inibição de mTORC1 está associada com redução da adiposidade. 
Diversos estudos também avaliaram os efeitos da ativação de mTORC1 em adipócitos. Em um estudo in vitro, ZHANG et al., 2009 demonstraram que a ativação constitutiva do mTORC1 (deleção de TSC2) potencializa o processo de adipogênese e a expressão de PPAR $\gamma$. In vivo, a deleção de 4E-BP que mimetiza a ativação de mTORC1 (4E-BP é fosforilada e inibida por mTORC1) também está associada com um aumento da deposição lipídica e adiposidade em camundongos (LE BACQUER,2007). Entretanto, em estudo publicado pelo nosso laboratório, encontramos que a ativação constitutiva de mTORC1, por meio da deleção de TSC1 em adipócitos, induziu em camundongos uma importante redução da adiposidade visceral que foi associada ao browning e aumento da atividade oxidativa mitocondrial deste tecido (MAGDALON 2016). Em um trabalho em colaboração com o Prof Sabatini encontramos também que a superexpressão de DEPTOR, uma proteína que compõem e inibe parcialmente o complexo 1 da mTOR, exacerba a adipogênese e a adiposidade subcutânea, por um mecanismo que envolve redução do feedback negativo catalisado por S6K1 em IRS e ativação de Akt (LAPLANTE,2012). Em conjunto estes dados sugerem a hipótese que um nível ótimo de atividade de mTORC1 é necessário para que as ações lipogênicas deste complexo prevaleçam e resultem em aumento de adiposidade (MAGDALON,2017).

Um aspecto comum encontrado praticamente em todos os estudos de ganho e perda de função de mTORC1 acima mencionados, são as alterações do conteúdo e atividade transcricional de PPAR $\gamma$. Enquanto a inibição de mTORC1 está associada com redução da expressão e atividade transcricional de $\operatorname{PPAR} \gamma$, a ativação constitutiva deste complexo promove aumento de conteúdo e atividade de PPAR $\gamma$. Os mecanismos pelos quais mTORC1 regula o conteúdo e atividade de PPAR $\gamma$ são completamente desconhecidos. Um outro aspecto interessante a ser considerado na interação entre mTORC1 e PPAR $\gamma$ são os achados que a ativação farmacológica de PPAR $\gamma$ com rosiglitazona está associada com um aumento da atividade de mTORC1 no tecido adiposo (BLANCHARD,2012). Em conjunto estes dados sugerem a existência de um mecanismo de retroalimentação positiva modulando a interação entre mTORC1 e PPAR $\gamma$. Neste sentido, Blanchard e colaboradores (BLANCHARD,2012) realizaram um estudo para investigar a hipótese de que a mTOR é um importante mediador do aumento da adiposidade subcutânea e da atividade da LPL (lipase de lipoproteínas) induzida pela ativação de PPAR $\gamma$ in vivo. Para isto, ratos tratados com a TZD rosiglitazona em combinação ou não com o inibidor farmacológico de mTOR denominado de rapamicina, foram avaliados para o perfil plasmático de lipídio, secreção e clearance de triacilglicerol, atividade da LPL e a expressão de diversos genes envolvidos na captação e esterificação de 
ácidos graxos a TAG. Em resumo foi encontrado neste estudo que mTORC1 participa ativamente no controle das alterações de homeostase lipídica e adiposidade, no aumento da atividade de LPL e clearance de lipídios induzida pela rosiglitazona. Entretanto, devido a inibição sistêmica de ambos os complexos da mTOR (mTORC1 e mTORC2) e diversos outros efeitos colaterais associados ao tratamento farmacológico com rapamicina, não foi possível neste estudo definir especificamente a participação de mTORC1 de adipócitos nos diversos efeitos da rosiglitazona no tecido adiposo branco e marrom. Assim, propusemos nesse estudo, utilizando a deleção genética tecido -específica do complexo 1 da mTOR em adipócitos, identificar quais ações induzidas pela ativação farmacológica de PPAR $\gamma$ por rosiglitazona são mediadas especificamente por esse complexo. 


\section{Justificativa}

Dados da Organização Mundial da Saúde (OMS) indicam que a prevalência do sobrepeso e obesidade no mundo quase triplicou nas últimas décadas, alcançando em 2016 mais de 1,9 bilhões de adultos com excesso de peso, incluindo entre estes 650 milhões de obesos. A OMS ainda afirma que o excesso de peso e obesidade estão associados a maior índice de mortalidade quando comparado à desnutrição (WHO,2018).

Dada a gravidade da situação, a compreensão dos mecanismos envolvidos no controle da adiposidade é fundamental para que estratégias farmacológicas e genéticas possam ser desenvolvidas com o objetivo de atenuar o desenvolvimento da obesidade e doenças crônicas associadas.

Assim, no presente projeto foram investigadas as inter-relações entre dois importantes reguladores do metabolismo lipídico e adiposidade, o sensor de lipídios e receptor nuclear PPAR $\gamma$ e o sensor de aminoácidos e fatores de crescimento mTORC1. Os dados obtidos neste estudo auxiliarão na compreensão dos mecanismos envolvidos na formação e manutenção da massa adiposa em mamíferos.

\section{Hipótese}

O complexo 1 da mTOR é importante para ações metabólicas no tecido adiposo induzidas por ativadores de PPAR $\gamma$ 


\section{Objetivos}

\subsection{Objetivo geral}

Investigar o envolvimento do complexo 1 da mTOR de adipócitos nas alterações morfológicas, metabólicas e secretórias do tecido adiposo branco e marrom de camundongos induzidas pela ativação farmacológica de PPAR $\gamma$ com rosiglitazona.

\subsection{Objetivo específicos}

Investigar o envolvimento do complexo 1 da mTOR:

a) na redistribuição de gordura visceral para a subcutânea e aumento da massa do tecido adiposo marrom induzidos pela ativação farmacológica de PPAR $\gamma$;

b) nas alterações da expressão gênica do tecido adiposo branco e marrom induzidos pela ativação farmacológica de PPAR $\gamma$;

c) na biogênese mitocondrial e aumento do conteúdo de UCP1 do tecido adiposo induzido pela ativação farmacológica de PPAR $\gamma$;

d) nas alterações do lipidoma do tecido adiposo branco induzidos pela ativação farmacológica de PPAR $\gamma$;

e) nas alterações no perfil de leucócitos do tecido adiposo. 


\section{Material e métodos}

\subsection{Animais}

Todos os protocolos realizados foram aprovados pelo Comitê de Ética do Instituto de Ciências Biomédicas da Universidade de São Paulo (ICB-USP) (CEUA protocolo 115/2016). Foram utilizados nos protocolos, camundongos com background C57BL/6J com ou sem inativação específica do complexo 1 da mTOR em adipócitos produzidos pela deleção de RAPTOR (mTORC1) pelo sistema Cre-lox. Para isto, camundongos com RAPTOR floxeados foram cruzados com camundongos que expressam a enzima Cre-recombinase sob controle do promotor da adiponectina produzindo na geração F1 animais RAPTOR flox/wt adiponectinaCre +/-, onde wt significa selvagem. Estes animais da geração F1 foram cruzados com camundongos RAPTOR flox/flox produzindo na geração F2 camundongos com genótipo RAPTOR flox/flox adiponectinaCre $+/$ - que foram posteriormente cruzados com camundongos RAPTOR flox/flox. Assim na geração F3, foram produzidos camundongos RAPTOR flox/flox adiponectinaCre +/- (ARapKO, com deleção de RAPTOR em adipócitos) e RAPTORflox/flox adiponectinaCre -/- (ARapWT).

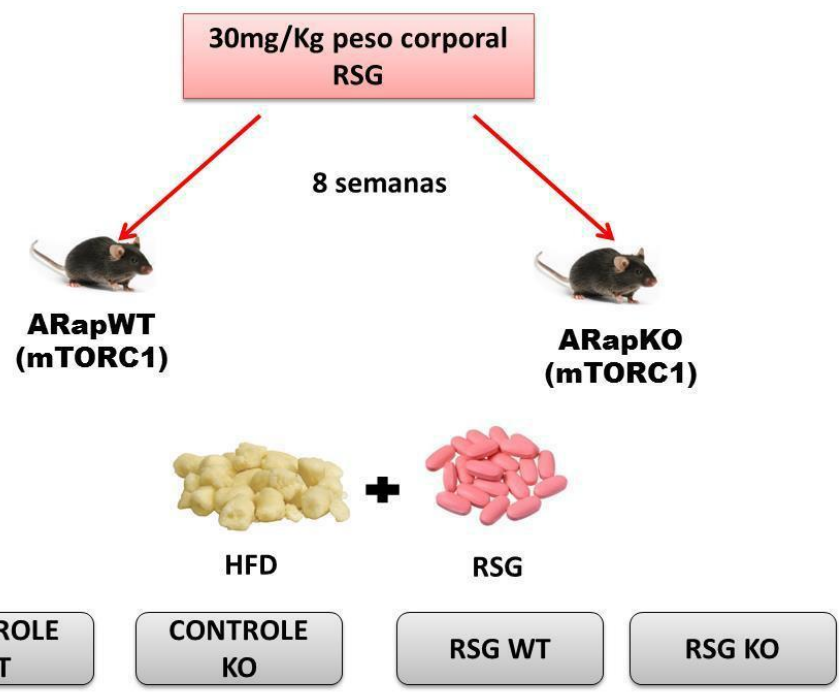

Figura 4. Desenho experimental 


\subsection{Genotipagem}

Todos os camundongos utilizados nos experimentos foram genotipados. Para isto, os camundongos foram anestesiados com isoflurano e um pedaço de $0,2 \mathrm{~cm}$ da cauda foi excisado. A extração do DNA caudal foi realizada por digestão com $\mathrm{NaOH} 50 \mathrm{mM}$ por 12 minutos a $95^{\circ} \mathrm{C}$, seguido de neutralização com $1 \mathrm{M}$ Tris- $\mathrm{HCl}(\mathrm{pH} 6,8)$ e centrifugação por $15 \mathrm{~min}$ a $13000 \mathrm{rpm}$. O sobrenadante então foi retirado para reação em cadeia da polimerase (PCR) com o kit Platinum Taq DNA Polymerase (Life Technologies, Carlsbad, CA, EUA). Foram utilizados primers para Raptor $f / f$, e adiponectin-cre (Tabela 1)

Tabela 1. Sequência de primers utilizados na genotipagem.

\section{adiponectin-cre}

Controle interno sense

CTAGGCCACAGAATTGAAAGATCT

Controle interno antisense

GTAGGTGGAAATTCTAGCATCATCC

Mutante sense

CGAACGCACTGATTTCGACC

Mutante antisense

AACCAGGCGTTTTCGTTCTGC

\section{Raptor $^{\text {J/f }}$}

Sense

CTCAGTAGTGGTATGTGCTCAG

Antisense

GGGTACAGTATGTCAGCACAG

As amostras foram corridas em gel de agarose $2 \%$ para a separação dos produtos de PCR como demonstrado na Figura 5.

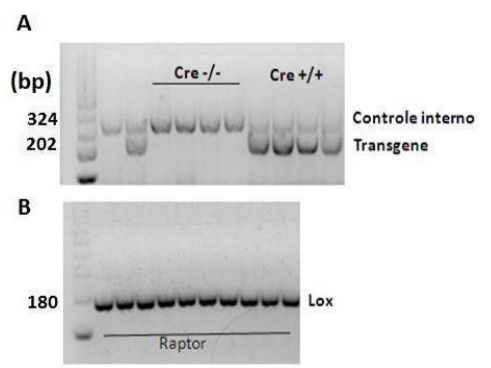

Figura 5. Padrão de bandas dos géis de genotipagem para adiponectina-cre (A), Raptor Lox (B) 


\subsection{Condições ambientais, dieta, peso corporal e consumo alimentar}

Todos os camundongos foram mantidos no biotério do ICB-USP, sob temperatura de $25^{\circ} \mathrm{C} \pm 2{ }^{\circ} \mathrm{C}$, com ciclo claro/escuro de 12 horas. Camundongos foram alimentados com dieta hiperlipídica (HFD) do inglês high-fat diet composta por $20 \%$ de carboidratos, $20 \%$ de proteínas e $60 \%$ de lipídeos, em Kcal. O consumo alimentar e o peso corporal foram avaliados semanalmente.

Tabela 2. Composição da HFD (g/kg).

\begin{tabular}{cc}
\hline Ingrediente & HFD \\
\cline { 2 - 2 } & \\
\hline Caseína & 258,4 \\
\hline L-cistina & 3,9 \\
\hline Amido de milho & - \\
\hline Maltodextrina & 161,5 \\
\hline Sacarose & 88,9 \\
\hline Celulose & 74,1 \\
\hline Óleo de soja & 32,3 \\
\hline Banha de porco & 316,6 \\
\hline Mix mineral AIN93M & 47,9 \\
\hline Mix vitamínico & 13,7 \\
\hline Bitartarato de colina & 2,6 \\
\hline
\end{tabular}

\subsection{Dosagem de rosiglitazona e eutanásia}

A TZD utilizada foi a rosiglitazona (AVANDIA®), que foi macerada e adicionada à dieta na dose de $30 \mathrm{mg} / \mathrm{kg} / \mathrm{dia}$, estabelecida no Protocolo 1. Após 8 semanas de tratamento, os animais foram submetidos à eutanásia após jejum de 12 horas e anestesia com isofluorano, e tiveram seus tecidos adiposos (epididimal, inguinal, retroperitoneal e marrom), coração, fígado, músculo gastrocnêmio e sangue coletados e 
armazenados para as análises.

\subsection{Histologia}

Fragmentos de tecido adiposo inguinal e marrom e fígado foram fixados em paraformaldeído $4 \%$ por 24 horas e armazenados em etanol $70 \%$ para posterior inclusão em parafina. Cortes semi-seriados de $5 \mu \mathrm{m}$ foram corados com hematoxilina/eosina $(\mathrm{H} / \mathrm{E})$. As imagens foram obtidas em microscópio ZEISS, digitalizadas e analisadas pelo software ZEN. Foi utilizada a objetiva de 20x. Para a análise de área dos adipócitos do tecido adiposo inguinal, utilizamos o software Image $\mathrm{J}$, onde medimos fotomicrografias de mesma resolução (20x), com a medida de cerca de 350 adipócitos por animal.

\subsection{Teste de tolerância à glicose}

$\mathrm{Na} 6^{\mathrm{a}}$ semana de protocolo, após jejum de 8 horas, foi injetada glicose intraperitoneal ( $1 \mathrm{~g} / \mathrm{kg}$ peso corporal) nos camundongos. A glicemia foi determinada através do sangue da veia caudal antes e 15, 30, 45, 60, 90 e 120 minutos após injeção da glicose usando o glicosímetro OneTouch Johnson \& Johnson.(MAGDALON,2016).

\subsection{Teste de Tolerância à Insulina}

$\mathrm{Na} 7^{\mathrm{a}}$ semana de protocolo, após jejum de 4 horas, foi administrada via intraperitoneal 0,5 $\mathrm{U}$ insulina/Kg peso corporal. A glicemia foi medida nos tempos 0,5 , 10, 15, 20 e 30 minutos com glicosímetro OneTouch Johnson \& Johnson (MAGDALON,2016).

\subsection{Consumo de $\mathrm{O}_{2}$ Tecidual}

Para análise de consumo de $\mathrm{O} 2$ basal, fragmentos de tecido adiposo inguinal e marrom ( 30 e $15 \mathrm{mg}$, respectivamente) foram incubados em DMEM-4\% BSA a $37^{\circ} \mathrm{C}$ sob agitação. $\mathrm{O}$ cons umo de $\mathrm{O}_{2}$ foi medido no Oroboros Oxygraph-2K por aproximadamente 15 minutos. Os valores foram expressos por peso de tecido (MAGDALON,2016). 


\subsection{Extração de RNA e transcrição reversa}

Amostras de tecido adiposo inguinal e marrom ( $50 \mathrm{mg})$ fora m homogeneizadas com $1 \mathrm{~mL}$ Trizol Reagent (Life Technologies, USA), seguido da adição de 0,2 mL clorofórmio, agitação por 15 segundos e centrifugação a 12000 g por 15 min a $4^{\circ} \mathrm{C}$. Após separação da fase superior aquosa, foi adicionado $0,6 \mathrm{~mL}$ de isopropanol $100 \%$ seguida de incubação à temperatura ambiente por 10 minutos e centrifugação a $12000 \mathrm{~g}$ por 15 min a $4^{\circ} \mathrm{C}$. O pellet de RNA foi então lavado com $75 \%$ etanol e centrifugado a 7500 g por 5 minutos. O pellet de RNA foi ressuspenso em água isenta de RNase e quantificado em espectrofotômetro Nanodrop 2000 (Thermo Scientific, USA) a $260 \mathrm{~nm}$. Para a reação de transcrição reversa, foram incubados a $65^{\circ} \mathrm{C}$ por $5 \mathrm{~min}$ a mistura de 1 $\mu \mathrm{g}$ de RNA total diluído em água isenta de RNase totalizando $12 \mu \mathrm{L}, 1 \mu \mathrm{L} 10 \mathrm{mM}$ dNTP e $1 \mu \mathrm{L} 50 \mu \mathrm{M}$ oligo-dT. Em seguida, foram adicionados $4 \mu \mathrm{L} 5 \mathrm{X}$ First Strand Buffer, $1 \mu \mathrm{L}$ 0,1 M DTT e $1 \mu \mathrm{L}$ Superscript III reverse transcriptase (200 U/ $\mu \mathrm{L})$ (Life Technologies, USA). Seguiu-se com a incubação a $50^{\circ} \mathrm{C}$ por $1 \mathrm{~h}, 70^{\circ} \mathrm{C}$ por 15 min e $4^{\circ} \mathrm{C}$ por 10 min. O cDNA resultante foi então diluído 25 vezes em água isenta de RNase e estocado a $-20^{\circ} \mathrm{C}$ (BELCHIOR,2015).

\subsection{PCR em Tempo Real}

O PCR em tempo real foi utilizado para quantificação dos níveis de RNAm de proteínas de interesse. Para cada reação de PCR, foram utilizados $5 \mu \mathrm{L}$ cDNA, 1,2 $\mu \mathrm{L}$ água isenta de RNase, $10 \mu \mathrm{L}$ SYBR Green (Sigma-Aldrich) e $1 \mu \mathrm{L}$ mistura de primer forward e reverse a $5 \mu \mathrm{M}$. As amostras foram então incubadas em RotorGene (Qiagen) por 40 ciclos, seguido de melting. A análise da expressão gênica foi realizada por quantificação relativa pelo método de CT comparativo $(\mathrm{Ct})$. Os dados foram apresentados como a razão entre o gene alvo e a média de genes de referência (B2m, 36 b4 e Hprt1). Os primers utilizados para esta análise estão na Tabela 3. 


\subsection{Western Blot}

Para a medida do conteúdo de proteínas de interesse, amostras de tecido adiposo inguinal foram homogeneizadas em tampão contendo em mM: 50 HEPES, $40 \mathrm{NaCl}, 50$ NaF, 2 EDTA, 10 pirofosfato de sódio, 10 glicerofosfato de sódio, 2 ortavanadato de sódio, 1\% Triton-X 100 e inibidor de protease livre de EDTA (Roche Life Science, Pleasanton, CA, EUA). As amostras foram centrifugadas a $11000 \mathrm{~g}$ por $10 \mathrm{~min}$ a $4^{\circ} \mathrm{C} . \mathrm{O}$ método de Pierce BCA Protein Assay Kit (Thermo Scientific, Rockford, IL, EUA) foi utilizado para medir a concentração de proteínas segundo as instruções do fabricante. Foram utilizadas $40 \mu \mathrm{g}$ de proteína para separação em gel. Após transferência em membrana PVDF, foi realizado bloqueio por $1 \mathrm{~h}$ em tampão $5 \%$ de leite e incubada durante a noite com o anticorpo primário de interesse (diluição 1:1000) em tampão 5\% leite. Os seguintes anticorpos foram utilizados: Akt (\#9685s), 4E-BP1 (\#9452), p4EBP1(\#2855s) e UCP-1 (\#14670). Após lavagem (TBS-T), a membrana foi incubada com anticorpo secundário conjugado à peroxidase (diluição 1:5000) em tampão 5\% leite por 1h. Após incubação com anticorpo secundário, a membrana foi novamente lavada (TBS-T) e então revelada com a utilização do equipamento Syngene®. 
Tabela 3. Primers utilizados no PCR em tempo real.

\begin{tabular}{|c|c|c|}
\hline Gene & Forward $\left(5^{\prime}-3^{\prime}\right)$ & Reverse (3'-5') \\
\hline ADIPONEC & CGTGGAGCTCAGCAGTACCC & TCGGGCTCCTCCGGGCTATT \\
\hline$A T G L$ & GGTCCTCTGCATCCCTCCTT & CTGTCCTGAGGGCAGATGTC \\
\hline$B 2 M$ & ACCGTCTACTGGGATCGAGA & TGCTATTTCTTTCTGCGTGCAT \\
\hline CD36 & TGAATGGTTGAGACCCCGTG & CGTGGCCCGGTTCTACTAAT \\
\hline$D G A T 1$ & GCTCCAGCCCATACCCGGGA & TGTCAGGGCACCCACTGCCA \\
\hline FABP4 & TGAAATCACCGCAGACGACA & ACACATTCCACCACCAGCTT \\
\hline FASN & AGATGGAAGGCTGGGCTCTA & CATTGTGTGTGCCTGCTTGG \\
\hline PEPCK & CGATGACATCGCCTGGATGA & TCTTGCCCTTGTGTTCTGCA \\
\hline$I L 1 B$ & GCCACCTTTTGACAGTGATGAG & TGATGTGCTGCTGCTGCGAGATT \\
\hline HPRT1 & AGCAGTACAGCCCCAAAATG & ATCCAACAAAGTCTGGCCTGT \\
\hline$P G C 1 A$ & ACTCTGCATTTGGTTTTGCTGA & CCCAGCAACACAGCCTCTAA \\
\hline PPARG & CGGGCTGAGAAGTCACGTT & TGTGTCAACCATGGTAATTTCAG \\
\hline$U C P 1$ & AGGCTTCCAGTACCATTAGGT & CTGAGTGAGGCAAAGCTGATTT \\
\hline NLRP3 & GGCAACAATGATCTTGGCGA & TTCACCCAACTGTAGGCTCT \\
\hline$\overline{C D 86}$ & TGGTCTGGCAAGACAACACA & TCTCTTCCACTCTCTAGGGAGCT \\
\hline$T N F A$ & AGCCCACGTCGTAGCAAACCA & GCAGGGGCTCTTGACGGCAG \\
\hline DUSP6 & CGTTCTACCTGGAAGCTGGC & CTGCACGAGCCGTCTAGATT \\
\hline$M C P 1$ & TCAGCCAGATGCAGTTAACGCCC & AGGCATCACAGTCCGAGTCACA \\
\hline$A S C-P Y C A R D$ & GCCAGAACAGGACACTTTGTG & ACACTGCCATGCAAAGCATC \\
\hline$D S B A-L$ & GGCTGGGCTTTGAGGTCCTA & ACTGGCCTTTTCGGGGAAC \\
\hline$D B T$ & CAGACTGACCTGTGTTCGCT & GTGACGTGGCTGACTGTACT \\
\hline$D L D$ & CCAGGTGCTGGAGAAATGGT & GCCTCTGATAAGGTCGGATGC \\
\hline$B C K D K$ & TGAGGATTGCTCACCGCATC & GGTCCTTGATCGGAGGGAAG \\
\hline$B C K D H B$ & AGTCCCTGCAGTATGGGCAAA & CCTGAGCGGTAGCGATACTT \\
\hline BCKDHA & TGGCTAGATCTCACCCCAGC & ATGCCGGAGATGACATTGGG \\
\hline$D B T$ & CAGACTGACCTGTGTTCGCT & GTGACGTGGCTGACTGTACT \\
\hline NDUFB5 & GCATCCGATATCAAGATGGATCG & CTTTAACCGTAACTCAGCCTTTTCA \\
\hline MFN2 & TGGAGTCAACACCATCAGGG & GGAACAGAGGAGAAGTTTCTAGC \\
\hline F1FO-ATPASE & TCCACCCGGATTCCGCCATG & GAGCCGTGCTCTCCCCCAAAT \\
\hline$S D H B$ & CCCAGGAGGGCAAGCAA & GTACAGCCCGTCCAGCTTCT \\
\hline
\end{tabular}




\subsection{Células Imunes Residentes No Tecido Adiposo}

As células imunes residentes no tecido adiposo foram isoladas através de digestão do tecido adiposo epididimal com colagenase. Para isso, o tecido adiposo epididimal foi picado em pequenos fragmentos e incubados em $4 \mathrm{~mL}$ de tampão DMEM contendo $20 \mathrm{mM}$ HEPES, 4\% albumina bovina sérica (BSA), $1 \mathrm{mg} / \mathrm{mL}$ de colagenase II (Sigma Chemical, St. Louis, MO, Estados Unidos), pH 7,4 por cerca de 45 minutos a $37^{\circ} \mathrm{C}$ em banho-maria com agitação orbital (150 rpm). Em seguida, as amostras foram filtradas em peneira plástica com malha fina (que retém restos teciduais e vasos não digeridos) e acrescida de $25 \mathrm{~mL}$ de DMEM contendo 2\% albumina. Os adipócitos que emergiram a superfície do tampão foram retirados e a fração estroma-vascular foi isolada por centrifugação por 10 minutos a $1500 \mathrm{rpm}$. O pellet de cél ulas formado que contém leucócitos, células endoteliais, pré-adipócitos entre outras, foi re-suspenso em tampão de lise de hemácias, submetidos à centrifugação por 10 min a $1500 \mathrm{rpm}$, filtrados em filtro $70 \mu \mathrm{m}$, novamente re-suspenso em PBS contendo $2 \%$ de Soro Fetal Bovino (SFB) e destinado a marcação e análise por citometria de fluxo como descrito abaixo (PASCHOAL,2016).

\subsection{Marcação Celular Para Análise em Citometria De Fluxo}

Células da fração estroma-vascular foram transferidas para placa de 96 poços e centrifugadas para a retirada do sobrenadante. Células foram re-suspensas em $F c$ block, incubadas por 10 minutos à $4^{\circ} \mathrm{C}$, e acrescidas dos (10 uL de solução 1:100) de anticorpos seguida de incubação por $30 \mathrm{~min}$ à $4^{\circ} \mathrm{C}$. Em seguida as amostras foram novamente lavadas com PBS 2\% SFB, fixadas com tampão BD Cytofix e incubadas por 20 minutos à $4^{\circ} \mathrm{C}$. As células foram lavadas e as amostras avaliadas no citômetro de fluxo Canto II. O programa utilizado para aquisição de dados no BD canto II foi o DivaSofware $^{\mathrm{TM}}$. Foram adquiridos 50000 eventos por amostra e para a análise foi usado o software FlowJo 10.0.7.

\subsection{Imunofenotipagem}

Foram considerados macrófagos as células que apresentaram dupla marcação para $\mathrm{CD} 11 \mathrm{~b}^{+}$e $\mathrm{F} 4 / 80^{+}$na superfície. Nesta população de macrófagos, as células 
positivas para $\mathrm{CD}_{206}{ }^{+}$e negativas para $\mathrm{CD} 11 \mathrm{c}^{-}$e $\mathrm{CD}^{-} 6^{-}$foram consideradas como de fenótipo M2 e as positivas para $\mathrm{CD} 11 \mathrm{c}^{+}$e $\mathrm{CD}^{+} 6^{+}$e negativas para $\mathrm{CD} 206^{-}$como M1. Células que expressam CD4+, CD25+ e Foxp3+ foram consideradas como linfócitos Treg. Os anticorpos utilizados foram F4/80-APC, CD11c-FITC, CD206-PE, CD4-FITC e CD25-APC (Becton Dickinson, USA), CD11b-PB, F4/80-PE, CD206-FITC e CD86APC (Biolegend, USA) (PASCHOAL,2016).

\subsection{Análises séricas}

Após a eutanásia, o sangue foi coletado e centrifugado a $2000 \mathrm{rpm}$ por 15 minutos à $4^{\circ} \mathrm{C}$, o soro foi retirado e armazenado à $-80^{\circ} \mathrm{C}$. Os níveis séricos de triacilgliceróis (TAG) e glicose foram determinados por método colorimétrico conforme orientações do fabricante (Labtest, Lagoa Santa, MG, Brasil). Adiponectina (EZHADP61K, Merck-Milipore), insulina (EZRMI-13K, Merck-Milipore) e leptina (\#90030, Crystal Chem) foram quantificadas usando kits ELISA. Os níveis séricos de BCAA foram medidos por método colorimétrico (\#K564-100, BioVision). Todas as análises foram executadas seguindo as instruções do fabricante.

\subsection{Análise lipidômica por cromatografia líquida reversa (RPLC), ionização por} eletropray (ESI) e tempo de espectrometria de massa de vôo (TOFMS)

A análise do lipidoma do tecido adiposo epididimal foi realizada por cromatografia líquida acoplada à espectrometria de massa (LC-MS) utilizando uma mistura de padrões internos de lipídios para semi-quantificação de espécies moleculares de lipídios relatadas.

\subsection{Extração de lipídeos}

A extração lipídica foi realizada de acordo com o método estabelecido por Matyash et al. (2008). O tecido adiposo epididimal $(100 \mathrm{mg} / \mathrm{mL})$ foi homogeneizado em gelo com tampão de fosfato $10 \mathrm{mM}(\mathrm{pH} \mathrm{7,4)}$ contendo mesilato de deferoxamina 100 $\mu \mathrm{M}$. Resumidamente, $100 \mu \mathrm{L}$ de tecido adiposo $(10 \mathrm{mg})$ foram misturados com $200 \mu \mathrm{L}$ 
de metanol gelado e $100 \mu \mathrm{L}$ de padrões internos $(10$ - $20 \mathrm{ng} / \mu \mathrm{L}$, Tabela 4). Após agitação durante 10 segundos, adicionou-se $1 \mathrm{ml}$ de éter metil-terc-butílico (MTBE) à mistura, que permaneceu sob agitação em temperatura ambiente por 1 hora. Em seguida, foram adicionados $300 \mu \mathrm{L}$ de água à mistura acompanhada de homogeneização e descansando em gelo durante 10 minutos. Após centrifugação a $10.000 \mathrm{~g}$ por 10 minutos a $4^{\circ} \mathrm{C}$, o sobrenadante contendo o extrato lipídico total foi transferido para um novo tubo e seco com nitrogênio. Os extrato lipídico total secos foram ressuspendidos em isopropanol e o volume de injeção foi ajustado em $1 \mu \mathrm{L}$ (representando $1 \%$ de 100 $\mathrm{mg}$ de tecido / $\mathrm{mL}$ ).

\subsection{Aquisição e análise de lipídeos}

O extrato lipídico total foi analisado por ESI-TOFMS (Triple TOF 6600, Sciex, Concord, EUA) interligados com um CL de alto desempenho (UHPLC Nexera, Shimadzu, Kyoto, Japão). As amostras foram carregadas em coluna CORTECS® (UPLC® C18, 1,6 $\mu \mathrm{m}, 2.1 \mathrm{~mm}$ i.d. $\mathrm{x} 100 \mathrm{~mm}$ ) com um caudal de $0,2 \mathrm{~mL}$ min-1 e a temperatura mantida a $35^{\circ} \mathrm{C}$. Para RPLC, a fase móvel A consistiu em água/ acetonitrila (60:40), enquanto a fase móvel B composta de isopropanol/ acetonitrila/ água (88:10:2). As fases móveis A e B continham acetato de amônio ou ácido fórmico (a uma concentração final de $10 \mathrm{mM}$ ) para experimentos realizados em modo de ionização negativo ou positivo, respectivamente. $\mathrm{O}$ gradiente linear durante RPLC foi o seguinte: de 40 a 100\% B durante os primeiros 10 minutos, manteve-se em $100 \%$ B de 10 a 12 minutos, diminuindo de 100 para $40 \%$ de B durante 12-13 minutos, e mantido a 40\% B de 13-20 minutos. A MS foi operada em modos de ionização positiva e negativa, e a faixa de varredura ajustada em uma relação massacarga de 200-2000 Da. Os dados para a identificação e quantificação das espécies moleculares de lipídios foram obtidos pela aquisição de informações dependentes (IDA®). A aquisição de dados foi realizada com ciclo de tempo de 1,05 segundos e tempo de aquisição de 100 ms para a varredura MS1 e tempo de aquisição de 25 ms para obter os 36 íons precursores superiores. A aquisição de dados foi realizada usando o Analyst@ 1.7.1 com uma tensão de pulverização iônica de $-4,5 \mathrm{kV}$ e $5,5 \mathrm{kV}$ (para modos negativo e positivo, respectivamente) e a tensão do cone em +/- 80 V. O gás foi ajustado a 25 psi, gases nebulizadores e aquecedores a 45 psi e aquecedor de interface de $450^{\circ} \mathrm{C}$. Os dados MS/MS foram analisados com PeakView ${ }^{\circledR}$, e as espécies moleculares de lipídios foram identificadas por inspeção 
visual baseada na massa dos compostos com a utilização de buscador desenvolvido em Excel direcionado pelo Lipid Maps, disponível em:

(link:http://www.lipidmaps.org/tools/structuredrawing/masscalc.php).

A quantificação lipídica foi realizada com o MultiQuant@, onde as áreas de pico de íons precursores foram normalizadas pelos padrões internos.

Tabela 4. Padrões internos de lipídeos.

\begin{tabular}{|c|c|c|}
\hline Padrão Interno & Classe Lipídica & 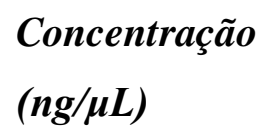 \\
\hline $\begin{array}{l}\text { 1,2-diheptadecanoyl-sn-glycero-3-phosphocholine } \\
(\text { PC 17:0/17:0) }\end{array}$ & $P C$ & 18.8 \\
\hline $\begin{array}{l}\text { 1,2-diheptadecanoyl-sn-glycero-3-phosphoethanolamine } \\
(\text { PE 17:0/17:0) }\end{array}$ & $P E$ & 18.8 \\
\hline $\begin{array}{l}\text { 1,1',2,2'-tetramyristoyl cardiolipin } \\
(\text { CL } 14: 0)_{4}\end{array}$ & $C L$ & 18.8 \\
\hline $\begin{array}{l}\text { 1,2-diheptadecanoyl-sn-glycero-3-phosphoglycerol } \\
(P G \text { 17:0/17:0) }\end{array}$ & $P G$ & 20.0 \\
\hline $\begin{array}{l}\text { 1-heptadecanoyl-2-hydroxy-sn-glycero-3-phosphocholine } \\
\text { (LysoPC 17:0) }\end{array}$ & Lyso & 18.8 \\
\hline $\begin{array}{l}\text { N-heptadecanoyl-D-erytro-sphingosylphosphorylcholine } \\
(17: 0 \mathrm{SM})\end{array}$ & $S M$ & 15.0 \\
\hline $\begin{array}{l}\text { N-decanoyl-D-erytro-sphingosine } \\
\text { (10:0 Cer) }\end{array}$ & Cer & 10.0 \\
\hline
\end{tabular}

\subsection{Análise Estatística}

Os valores estão apresentados como média \pm erro padrão. Foi utilizada análise de variância ANOVA Two-way com pós-teste Tukey. O nível de significância estabelecido foi de $5 \%$, em que $\mathrm{p} \leq 0,05$. O pacote estatístico utilizado foi o Statistical Graph Prism $5.0^{\circledR}$ (GraphPad Software Inc, San Diego, CA, EUA). 


\section{Resultado}

Nosso estudo teve início com experimentos em camundongos selvagens C57BL/6J alimentados com dieta hiperlipídica e tratados com rosiglitazona nas doses de 5, 15 e 30 $\mathrm{mg} / \mathrm{kg}$ de peso corporal afim de encontrarmos dose que reproduza as principais ações desta TZD em humanos como a redistribuição de tecido adiposo, caracterizad a por redução nos depósitos viscerais e possível aumento nos depósitos subcutâneos e/ou do tecido adiposo marrom. Como ilustrado na Figura 6, o consumo de dieta hiperlipídica aumentou significativamente o peso corporal final, ganho de peso dos camundongos e a massa dos tecidos adiposos epididimal, retroperitoneal, inguinal e marrom. Já o tratamento com rosiglitazona independentemente da dose, não afetou o peso corporal final nem o ganho de peso dos animais, porém, atenuou o aumento de massa dos tecidos adiposos epididimal e retroperitoneal nas dosagens de 15 e $30 \mathrm{mg}$, além de aumentar a massa do tecido adiposo marrom. Assim, baseados nessas alterações de peso dos tecidos adiposos retroperitoneal e marrom induzidas pela rosiglitazona nas doses de 15 e $30 \mathrm{mg}$ (Figura 6) em camundongos alimentados com dieta hiperlipídica, escolhemos a dose de $30 \mathrm{mg} / \mathrm{kg}$ de peso corporal para a utilização nos protocolos subsequentes em animais com deficiência de mTORC1 (deleção de RAPTOR). 

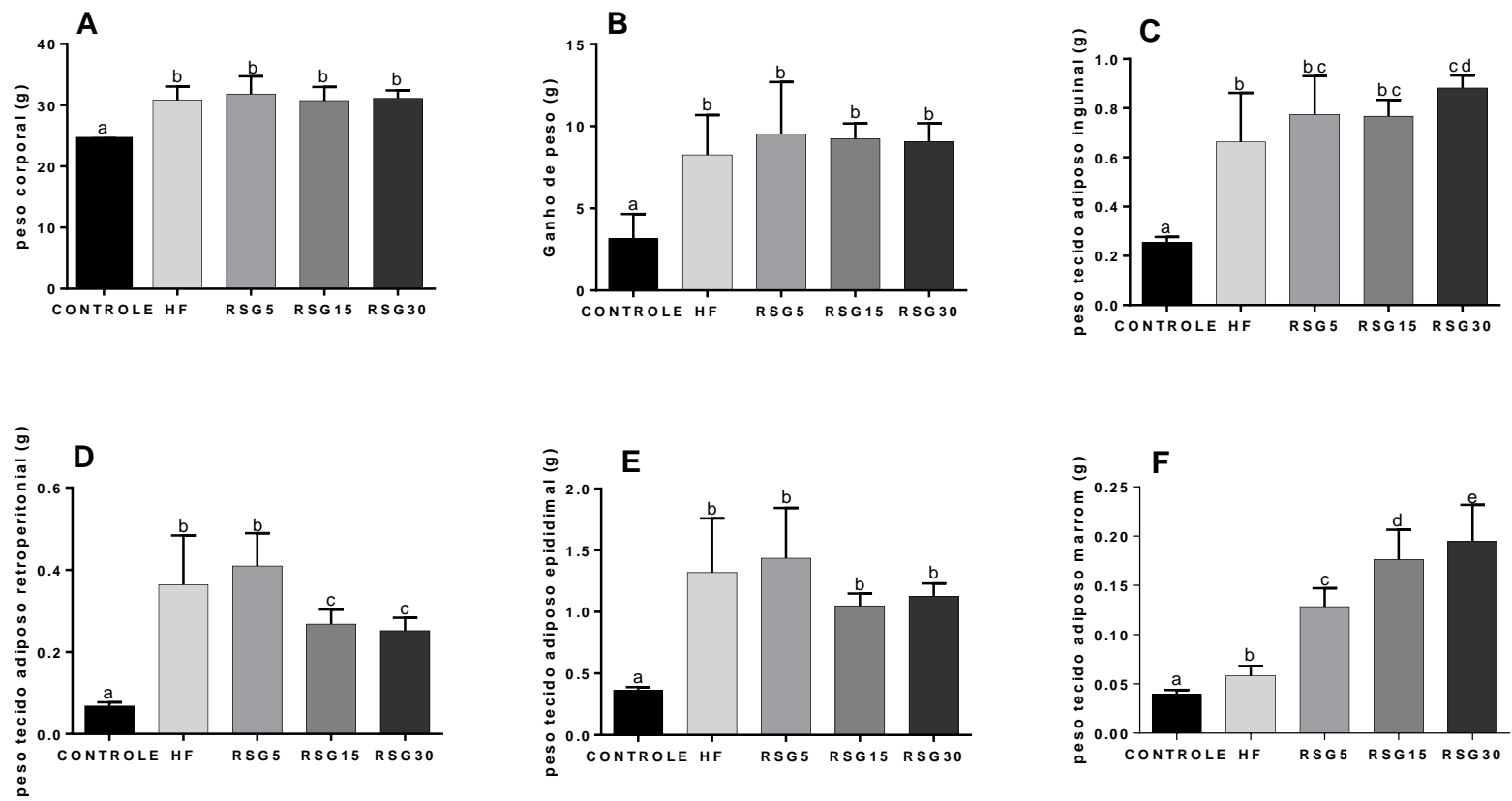

Figura 6. Peso corporal (A), ganho de peso (B), e pesos do tecido adiposo inguinal (C), tecido adiposo retroperitoneal (D), tecido adiposo epididimal (E) e tecido adiposo marrom $(\mathrm{G})$ de camundongos $\mathrm{C} 57 \mathrm{BL} / 6 \mathrm{~J}$ alimentados com dieta controle ou dieta hiperlipídica (HFD) associada à diferentes doses de rosiglitazona $(0,5,15,30 \mathrm{mg} / \mathrm{kg}$ de peso corporal por dia). Dados expressos em média e erro padrão. Letras diferentes indicam diferenças estatísticas, $\mathrm{p} \leq 0,05$. Anova two way. $(\mathrm{n}=5$ por grupo)

Definida a dose de rosiglitazona, iniciamos nossos estudos com o objetivo de investigar o envolvimento de mTORC1 nas ações metabólicas promovidas pela ativação farmacológica de PPAR $\gamma$. Para isto, camundongos controles ou com deficiência de mTORC1 em adipócitos alimentados com dieta hiperlipidica foram tratados ou não com rosiglitazona por 8 semanas. Como ilustrado na Figura 7A, camundongos com deleção de raptor em adipócitos apresentaram reduzido conteúdo de 4E-BP fosforilada no tecido adiposo inguinal, um produto da atividade de mTORC1, confirmando assim a deficiência deste complexo. Camundongos com deficiência de mTORC1 (ARapKO) em adipócitos apresentaram menor ganho de peso, menor massa dos tecidos adiposos epididimal, retroperitoneal e marrom e aumento nas massas do fígado e coração quando comparados aos animais sem a deleção de raptor (ARapWT), apesar da ausência de diferenças no consumo alimentar. $\mathrm{O}$ tratamento com rosiglitazona não induziu 
alterações significativas no ganho de peso, consumo alimentar e massas do tecido adiposo inguinal e fígado, mas reduziu a massa dos depósitos viscerais epididimal e retroperitoneal e aumentou as massas do tecido adiposo marrom e coração nos animais controles ARapWT. Nos animais com deleção de raptor (ARapKO) em adipócitos, ao contrário dos controles, a rosiglitazona não reduziu a massa dos depósitos viscerais epididimal e retroperitoneal e não aumentou a massa do tecido adiposo marrom, sugerindo que estas ações possam ser dependentes de mTORC1 (Fig. 7 E, F e G).
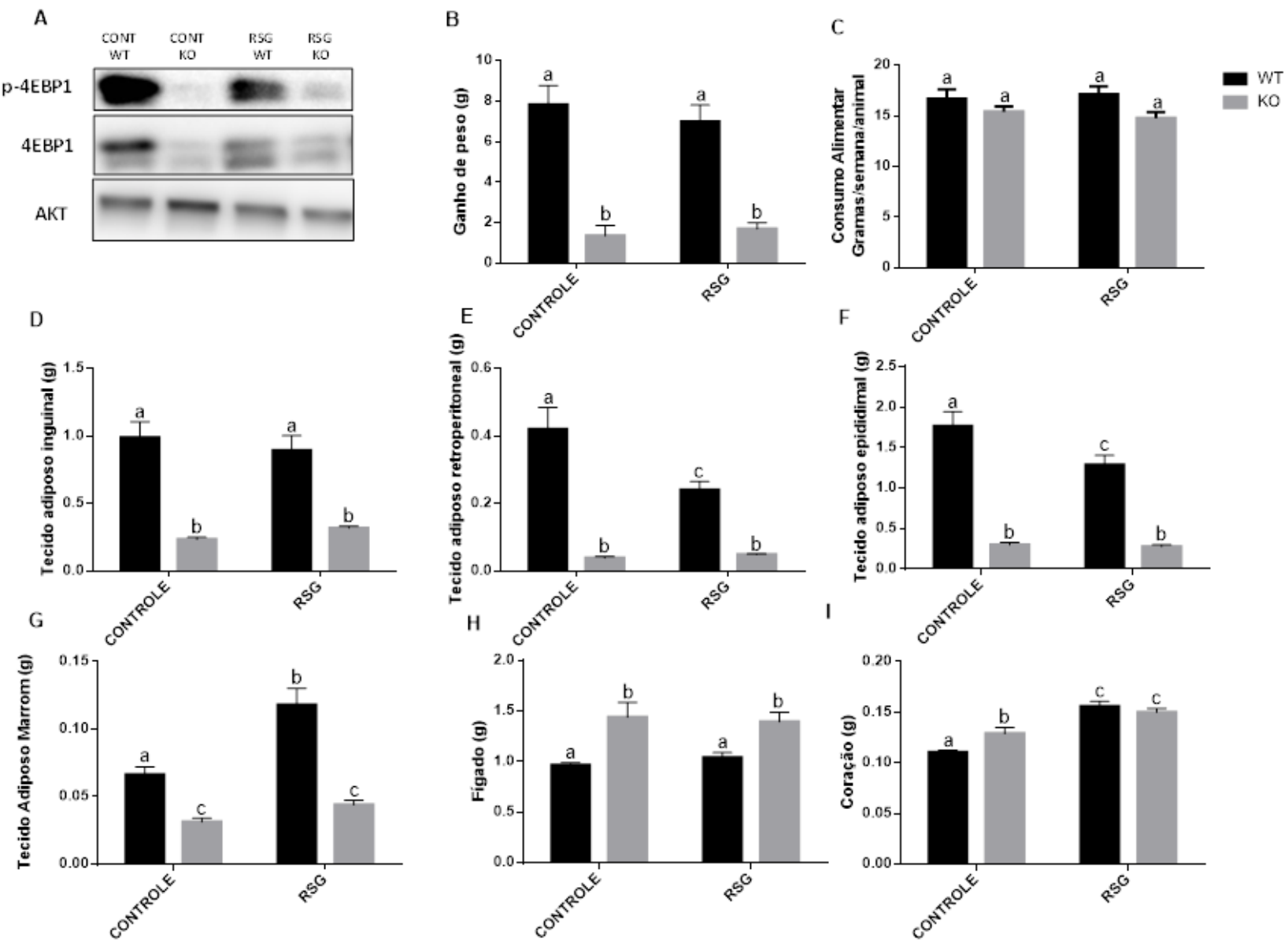

Figura 7. Expressão de proteínas relacionadas a via da mTOR no tecido adiposo inguinal (A), ganho de peso (B), consumo alimentar (C), tecido adiposo inguinal (D), retroperitoneal $(\mathrm{E})$, epididimal $(\mathrm{F})$, marrom $(\mathrm{G})$, fígado $(\mathrm{H})$ e coração (I) de camundongos ARapWT e ARapKO alimentados com dieta hiperlipídica tratados ou não com rosiglitazona (RSG) na dose de $30 \mathrm{mg} / \mathrm{kg} /$ dia durante 8 semanas. ANOVA Two-way pósteste de Tukey. Letras diferentes indicam diferenças estatísticas, $p \leq 0,05$. ( $n=10$ animais por grupo) 
Analisamos posteriormente a distribuição dos adipócitos de acordo com sua área em cortes histológicos do tecido adiposo inguinal. Como ilustrado na Figura 8, a deleção de raptor aumentou a porcentagem de adipócitos com área pequena nas faixas de 0-500 e 500-1000 e reduziu a porcentagem de adipócitos grandes com área de 30003500 e 3500-4000. Já o tratamento com rosiglitazona aumentou a porcentagem de adipócitos com área média entre 1000-2500 e reduziu a porcentagem de adipócitos com área maior. Entre estes efeitos da rosiglitazona o aumento da porcentagem de área média entre 1000-2500 foi abolido pela deficiência de mTORC1, já que o mesmo não foi observado no grupo ARapKO tratado com rosiglitazona.

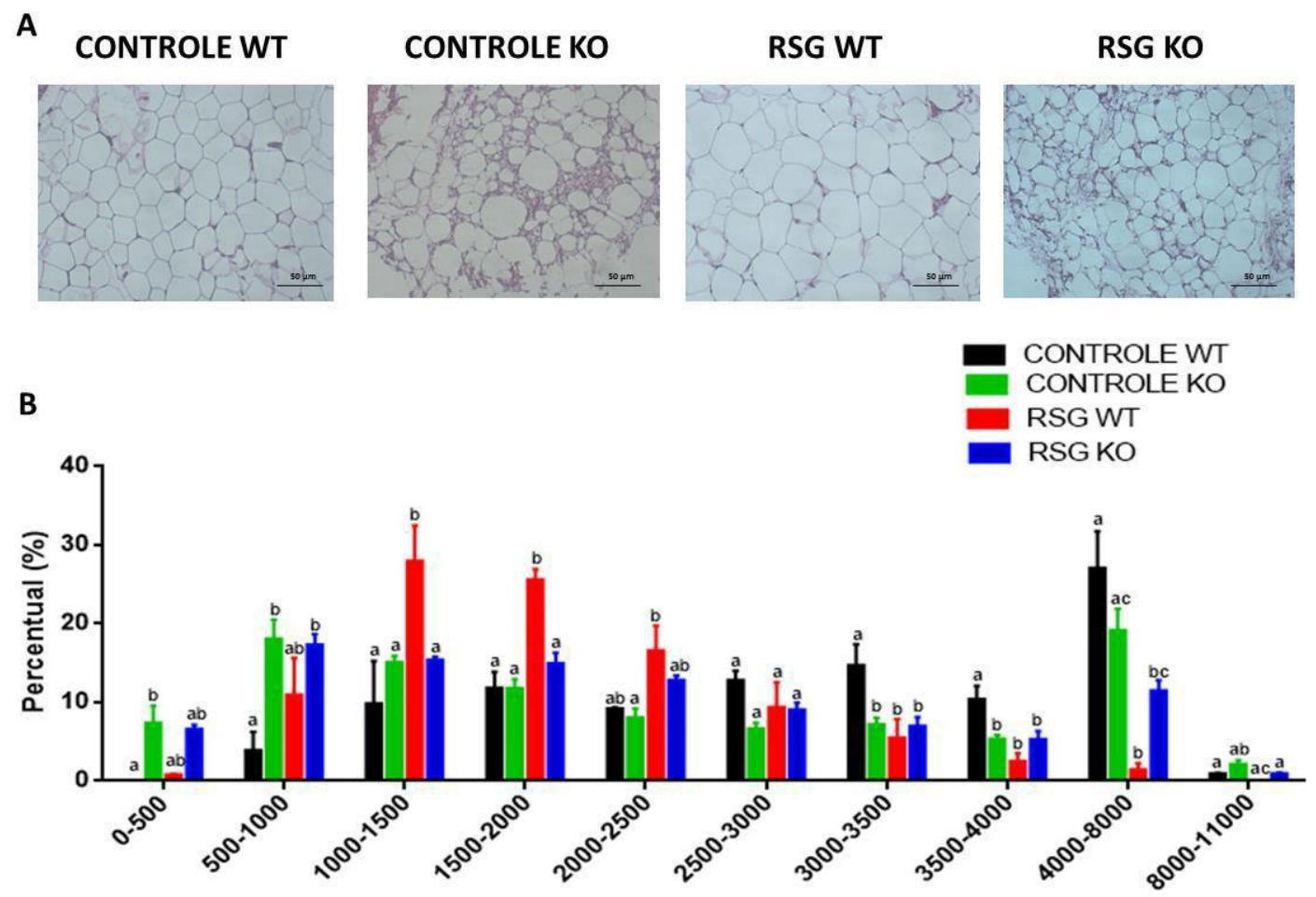

Figura 8. Análise morfológica do tecido adiposo inguinal. Fotomicrografias representativas de cortes do tecido adiposo inguinal coradas com hematoxilina e eosina (A) e distribuição em porcentagem dos adipócitos por área (B) em camundongos ARapWT e ARapKO alimentados com dieta hiperlipídica tratados ou não com rosiglitazona na dose de $30 \mathrm{mg} / \mathrm{kg}$ / dia durante 8 semanas. ANOVA Two-way pós-teste de Tukey. Letras diferentes indicam diferenças estatísticas, $\mathrm{p} \leq 0,05$. $(\mathrm{n}=5$ animais por grupo). Objetiva $20 \mathrm{X}$ 
Realizamos também a análise morfológica do tecido adiposo marrom. Como ilustrado na Figura 9, todas as condições estudadas, ou seja, deleção de raptor, tratamento com rosiglitazona ou combinação dos dois, promoveram um aumento no número de adipócitos uniloculares no tecido adiposo marrom. Este efeito parece ser mais intenso em camundongos controles tratados com rosiglitazona, o que coincide com o aumento da massa tecidual.

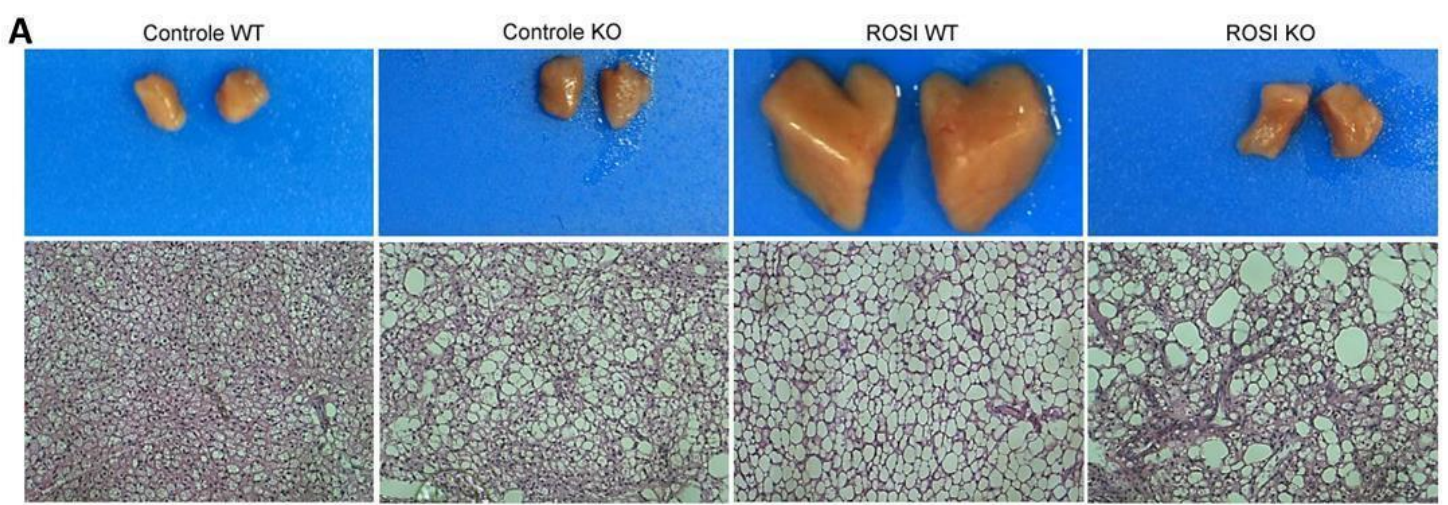

Figura 9. Imagens fotográficas e histológica do tecido adiposo marrom. Fotografia de tecido adiposo marrom e respectivas secções histológicas coradas com hematoxilina e eosina (A) em camundongos ARapWT e ARapKO alimentados com dieta hiperlipídica tratados ou não com rosiglitazona na dose de $30 \mathrm{mg} / \mathrm{kg} /$ dia durante 8 semanas. Objetiva de $20 \mathrm{X}$

Ao observamos imagens obtidas por fotomicrografia do fígado (Figura 10), vemos que a deleção de mTORC1 aumentou significativamente a infiltração lipídica, dado esse que reflete o aumento na massa observada nesse tecido, independentemente do tratamento com rosiglitazona. 


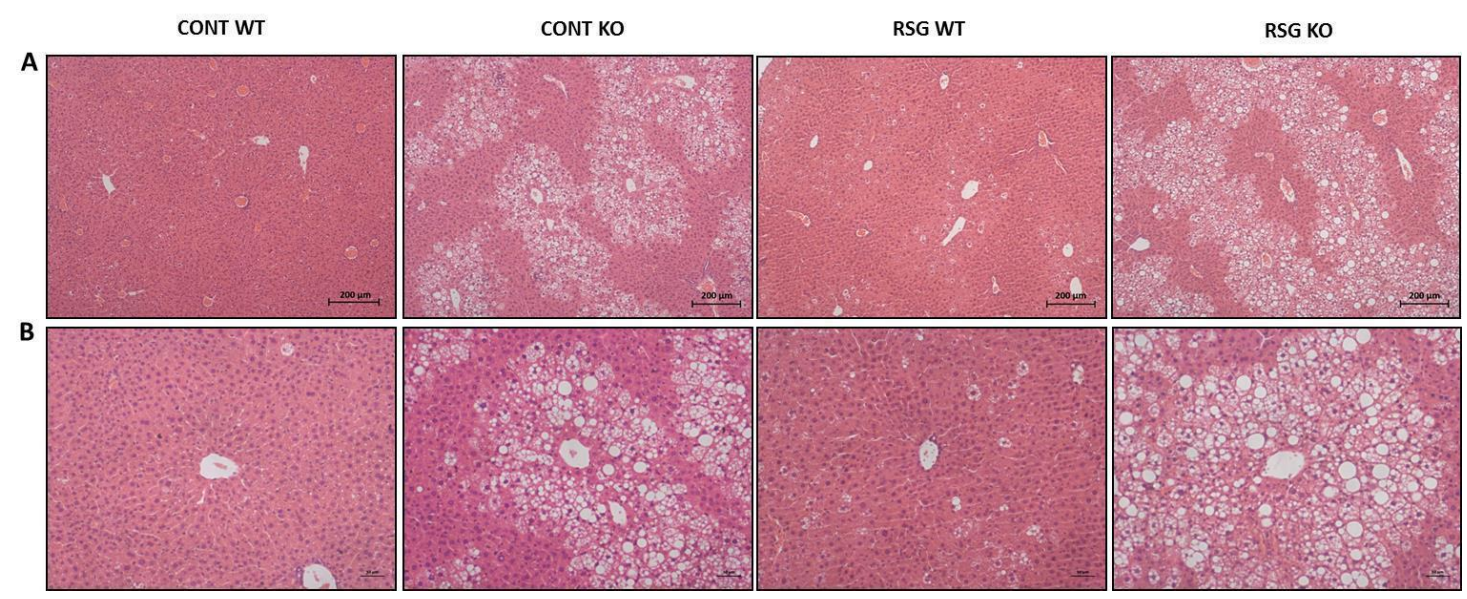

Figura 10. Histologia de fígado. Secções histológicas de fígado na objetiva de 10x (A) e 20x (B) coradas com hematoxilina e eosina em camundongos ARapWT e ARapKO alimentados com dieta hiperlipídica tratados ou não com rosiglitazona na dose de 30 $\mathrm{mg} / \mathrm{kg} /$ dia durante 8 semanas.

Sendo a rosiglitazona uma droga usada no tratamento do Diabetes do tipo 2, visto que melhora a homeostase glicêmica, realizamos ensaios in vivo afim de verificar a ação da rosiglitazona no metabolismo da glicose e sua relação com a via da mTORC1. Para tal, testes de tolerância à glicose e à insulina (GTT e ITT, respectivamente) foram conduzidos. Conforme ilustrado na Figura 11, a deleção de raptor em adipócitos não alterou significativamente a tolerância à glicose, mas induziu uma importante intolerância à insulina como evidenciado pelo reduzido kITT e hiperinsulinemia de jejum. $\mathrm{O}$ tratamento com rosiglitazona não induziu alterações significativas na homeostase da glicose em animais controles (ARapWT), mas aumentou a tolerância à glicose e reduziu significativamente a intolerância à insulina e a hiperinsulinemia de jejum nos camundongos deficiência de mTORC1 (ARapKO). Não houve alteração significativa na glicemia de jejum em nenhuma das condições estudadas. 

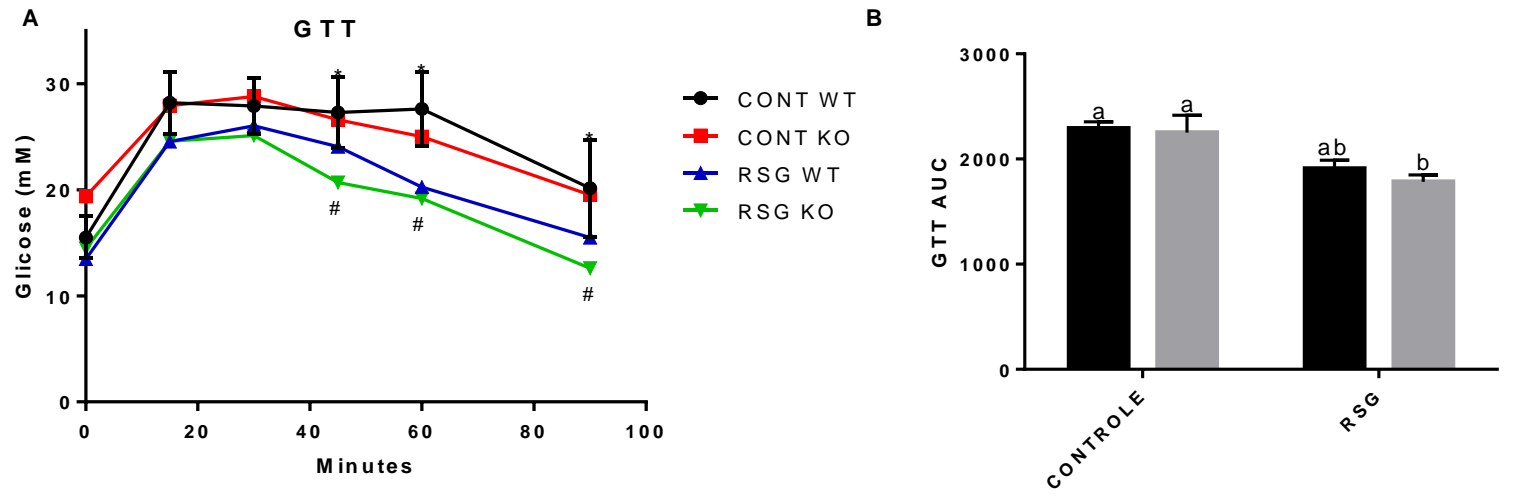

C

IT T

D
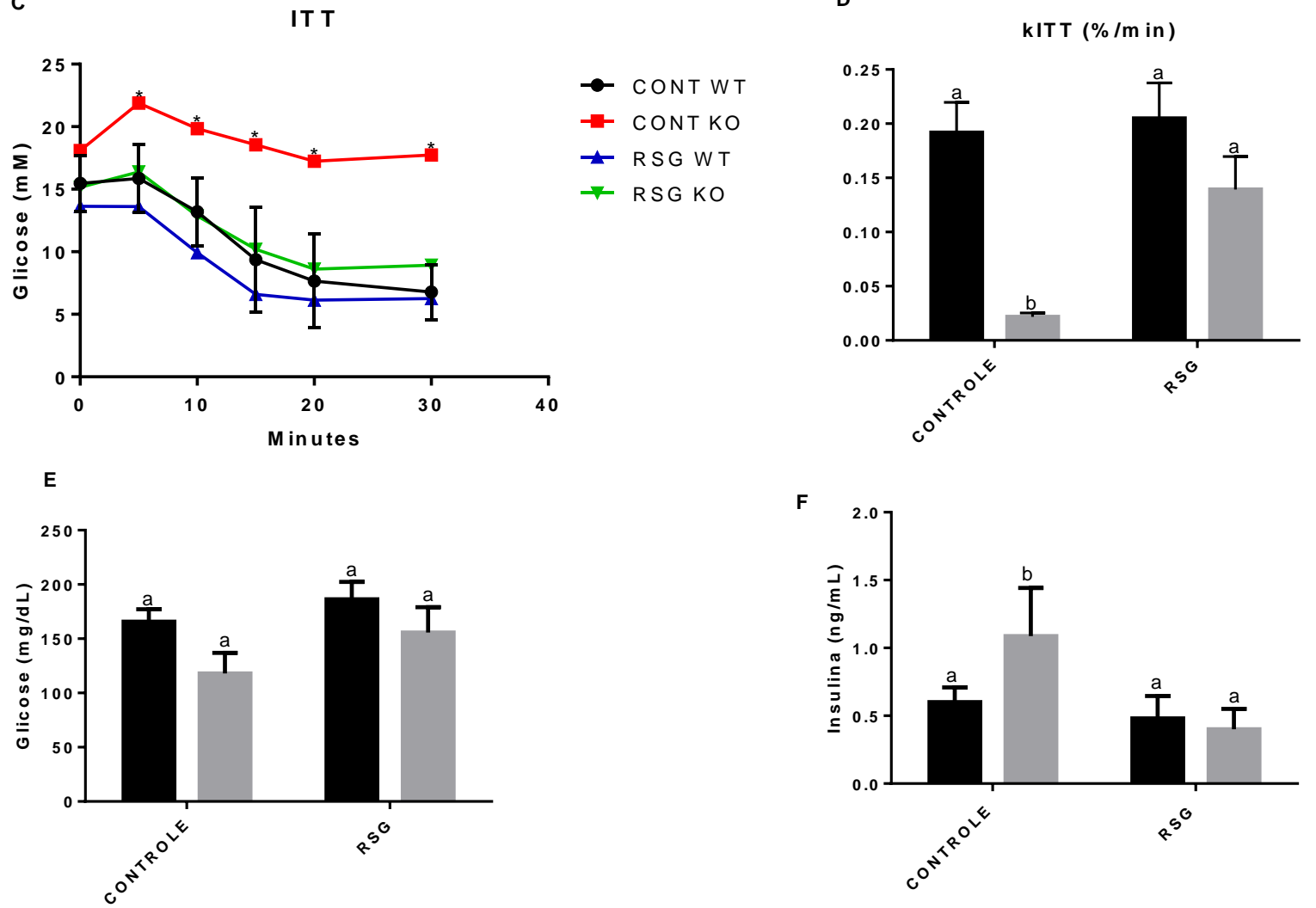

Figura 11. Teste de tolerância à glicose (GTT, A), área sob a curva GTT (B), teste de tolerância à insulina (ITT, C) e velocidade de decaimento da glicemia (kITT) (D), glicemia (E) e insulinemia (F) de jejum em camundongos ARapWT e ARapKO alimentados com dieta hiperlipídica tratados ou não com rosiglitazona na dose de 30 $\mathrm{mg} / \mathrm{kg} / \mathrm{dia}$ durante 8 semanas. ANOVA Two-way pós-teste de Tukey. Letras diferentes indicam diferenças estatísticas, $p \leq 0,05$. ( $n=10$ animais por grupo)

Analisamos também outros parâmetros séricos como os níveis de triacilglicerol e leptina. Como ilustrado na Figura 12, tanto a deleção de raptor em adipócitos quanto o tratamento 
com rosiglitazona reduziram significativamente os níveis séricos de triacilglicerol e leptina. Não houve entretanto efeito aditivo entre os dois tratamentos.

A

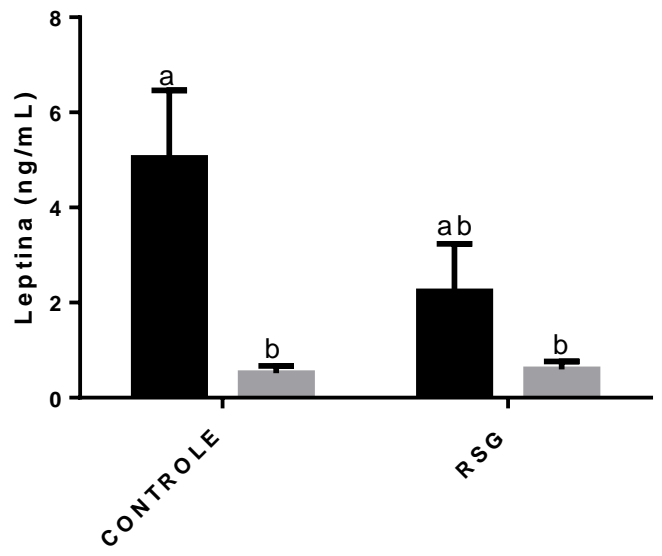

B

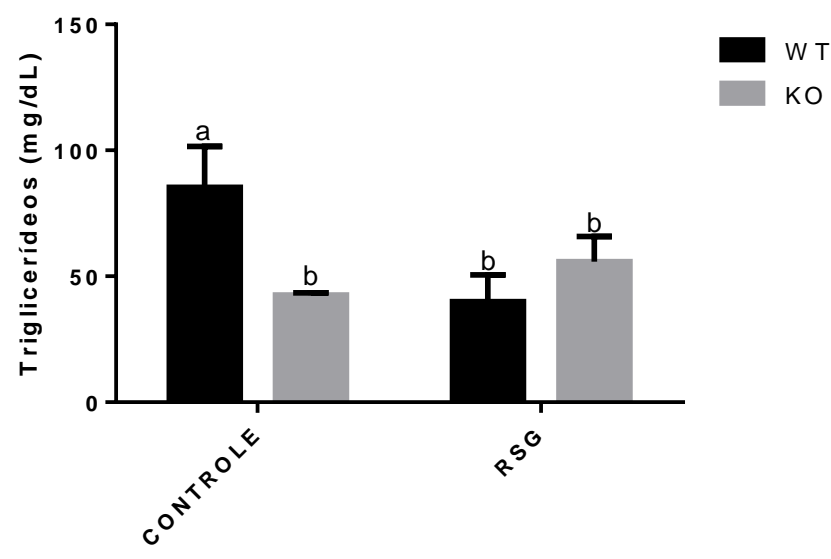

Figura 12. Níveis séricos de leptina (A) e triacilglicerol (B) de camundongos ARapWT e ARapKO alimentados com dieta hiperlipídica tratados ou não com rosiglitazona na dose de $30 \mathrm{mg} / \mathrm{kg} / \mathrm{dia}$ durante 8 semanas. ANOVA Two-way pós-teste de Tukey. Letras diferentes indicam diferenças estatísticas, $p \leq 0,05$. ( $n=10$ animais por grupo)

Alterações da massa adiposa são geralmente associadas à processos inflamatórios e alterações no perfil dos leucócitos residentes no tecido adiposo. Como ilustrado na Figura 13, análise da composição celular da fração estroma vascular do tecido adiposo por citometria de fluxo identificou que a redução de massa do tecido adiposo induzida pela deficiência de mTORC1 é associada com processo inflamatório tecidual caracterizado pelo aumento na porcentagem de macrófagos M1 (tendência), linfócitos $\mathrm{T}$ citotóxicos, linfócitos $\mathrm{B}$ e neutrófilos. Interessantemente o tratamento com rosiglitazona não afetou a porcentagem de leucócitos residentes no tecido adiposo epididimal de camundongos ARapWT e ARapKO. 

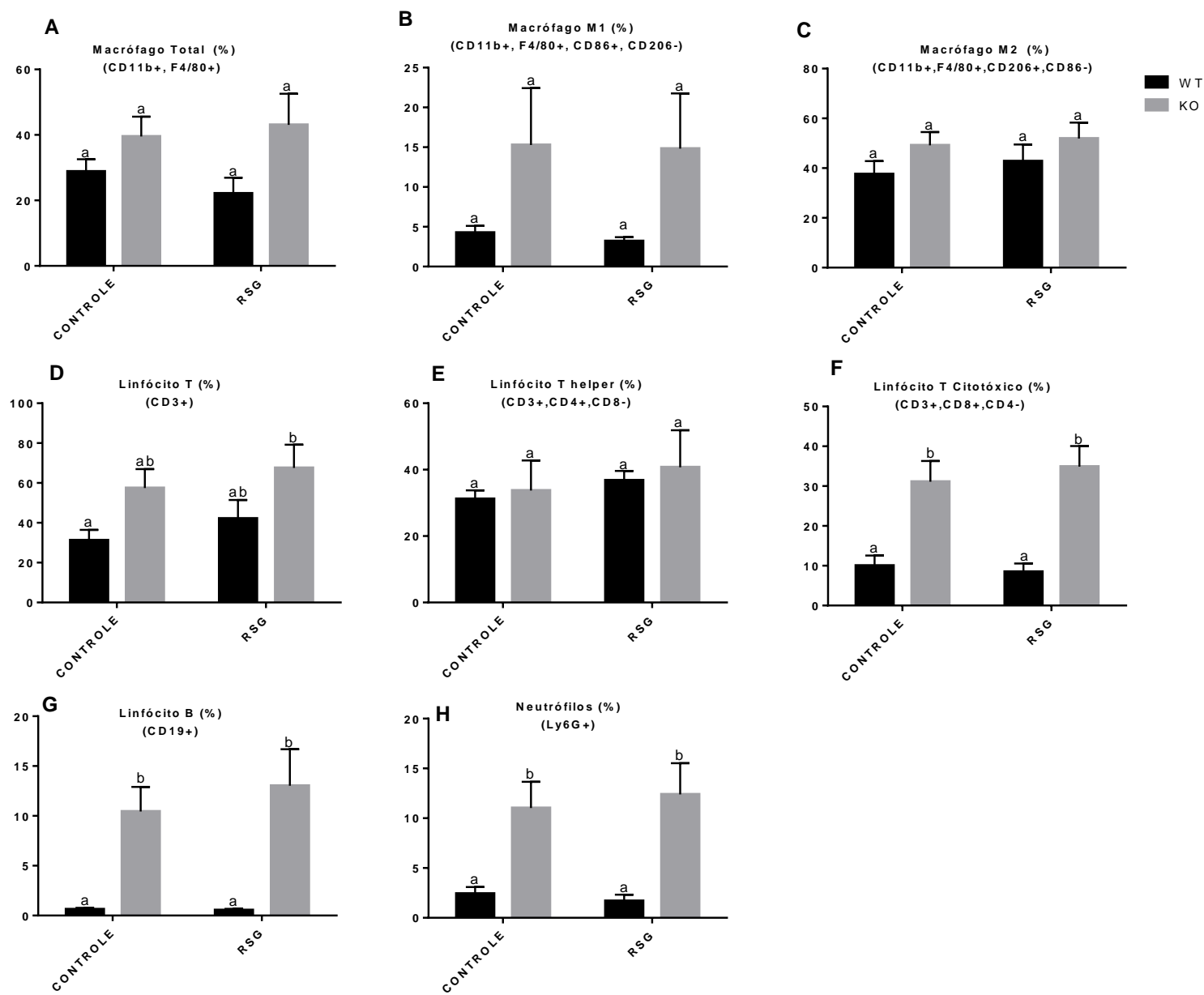

Figura 13. Perfil inflamatório do tecido adiposo epididimal. Perfil de leucócitos residentes no tecido adiposo epididimal de camundongos ARapWT e ARapKO alimentados com dieta hiperlipídica tratados ou não com rosiglitazona (30 mg/kg/dia) por 8 semanas. Macrófagos totais (A), macrófagos M1 (B), macrófagos M2 (C), linfócito $T(D)$, linfócito $T$ helper $(E)$, linfócito $T$ citotóxico $(F)$, linfócito $B(G)$ e neutrófilo (H). ANOVA Two-way pós-teste de Tukey. Letras diferentes indicam diferenças estatísticas, $p \leq 0,05$. ( $n=10$ animais por grupo)

Além da infiltração de leucócitos, avaliamos também a expressão gênica de proteínas envolvidas em respostas inflamatórias teciduais. Como ilustrado na Figura 14, a deficiência de mTORC1 aumentou significativamente o conteúdo de mRNA de NLRP3, DUSP6, ASC-PYCARD e IL1 $\beta$ da via do NLRP3-inflamassoma, bem como, de MCP1, uma quimiocina de atração de macrófagos, CD86, um marcador de macrófagos do tipo M1 e da citocina pró-inflamatória TNFa no tecido adiposo. O tratamento com rosiglitazona não afetou estes parâmetros nos animais controles (ARapWT), mas, com exceção de MCP-1 e CD86, bloqueou o aumento destes em 
camundongos ARapKO.
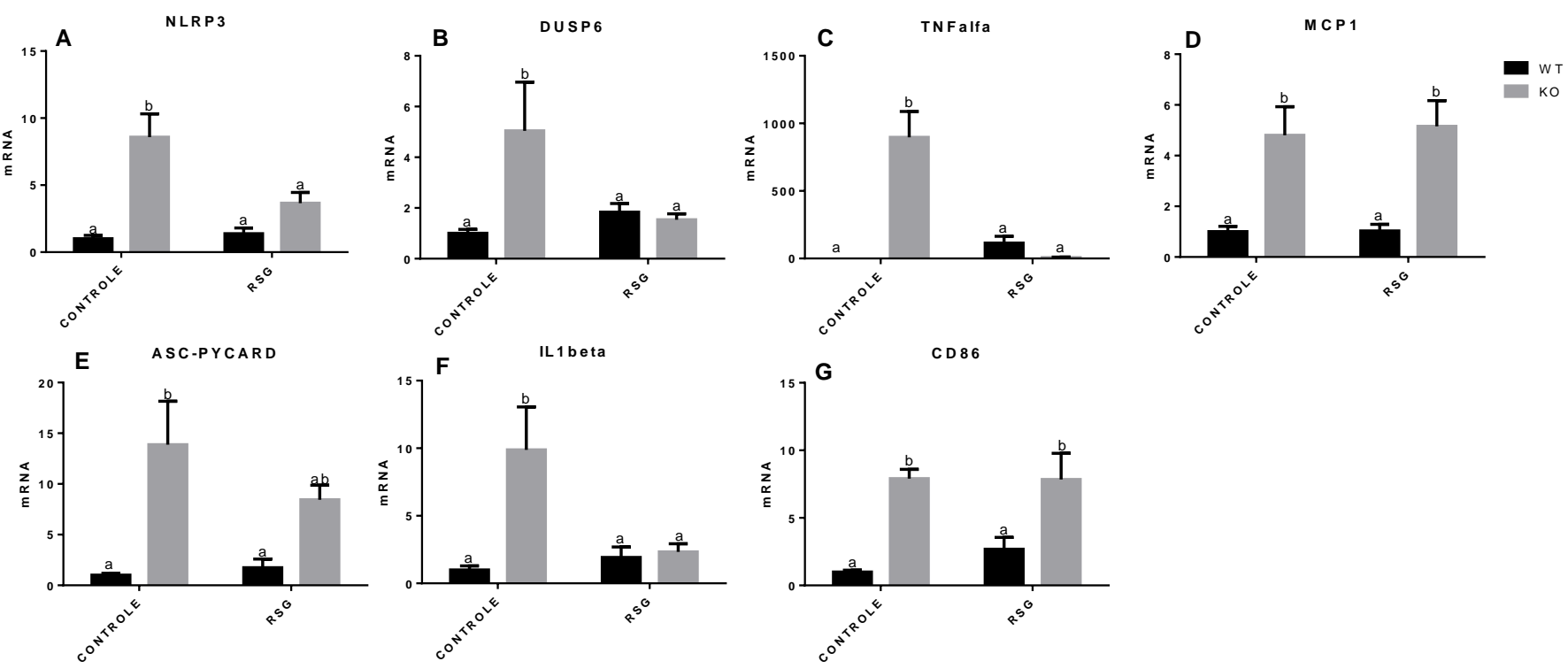

Figura 14. Expressão gênica de marcadores inflamatórios. Conteúdo de mRNA de NLRP3 (A), DUSP6 (B), TNF $\alpha$ (C), MCP1 (D), ASC-PYCARD (E), IL1 $\beta$ (F), CD86 (G) no tecido adiposo inguinal em camundongos ARapWT e ARapKO alimentados com dieta hiperlipídica tratados ou não com rosiglitazona na dose de $30 \mathrm{mg} / \mathrm{kg} /$ dia durante 8 semanas. ANOVA Two- way pós-teste de Tukey. Letras diferentes indicam diferenças estatísticas, $\mathrm{p} \leq 0,05$. ( $\mathrm{n}=10$ animais por grupo em IL1 $\beta$, TNF $\alpha$ e CD86) ( $n=5$ animais nos demais).

Outras ações importantes responsáveis pela melhora na homeostase glicêmica promovidas pelo uso da rosiglitazona são o aumento nos níveis de adiponectina e redução nos de aminoácidos de cadeia ramificada (BCAA) circulantes. Assim, buscamos investigar se tais efeitos eram dependentes da mTORC1. Como ilustrado na Figura 15A, a deleção de raptor em adipócitos reduziu significativamente os níveis séricos de adiponectina, bem como, o conteúdo de mRNA de adiponectina e Dsbl-A (proteína similar a oxidoredutase com ligação dissulfeto A), uma proteína localizada no retículo endoplasmático responsável pela multimerização da adiponectina, nos tecidos adiposos marrome inguinal. O tratamento com rosiglitazona aumentou os níveis séricos de adiponectina, sem alterar significativamente os níveis de mRNA da adiponectina e Dsbl-A no tecido adiposo de camundongos controles ARapWT. Em contraste aos controles, o tratamento com rosiglitazona não alterou os níveis séricos de adiponectina 
em camundongos com deleção de raptor em adipócitos. Esses dados sugerem que o aumento nos níveis séricos de adiponectina induzido pela rosiglitazona parece ser dependente de mTORC1.
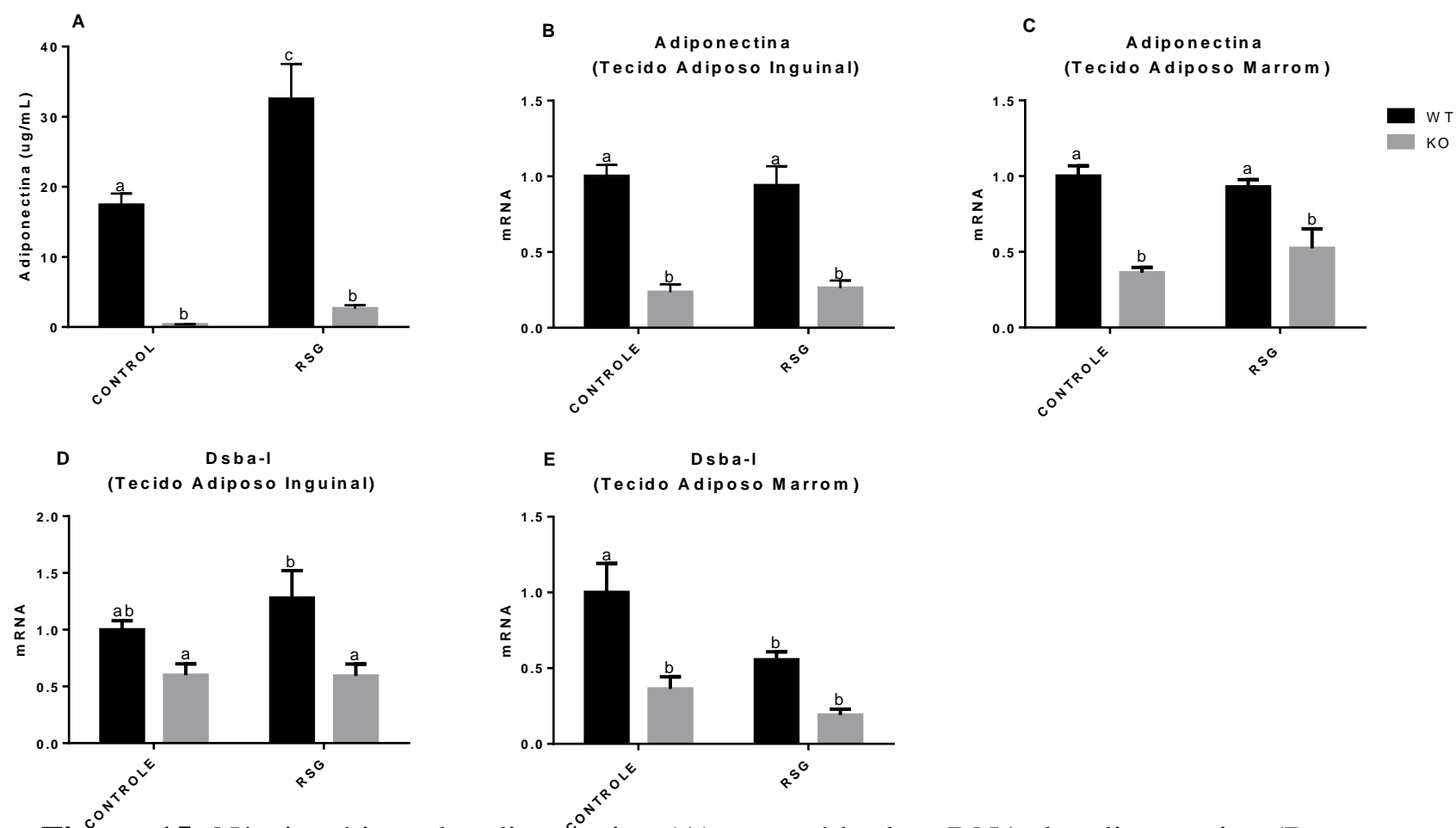

Figura 15. Níveis séricos de adiponectina (A), conteúdo de mRNA de adiponectina (B e C) e Dsba-1 (D e E) nos tecidos adiposos inguinal e marrom, respectivamente, de camundongos ARapWT e ARapKO alimentados com dieta hiperlipídica tratados ou não com rosiglitazona na dose de $30 \mathrm{mg} / \mathrm{kg} / \mathrm{dia}$ durante 8 semanas. ANOVA Two-way pós-teste de Tukey. Letras diferentes indicam diferenças estatísticas, $p \leq 0,05$.( $n=10$ animais por grupo)

Estudos prévios do nosso grupo demonstraram que a ativação farmacológica de PPAR $\gamma$ com rosiglitazona reduz os níveis séricos de BCAA por mecanis mo que envolve o aumento da oxidação destes aminoácidos no tecido adiposo. Aqui nós investigamos uma possível participação de mTORC1 nestas ações da rosiglitazona. Como ilustrado na Figura 16, a deficiência de mTORC1 em adipócitos não alterou os níveis séricos de BCAA e o conteúdo de mRNA das proteínas BCKDHA, BCKDK, DBT e DLD no tecido adiposo inguinal. No tecido adiposo marrom, entretanto, a deficiência de mTORC1 reduziu o conteúdo de mRNA da BCKDHA E DBT, sem alterar a expressão de BCKDHA e BCKDK. Corroborando dados prévios do grupo, o tratamento com 
rosiglitazona reduziu os níveis séricos de BCAA e aumentou o conteúdo de mRNA de BCKDHA, BCKDK, DBT e DLD no tecido adiposo branco dos camundongos controles (ARapWT), efeitos estes que foram completamente bloqueados pela deficiência de mTORC1. No tecido adiposo marrom, entretanto, o tratamento com rosiglitazona reduziu o conteúdo de mRNA de BCKDHA e DBT camundongos controles (ARapWT), mas não nos ARapKO.
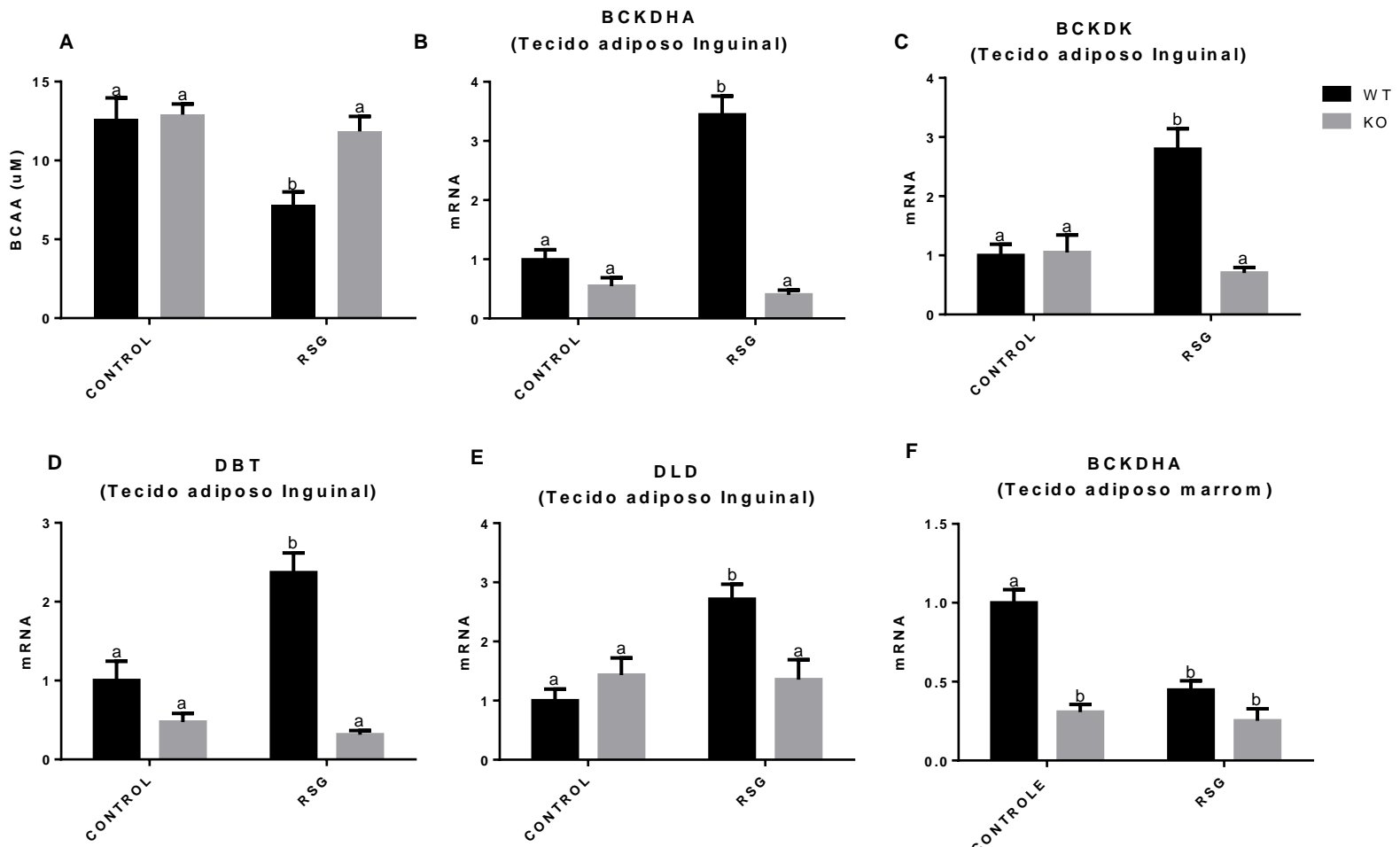

$\mathbf{F}$
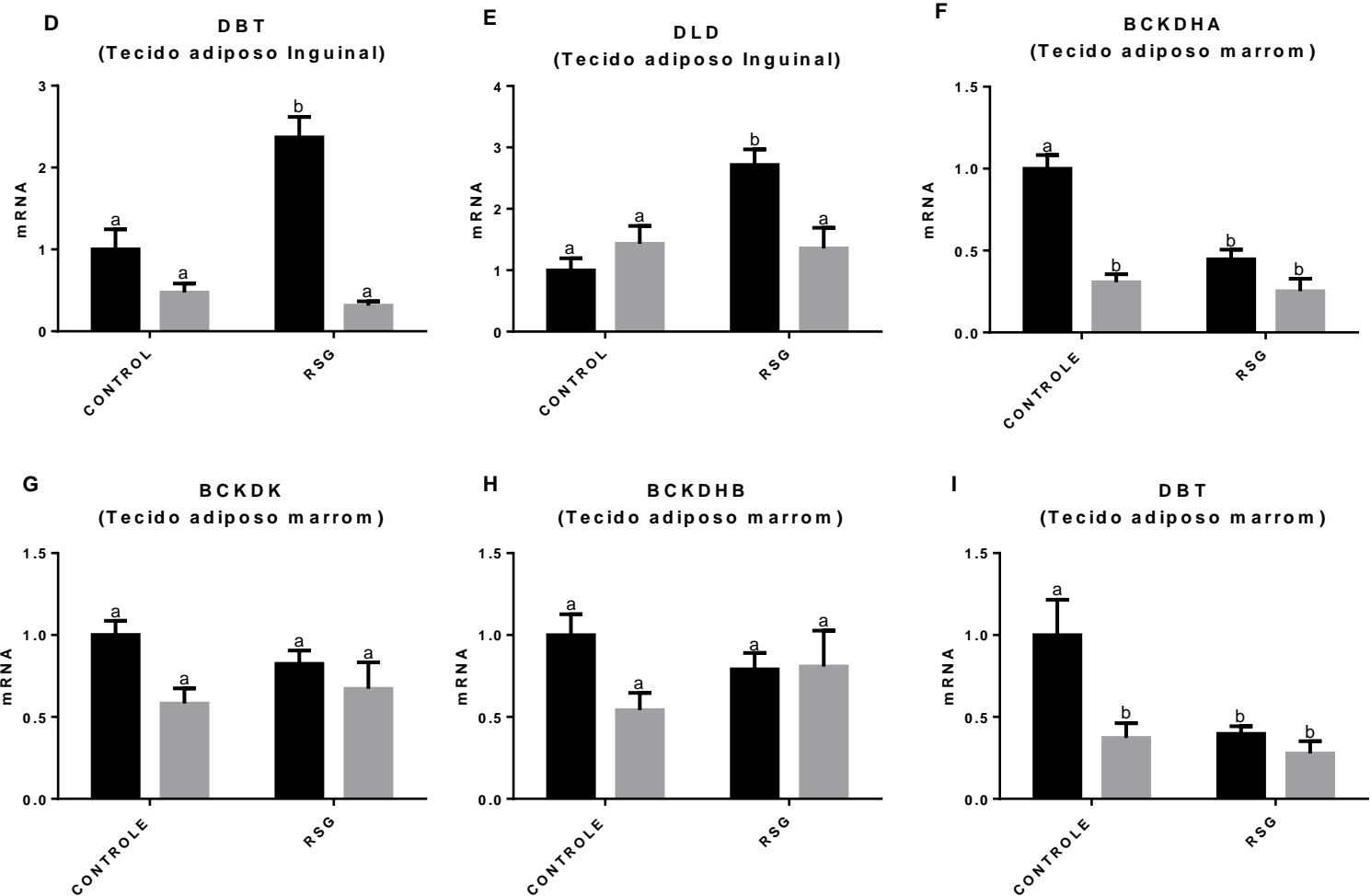

Figura 16. Metabolismo de BCAA. Níveis séricos de BCAA (A) e conteúdo de mRNA de enzimas do metabolismo do BCAA (BCKDHA, BCKDK, DBT E DLD) nos tecidos adiposos inguinal (B,C,D e E) e marrom (F,G,H e I) de camundongos ARapWT e ARapKO alimentados com dieta hiperlipídica tratados ou não com rosiglitazona na 
dose de $30 \mathrm{mg} / \mathrm{kg} /$ dia durante 8 semanas. ANOVA Two-way pós-teste de Tukey. Letras diferentes indicam diferenças estatísticas, $p \leq 0,05$. ( $n=10$ animais por grupo).

Posteriormente, investigamos possíveis efeitos da rosiglitazona e deleção de raptor no consumo de oxigênio e assim gasto energético dos tecidos adiposos branco e marrom. Corroborando os dados anteriores, tanto a deficiência de mTORC1 quanto o tratamento com rosiglitazona aumentaram o consumo de oxigênio no tecido adiposo branco. Não houve, entretanto, efeito aditivo quando combinados. No tecido adiposo marrom, houve somente a redução no consumo de oxigênio induzida pela deleção de raptor (Figura 17)

A

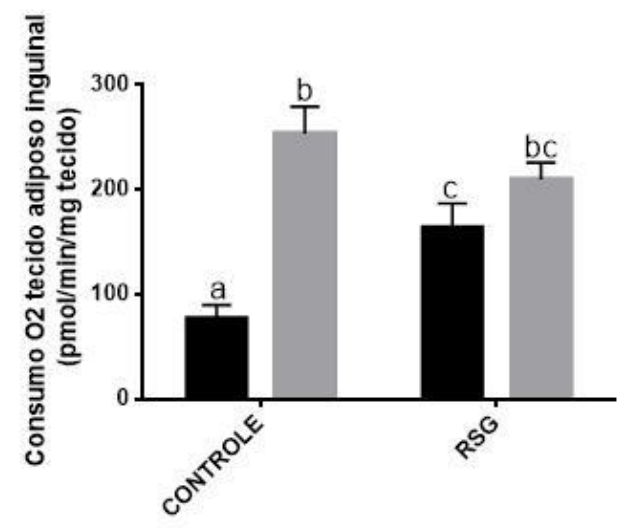

B

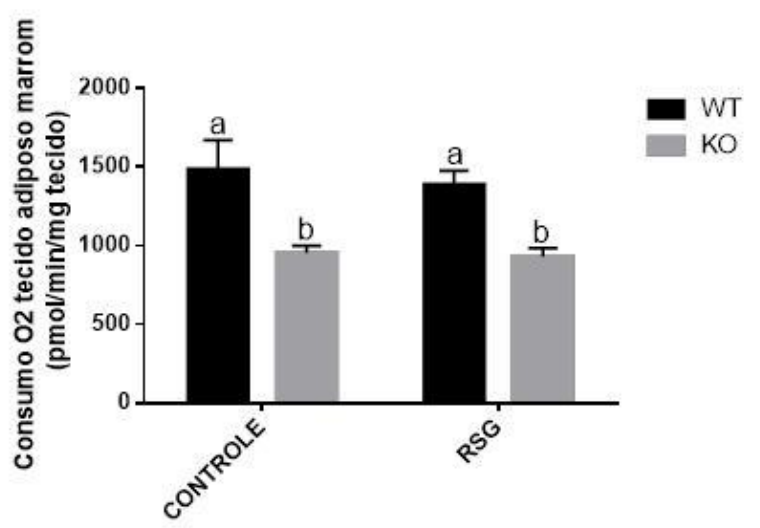

Figura 17. Consumo de O2. Consumo de $\mathrm{O} 2$ nos tecidos adiposos inguinal (A) e marrom (B) de camundongos ARapWT e ARapKO alimentados com dieta hiperlipídica e tratados ou não com rosiglitazona (30 mg/ kg/ dia) por 8 semanas. ANOVA Two-way pós-teste de Tukey, $p \leq 0,05$. Letras diferentes indicam diferenças estatísticas. ( $n=10$ animais por grupo)

Investigamos posteriormente uma possível participação do processo de browning no aumento do gasto energético apresentado pelo tecido adiposo branco. Como ilustrado na Figura 18, a deficiência de mTORC1 em adipócitos aumentou significativamente o conteúdo proteico e de mRNA de UCP1 no tecido adiposo inguinal (Figura 18A e B ). Camundongos ARapKO também apresentaram conteúdo aumentado de mRNA de PGC1 $\alpha$ no tecido adiposo inguinal, um coativador da atividade transcricional de diversos receptores nucleares incluindo PPAR $\gamma$. Tratamento com rosiglitazona por outro lado não alterou significativamente UCP1 ou PGC1 $\alpha$. Ao analisarmos no tecido adiposo inguinal a 
expressão de genes relacionados à função mitocondrial (Figura 18), vimos que todos apresentaram um mesmo perfil de aumento ou tendência de aumento na ausência de mTORC1 (ARapKO). Foi avaliada a expressão das seguintes proteínas associadas a função mitocondrial: F1F0-ATPase, que sintetiza e/ou hidrolisa ATP dependendo do gradiente eletroquímico transmembrana; NDUFB5, subunidades mitocondrial do complexo da cadeia de transporte de elétrons I (NADH desidrogenase [ubiquinona] 1 beta subcomplexo 5); SDHB, complexo succinato desidrogenase, subunidade B, MFN2, mitofusina relacionada à fusão mitocondrial; e CPT1 $\alpha$, carnitina acyltransferase 1 que participa na oxidação de ácidos graxos. Já no tratamento com rosiglitazona observamos uma tendência de aumento apenas para F1F0-ATPase e MFN2.


Figura 18. Conteúdo de proteína UCP-1 (A). Conteúdo de mRNA de UCP-1 (B), PGC1 $\alpha$, NDUFB5 (D), CPT1 $\alpha$ (E), SDHB (F), MFN2 (G), F1F0-ATPase (H) no tecido adiposo inguinal de camundongos ARapWT e ARapKO alimentados com dieta hiperlipídica tratados ou não com rosiglitazona na dose de $30 \mathrm{mg} / \mathrm{kg} / \mathrm{dia}$ durante 8 semanas. ANOVA Two- way pós-teste de Tukey. Letras diferentes indicam diferenças estatísticas, $\mathrm{p} \leq 0,05$. $(\mathrm{n}=5$ animais por grupo) 
Algumas proteínas relacionadas ao metabolismo lipídico também foram analisadas por expresão gênica no tecido adiposo inguinal (Figura 19). Podemos observar na Figura 19 que a deficiência de mTORC1 reduziu o conteúdo de mRNA de CD36 (transportador de ácido graxo) e PEPCK (síntese de glicerol 3-fosfato via gliceroneogênese) e aumentou o da enzima FAS (síntese de ácidos graxos) no tecido adiposo inguinal. Tratamento com rosiglitazona aumentou o conteúdo de mRNA de CD36 e PEPCK nos animais controles, efeito este que foi bloqueado pela deficiência de mTORC1. Tratamento com rosiglitazona reduziu o conteúdo de FAS no inguinal de camundongos ARapKO. Não encontramos diferenças significativas no conteúdo de mRNA da ATGL (lipólise), DGAT (síntese de TAG) e FABP4 (transportador de ácidos graxos) e PPAR $\gamma 1$ entre as diferentes condições. 

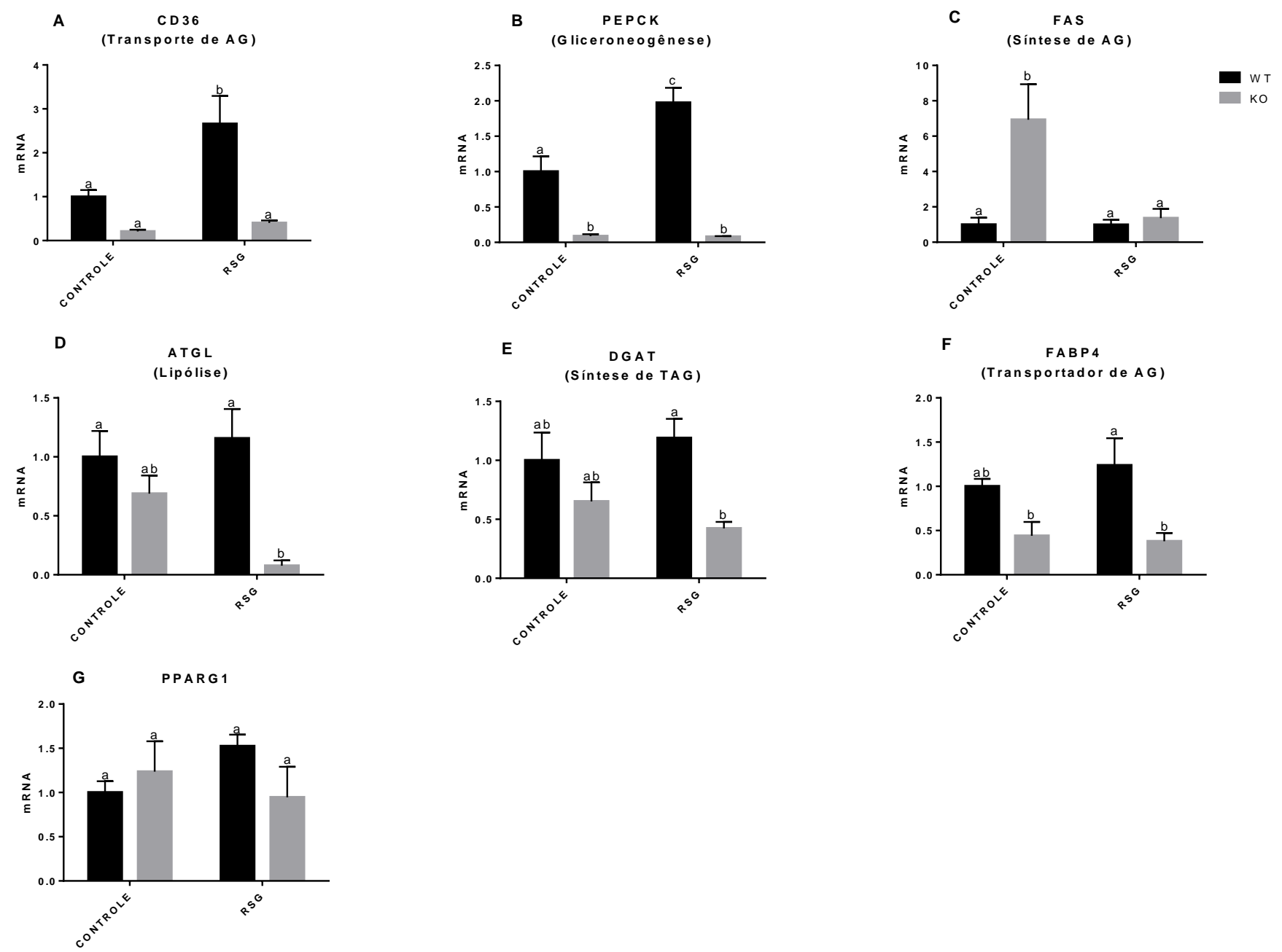

Figura 19. Expressão gênica no tecido adiposo inguinal. Conteúdo de mRNA de CD36 (A), PEPCK (B), FAS (C), ATGL (D), DGAT (E), FABP4 (F) PPAR $\gamma 1$ (G) no tecido adiposo inguinal de camundongos ARapWT e ARapKO alimentados com dieta hiperlipídica tratados ou não com rosiglitazona na dose de $30 \mathrm{mg} / \mathrm{kg} /$ dia durante 8 semanas. ANOVA Two- way pós-teste de Tukey. Significância de $p \leq 0,05$. Letras diferentes indicam diferenças estatísticas.( $\mathrm{n}=5$ animais por grupo) 
Com o intuito de identificar, em larga escala, alterações no perfil lipídico do tecido adiposo epididimal, realizamos uma análise de lipidômica (Figuras 20, 21 e 22) por espectrometria de massas. Com essa análise, conseguimos identificar e quantificar aproximadamente 350 lipídeos das mais diferentes classes como triacilgliceróis, diacilgliceróis, fosfolipídeos, ceramidas, cobrindo cerca de $80 \%$ de todos os lipídeos presentes nas amostras. A partir dessa identificação, geramos um Heatmap (Figura 21) dos 50 compostos lipídicos com maior diferença estatística, onde as amostras foram agrupadas por similaridade em seu grupo experimental correto, conforme mostrado em análise de PCA (do inglês, Principal Component Analysis, usada para verificar a distribuição dos dados por grupos) na Figura 20, indicando que existem padrões característicos de perfil lipídico entre as diferentes condições experimentais.

Entre todos os lipídeos identificados, os mais abundantes foram os triacilgliceróis (TAG), com cerca de 130 espécies diferentes. Entre os TAG identificados, 27 espécies com maior diferença significativa, apresentaram distribuição compatível com as condições experimentais obtidas, já que todos os grupos apresentaram menor quantidade de TAG que o grupo ARapWT sem tratamento com rosiglitazona, mostrando que tanto a droga quanto a deleção de raptor diminuem a deposição de TAG nesse depósito. Outra classe de lipídeos que interessantemente mostrou-se alterada com o tratamento de rosiglitazona numa relação efeito-dependente de mTORC1 foram as cardiolipinas (Figura 21-B), importantes componentes da membrana mitocondrial interna, cujas alterações em seu conteúdo e estrutura tem sido relacionados a disfunção mitocondrial que pode estar associados a doenças como diabetes, esteatose hepática não-alcoólica, doença de Parkinson, entre outras (PARADIES, 2014).

Além das cardiolipinas, a fosfatidiletanolamina (PE), que também é importante para função mitocondrial, foi aumentada pela rosiglitazona de maneira dependente de mTORC1. Outra classe de lipídeos de importante papel metabólico são as ceramidas, esfingolipídeos que modulam a sinalização celular. Sendo assim, buscamos analisar entre as diversas espécies de ceramidas, as que sofreram alterações decorrentes da deleção de mTORC1 e/ou tratamento com rosiglitazona. Interessantemente, encontramos respostas distintas para a diferentes espécies de ceramidas (Figura 21D, E e F). Houve um aumento no percentual de ceramidas de cadeia longa (C:16-18), além de redução no percentual de ceramidas de cadeia muito longa (C:24) após tratamento com 
rosiglitazona, efeitos estes que foram dependentes de mTORC1. O tratamento com rosiglitazona aumentou também o conteúdo de Cer (d18:1/24:2) independentemente de mTORC1.

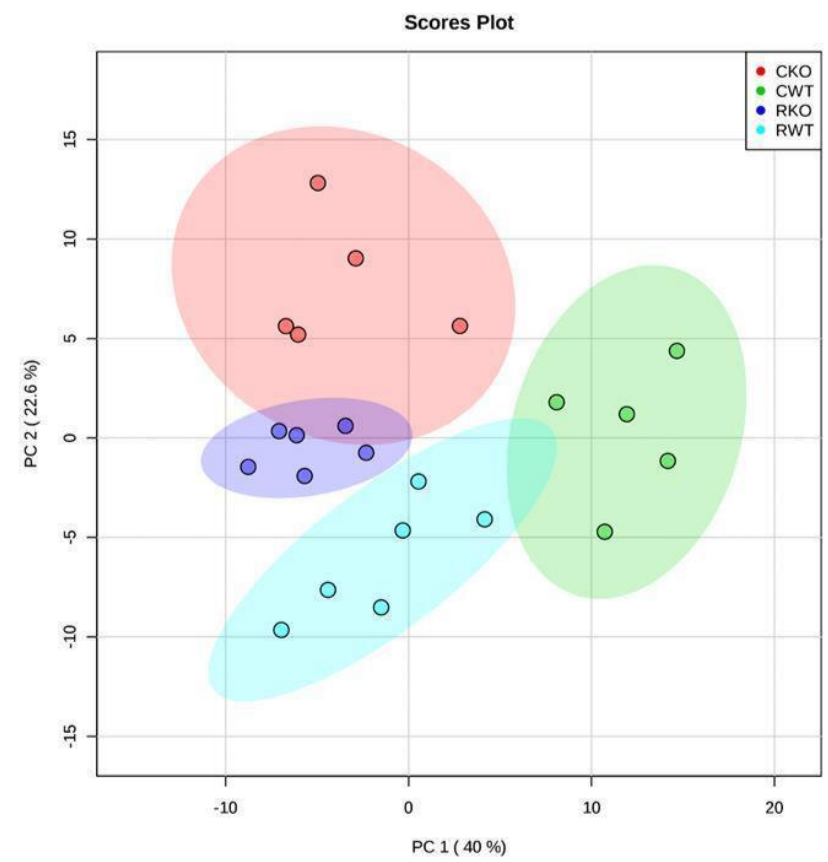

Figura 20. Análise de PCA de amostras de tecido adiposo epididimal de camundongos ARapWT e ARapKO alimentados com dieta hiperlipídica tratados ou não com rosiglitazona na dose de $30 \mathrm{mg} / \mathrm{kg} / \mathrm{dia}$ durante 8 semanas. ( $\mathrm{n}=6$ por grupo) 
A

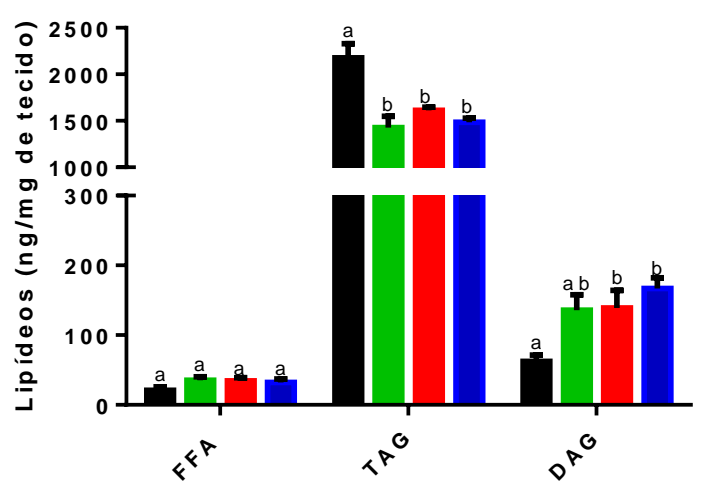

C

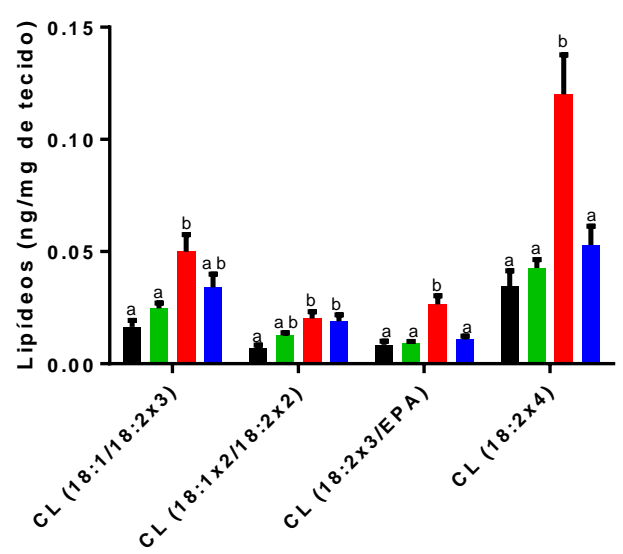

E

$$
\begin{aligned}
& \text { \% Ceramidas } \\
& \text { Cadeia Longa (C:16-C:18) }
\end{aligned}
$$

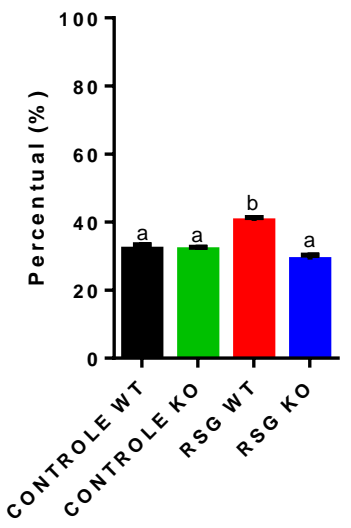

B

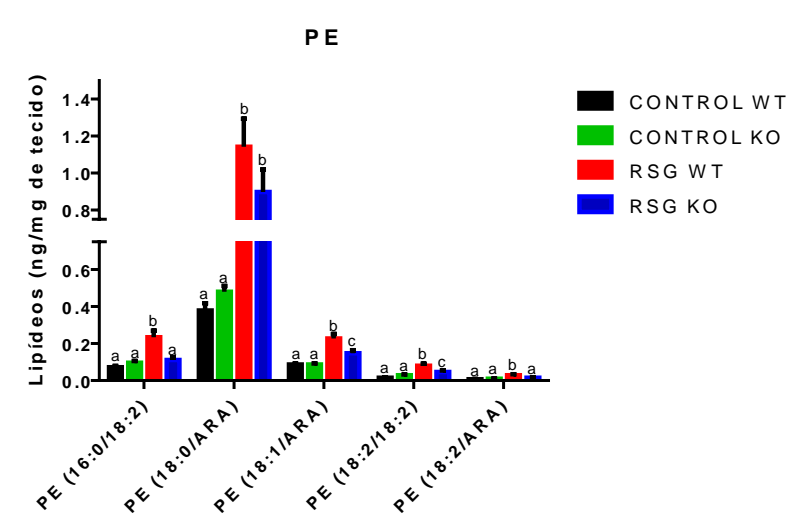

D

Ceramidas



$\mathbf{F}$

$\%$ Ceramidas

cadeia muito longa (C:24)

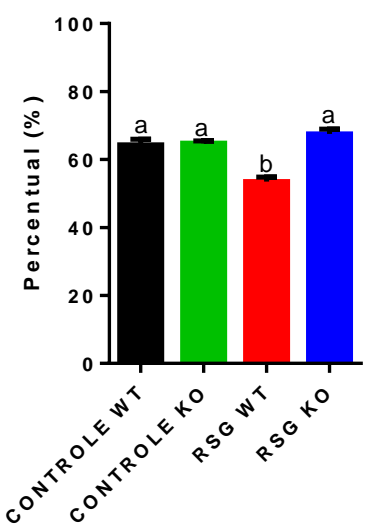

Figura 21. Lipídeos (A), PE (B), cardiolipina (C), ceramidas (D), \% ceramidas de cadeia longa (E) e \% ceramidas de cadeia muito longa (F) identificados no tecido adiposo de camundongos ARapWT e ARapKO alimentados com dieta hiperlipídica tratados ou não com rosiglitazona na dose de $30 \mathrm{mg} / \mathrm{kg} /$ dia durante 8 semanas. ( $\mathrm{n}=6$ por grupo) 




Figura 22. Heatmap dos 50 lipídeos mais alterados significativamente identificados no tecido adiposo epididimal de camundongos ARapWT e ARapKO alimentados com dieta hiperlipídica tratados ou não com rosiglitazona na dose de $30 \mathrm{mg} / \mathrm{kg} /$ dia durante 8 semanas. Linhas horizontais indicam espécies de lipídeos e linhas verticais indicam as amostras. Análise estatística (Anova two-way) por meio do software Metaboanalyst. ( $\mathrm{n}=6$ por grupo) 


\section{Discussão}

Estudos prévios demonstraram que a inibição farmacológica de mTOR interfere nas ações da rosiglitazona quanto à homeostase lipídica e adiposidade, sugerindo uma inter-relação entre mTOR e PPAR $\gamma$ (BLANCHARD,2012). Porém, sabendo que os complexos 1 e 2 da mTOR possuem papéis distintos e a inibição farmacológica age de maneira sistêmica, não foi possível identificar a importância de cada complexo nesses estudos. Assim, nossa proposta foi investigar o envolvimento da mTORC1 nas ações metabólicas promovidas por um agonista de PPAR $\gamma$ (rosiglitazona), principalmente nos tecidos adiposos branco e marrom por meio de deleção genética de raptor (deficiência de mTORC1) especificamente em adipócitos. Interessantemente, nossos dados sugerem que o complexo 1 da mTOR é um mediador importante em diversas ações promovidas pela rosiglitazona, como os aumentos na massa do tecido adiposo marrom, na porcentagem de adipócitos de área média, nos níveis séricos de adiponectina, expressão gênica de CD36 e PEPCK e no conteúdo de lipídeos típicos de mitocôndria, como a cardiolipina e PE no tecido adiposo branco.

Diferentemente dos resultados obtidos com inibição farmacológica de mTOR (BLANCHARD,2012), a deleção genética de raptor associada a rosiglitazona não promoveu alterações no consumo alimentar, nem no ganho de peso. Ademais, observamos que o tratamento com rosiglitazona promoveu redistribuição de gordura dos depósitos viscerais para o tecido adiposo marrom, mas não para o subcutâneo como visto anteriormente em ratos. Esse aumento da massa do tecido adiposo marrom, foi completamente dependente de mTORC1. A rosiglitazona promoveu redução significativa nos depósitos viscerais, porém notamos que a deleção de mTORC1 nos adipócitos apresentou efeito mais expressivo, reiterando a importância desse sensor de nutrientes na regulação da adiposidade. Estudo conduzido em nosso laboratório por Magdalon (2016) utilizando camundongos geneticamente modificados com ativação constitutiva de mTORC1 pela deleção de TSC1 em adipócitos, observou que o tecido adiposo marrom aumentou nos animais $\mathrm{KO}$, mostrando o papel importante da mTORC1 no desenvolvimento desse tecido. Em estudo publicado recentemente (FAYYAD, 2019), pesquisadores identificaram que há aumento na adipogênese de adipócitos marrons in vitro de células mesenquimais do estroma vascular promovido pela rosiglitazona, e que esse efeito está associado à ativação das vias da MAPK e PI3K, vias essas relacionadas à atividade de mTORC1, levando-nos a supor que o aumento de massa do tecido adiposo marrom induzido pela rosiglitazona pode ser devido a 
hiperplasia, ou seja, aumento no número de adipócitos marrons. Neste sentido, estudos anteriores conduzidos em ratos com a utilização de rosiglitazona, mostraram que a ativação farmacológica de PPAR $\gamma$ aumentou o recrutamento de tecido adiposo marrom, com aumento da massa desse tecido, além do conteúdo de triacilgliceróis e DNA (FESTUCCIA, 2010).

Apesar de não apresentar alterações na massa, foram encontradas importantes modificações na celularidade do tecido adiposo inguinal nas diversas condições estudadas. Análise histológica do tecido adiposo inguinal revelou um aumento na porcentagem de adipócitos de área média nos grupos tratados com rosiglitazona (10002500), e o mesmo não ocorreu na ausência da mTORC1. Estudos apontaram para uma relação entre o tamanho do adipócito e resistência à insulina (ARNER,2010; LUNDGREN,2007; SKURK,2007). Em estudo conduzido por Lundgren e colaboradores (2007), foi observado que o aumento no diâmetro de adipócitos foi associado à resistência à insulina em indivíduos não-diabéticos, independente do IMC, contudo, essa associação não foi a mesma após o desenvolvimento de diabetes tipo 2, sugerindo que outros fatores podem estar relacionados à alterações no metabolismo da glicose. Além disso, outro estudo correlacionou o diâmetro de adipócitos com a secreção de adipocinas (SKURK, 2007), para isso, utilizaram células oriundas de tecido adiposo subcutâneo humano, posteriormente isolados e mantidos em cultura celular. Foi demonstrado nesse estudo que a secreção de adipocinas tais como IL-10, IL-6 e TNF $\alpha$ está correlacionado com o tamanho dos adipócitos, sugerindo um aumento na secreção de adipocinas pró-inflamatórias em adipócitos maiores. Contrariamente aos estudos que correlacionam o diâmetro menor dos adipócitos com maior sensibilidade à insulina, nossos dados indicaram que os animais com deleção de mTORC1 (ARapKO) apesar de terem adipócitos menores, apresentaram resistência à insulina, e que quando tratados com rosiglitazona, tiveram sua sensibilidade reestabelecida. A resistência à insulina observada nos animais KO, dá-se pela inabilidade de estocar lipídeos, haja vista a redução acentuada em todos os depósitos adiposos, resultando num acúmulo ectópico de gordura no fígado e indução de inflamação no tecido adiposo. Nossos dados publicados mostraram que esse quadro de inflamação no tecido adiposo induzido pela deleção de mTORC1 especificamente em adipócitos ocorre inclusive em animais que ingeriram dieta padrão (CHIMIN,2017). Nesse trabalho, mostramos o efeito anti-inflamatório da rosiglitazona (resumo em anexo), reduzindo a resistência à insulina sem alterar o peso corporal, além de reduzir a expressão gênica de marcadores pró- 
inflamatórios (NLRP3, DUSP e IL1 $\beta$ ). Esses efeitos da rosiglitazona são independentes de mTORC1, visto que ambos os grupos (ARapWT e ARapKO) tratados com a droga apresentaram a mesma alteração. Por outro lado, a deleção genética de mTORC1 aumentou o conteúdo tecidual de macrófagos M1 e a expressão gênica de CD86, um marcador de células ativadas, em conjunto com um aumento na população de neutrófilos e linfócitos $\mathrm{B}$, efeitos estes decorrentes da deleção de mTORC1 que não foram modulados pelo tratamento com rosiglitazona, mostrando que nem todos os parâmetros pró-inflamatórios foram revertidos.

A melhora na resistência à insulina resultante do tratamento com rosiglitazona está relacionada ao fato da ativação farmacológica de PPAR $\gamma$ melhorar o metabolismo lipídico. Como já visto por diversos estudos (FESTUCCIA,2009a ; LEE,2016) o PPAR $\gamma$ é fundamental no controle do metabolismo lipídico, e o tratamento com seu ligante, rosiglitazona, foi associado a uma melhora nos quadros de dislipidemias, diabetes tipo 2 e hipertrigliceridemia provocados pela obesidade visceral. No estudo de Blanchard e colaboradores (2012) que utilizou do tratamento combinado de rosiglitazona em conjunto com rapamicina, foi demonstrado que a mTOR, é um importante mediador de algumas ações induzidas pela ativação farmacológica de PPAR $\gamma$ como o aumento da adiposidade subcutânea, da captação e clearance de lipídios e da atividade da LPLe lipogênese. No presente estudo foram avaliados também alguns genes envolvidos no metabolismo lipídico, como CD36, FABP4 (transporte de ácidos graxos), PEPCK (síntese de glicerol fosfato) e FAS (síntese de ácidos graxos), e ATGL (lipólise) e DGAT (síntese de TAG). Entre estas proteínas, encontramos que a rosiglitazona aumentou significativamente a expressão de CD36 e PEPCK, efeitos estes que foram dependentes de mTORC1. Esse aumento encontrado nos níveis de RNA mensageiro de CD36 pela rosiglitazona já foi descrito na literatura (BALLESTEROS, 2014). A CD36 é uma proteína de membrana que facilita a captação de ácidos graxos pelos adipócitos, porém sua atuação já foi descrita em outras células, como músculo cardíaco e estriado esquelético. A presença de insulina, bem como a contração muscular, estimulam a translocação do CD36 e sua consequente ativação, que é mediada pela via da AMPK/PI3K, resultando na captação de ácidos graxos (GLATZ 2017). Devido ao seu papel fundamental nas alterações do metabolismo lipídico, a CD36, atualmente também denominado SR-B2, tem sido alvo de intervenção terapêutica (LIU,2014). Na mesma direção da CD36, tivemos o mesmo efeito para a 
PEPCK, que confirmou dados anteriores do nosso grupo que mostram que a rosiglitazona aumenta PEPCK (FESTUCCIA, 2009a). Esse aumento nessa enzima da via da gliceroneogênese, é descrito como um dos efeitos importantes na melhora da sensibilidade à insulina, por reduzir a liberação de ácido graxo no tecido adiposo e limitar o estoque ectópico de lipídeos (BEAUDOIN, 2017). Logo, nosso resultado da ação da rosiglitazona sobre a CD36 e PEPCK mediada pelo complexo 1 da mTOR, pode contribuir para um melhor entendimento de seu mecanismo e regulação, favorecendo novos alvos terapêuticos.

Efeitos clássicos da rosiglitazona relacionados à melhora na homeostase glicêmica estão ligados também aos níveis de adiponectina e BCAA circulantes. Esses aminoácidos de cadeia ramificada (leucina, isoleucina e valina), diferentemente de outros aminoácidos, são metabolizados fora do fígado, principalmente no tecido adiposo. Em quadro de obesidade, os níveis circulantes de BCAA encontram-se aumentados, os quais podem ser correlacionados com a incidência de diabetes tipo 2 (FELIG 1969; RAFECAS, 1991; WIJEKOON, 2004). Em estudo publicado recentemente por nosso laboratório (BLANCHARD, 2018), em que utilizamos de camundongos com deleção específica de PPAR $\gamma$ em adipócitos, vimos que o PPAR $\gamma$ é um dos principais reguladores do catabolismo de BCAA no tecido adiposo, e a utilização de agonista de PPAR $\gamma$ reduz os níveis séricos de BCAA, por mecanismo que envolve um aumento na oxidação dos mesmos no tecido adiposo. Ainda nesse estudo, vimos que ao tratar esses animais com rosiglitazona, observamos uma melhora na sensibilidade à insulina. No presente estudo, confirmamos esse efeito da rosiglitazona sobre o metabolismo de BCAA, somente no tecido adiposo inguinal, além de mostrarmos que mTORC1 é um importante mediador dessas ações. Encontramos também nesse estudo, a relação efeito-dependente do aumento de adiponectina circulante induzido por rosiglitazona mediado por mTORC1. Dados de estudos in vivo e in vitro que propuseram investigar a relação de adiponectina e BCAA sugerem que essa adipocina interfere em enzimas cruciais para a metabolização do BCAA (BCKD), e que a ausência de adiponectina reduz significativamente a atividade dessa enzima, refletindo no aumento de BCAA circulante (LIAN,2015). Por outro lado, estudo que utilizou-se de pacientes para comparar a relação de BCAA com adiponectina e leptina, concluiu que a relação dos níveis de BCAA e diabetes podem ser independentes de disfunções no tecido adiposo (CONNELLY,2017). Em conjunto, temos que BCAA e adiponectina estão relacionados à homeostase glicêmica e que o efeito da rosiglitazona sobre ambos é mediado por 
mTORC1.

O aumento nos níveis circulantes de adiponectina promovido pelo agonista de PPAR $\gamma$ já está bem descrito na literatura, porém os mecanismos estão envolvidos nesse efeito ainda não foram completamente elucidados (ACHARI, 2017). Nossos dados mostraram que esse efeito ocorre mediado via mTORC1, e nossa hipótese é de que essa mediação ocorra por vias pós-transcricionais, haja vista que a expressão gênica de adiponectina não alterou com o tratamento de RSG, tanto no tecido adiposo inguinal, quanto no marrom. Estudo com dados contrários aos nossos, mostraram que um dos mecanismos pelo qual o PPAR $\gamma$ aumento os níveis de adiponectina seja via interação entre PPAR $\gamma$ e o promotor PPRE, responsável pela transcrição do gene da adiponectina, resultando no aumento da transcrição desse gene (IWAKI, 2003). Porém, estudos apontam que a ativação de PPAR $\gamma$ pode regular também os níveis e secreção de adiponectina, processos pós-traducionais, aumentando níveis de Dsba-L, uma chaperona que facilita a multimerização e secreção de adiponectina, além de inibir uma chaperona do retículo endoplasmático Erp44, que atua inibindo a secreção de adiponectina. (LONG, 2010; JIN, 2015). Nossos dados referentes aos níveis de mRNA de Dsba-L sugerem uma tendência de aumento no tratamento com rosiglitazona, que parece ser dependente de mTORC1, corroborando com dados da literatura. Além disso, ao observarmos isoladamente os efeitos da transcrição de adiponectina na ausência de raptor, nossos dados indicam uma importante participação na transcrição desse gene.

Outro dado interessante mostrado em nosso estudo, por meio de análise lipidômica, que pode ser relacionado à adiponectina, é o aumento nos lipídeos típicos de mitocôndria (CL e PE), indicando a mesma relação de ação dependente de mTORC1. Estudo recente com adipócitos humanos mantidos em cultura celular e tratados com rosiglitazona observaram aumento significativo no conteúdo de cardiolipina nas células (LEE,2019). A cardiolipina (CL) é essencial para a função bioenergética mi tocondrial, e a oxidação enzi mática desse lipídeo sinaliza a mitofagia. Danos nesse sistema oxidativo da cardiolipina está relacionado com remodelamento patológico mitocondrial, resultando em disfunção mitocondrial associadas à diabetes e obesidade (LI, 2010). Em um estudo que buscou investigar a relação entre biogênese mitocondrial e adiponectina foi encontrado que a função mitocondrial está ligada à síntese de adiponectina nos adipócitos, mostrando a relação da disfunção mitocondrial no tecido adiposo num quadro de obesidade, aos níveis reduzidos de adiponectina (KOH, 2007). Em conjunto, nossos dados sugerem a hipótese de que o aumento dos níveis séricos de adiponectina, 
redução de BCAA circulantes e aumento no conteúdo de cardiolipina no tecido adiposo podem estar relacionados entre si, visto que estão diretamente ligados à função mitocondrial. Experimentos adicionais são necessários para confirmar nossa hipótese.

O tratamento com rosiglitazona também promove aumento no consumo de oxigênio inclusive em animais sem a deleção genética, mostrando que tanto a rosiglitazona quanto a deleção de mTORC1 podem aumentar o metabolismo oxidativo desse tecido. Ao contrário do inguinal, ao compararmos os dados obtidos de consumo de $\mathrm{O} 2$ no tecido adiposo marrom, vemos que houve uma redução no consumo por parte dos grupos ARapKO e que a rosiglitazona não promoveu alterações relevantes nesse aspecto para o tecido. Até então podemos observar que o efeito de aumento tecidual do tecido adiposo marrom promovido pela rosiglitazona, parece não ser proporcional ao aumento em sua capacidade funcional. Ambos os dados de consumo de $\mathrm{O} 2$ obtidos em nosso estudo vão de encontro aos achados de Polak (2008), que observou aumento no consumo de $\mathrm{O} 2$ no inguinal e redução no marrom. Por outro lado, em estudo de Schieke (2006) foi observada redução na atividade mitocondrial, na síntese de ATP e consumo de O2 após deleção de raptor em células HEK. Esses achados vão contra aos nossos dados e os de Polak (2008), porém é importante observar que o estudo de Schieke (2006) foi conduzido in vitro em células de rim (HEK). Em conjunto, vemos que o mTORC1 é importante regulador da função mitocondrial. Além da análise de consumo de oxigênio, genes importantes relacionado à função mitocondrial como PGCa, UCP-1, F1F0-ATPase, NDUFB5, SDHB, MFN2 e CPT1 $\alpha$ ), e a proteína UCP-1 foram aumentados no tecido adiposo inguinal com deficiência de mTORC1. A exceção para PGC1 $\alpha$, um coativador de diversos genes envolvidos na biogênese mitocondrial, metabolismo oxidativo, além do browning (HANDSCHIN, 2006), onde vimos um aumento em sua expressão gênica nos animais ARapKO sem tratamento com rosiglitazona, que por sua vez não promoveu alterações significativas em ambos os grupos (ARapWT e ARapKO). Estudo realizado pelo nosso grupo (MAGDALON, 2016), mostrou que a ativação constitutiva de mTORC1 aumenta a expressão de PGC $\alpha$ bem como de UCP-1 no tecido adiposo. Nossos dados referentes à expressão gênica e proteica de UCP-1, além de F1F0-ATPase, NDUFB5, SDHB, MFN2 e CPT1 $\alpha$ mostraram aumento relacionados somente à deleção de mTORC1 em adipócitos, sem alterações significativas relacionadas ao uso da rosiglitazona. Assim, baseados no estudo de nosso grupo (MAGDALON, 2016), bem como os de Polak (2008) e nossos achados, vemos que a mTORC1 é importante regulador do metabolismo mitocondrial. 
Em nosso estudo não encontramos efeito significativo resultante do tratamento com rosiglitazona nas análises de expressão gênica, contrariando esse efeito já descrito na literatura (FAYYAD, 2019; MERLIN, 2018). Além disso, diferentemente de nossos dados, Lee e colaboradores (2019) mostraram recentemente que o tratamento de rosiglitazona em adipócitos humanos mantidos em cultura celular apresentaram aumento na expressão gênica de NDUFB5, SDHB e CPT1 $\alpha$, genes esses relacionados à oxidação de ácidos graxos. Em conjunto, nossos dados leva-nos novamente à hipótese de que esse efeito ocorra em vias pós-transcricionais.

A obesidade visceral está associada ao desenvolvimento da resistência à insulina e intolerância à glicose, fenótipos que podem estar associados à inflamação de baixa intensidade no tecido adiposo e outros órgãos induzida pela ingestão de uma dieta hiperlipídica (GREGOR, 2011). Em estudo conduzido em nosso laboratório (PASCHOAL,2016), verificamos que a inibição farmacológica da mTORC1, promove um aumento na inflamação do tecido adiposo e a polarização de macrófagos para fenótipo pró-inflamatório. Acompanhando essa linha de investigação acerca da mTORC1 em nosso laboratório, em outro estudo publicado pelo nosso grupo, vimos que a ativação constitutiva da mTORC1 (TSC1) em células mielóides protege os camundongos da obesidade induzida por dieta hiperlipídica, além de promover redução de inflamação do tecido adiposo e melhora na tolerância à glicose, promovendo a polarização dos macrófagos para o perfil M2, anti-inflamatório, com significativo aumento no gasto energético. (PASCHOAL,2018).

Corroborando esses achados do nosso grupo, mostramos recentemente que a deleção de mTORC1 (raptor) especificamente em adipócitos promove inflamação do tecido adiposo que envolve infiltração leucocitária tecidual, ativação da via do inflamassoma-NLRP3, com aumento no estresse oxidativo e síntese de ceramidas (CHIMIN,2017). Nosso estudo mostrou que a deleção de raptor em adipócitos aumentou a expressão gênica de enzimas envolvidas na via de síntese de ceramidas de novo, e que a inibição deste processo com miriocina reverteu a inflamação do tecido adiposo, indicando as ceramidas como importante mediadores do fenótipo inflamatório do tecido adiposo em animais com deficiência de mTORC1 em adipócitos. As ceramidas exercem importante função metabólica enquanto lipídeo bioativo, regulando processos como a proliferação celular, apoptose e inflamação. A síntese de ceramidas pode ser estimulada por diversos mecanismos que envolvem exposição a níveis elevados de ácidos graxos, citocinas pró-inflamatórias e estresse oxidativo, condições 
essas encontradas principalmente em quadro de obesidade (MORAD,2013; KANG, 2013; HANNUN,2018). Vale ressaltar, que nossos dados confirmam estudo anterior que utilizou mesmo modelo de deleção genética de raptor em adipócitos, que mostrou redução acentuada de tecido adiposo mesmo quando os animais ingeriram dieta hiperlipídica. Além disso, observaram acúmulo de lipídeos no fígado e intolerância à insulina (LEE,2016). Dados em conjunto, temos que a falta de tecido adiposo ou a lipodistrofia também estão associados a complicações metabólicas, tais como aumento de vias pró-inflamatórias, e que um desenvolvimento normal do tecido adiposo é fundamental para a homeostase metabólica.

Ainda em relação às ceramidas, nossos dados mostraram diferentes efeitos sob diferentes espécies de ceramidas. Observamos um aumento no percentual de ceramidas de cadeia longa ( $\mathrm{n}$-acil $<21$ carbonos) no grupo tratado com rosiglitazona, bem como redução de ceramidas de cadeia muito longa (n-acil > 21 carbonos), somente na presença da mTORC1, além de uma tendência semelhante nas espécies Cer (d18:2/18:0) e Cer(d18:1/18:0), sendo esse mais um efeito dependente de mTORC1. Por outro lado, observamos efeito indepentende na espécie cer(d18:1/24:2), onde o aumento foi relativo ao tratamento com rosiglitazona. O consumo de dieta hiperlipídica induz a produção de ceramidas com consequente aumento na produção de ceramidas de cadeia longa C16-C18 (CHOI, 2015). Em estudo realizado com camundongos com deleção de CerS2, uma ceramida sintase envolvida com a síntese de ceramida de cadeia muito longa, mostrou que a deleção dessa sintase reduziu a produção de ceramidas de cadeia muito longa, levando a um efeito compensatório na ativação de CerS6 que levou a um aumento de ceramidas de cadeia longa. Esse aumento nos níveis de ceramidas de cadeia longa foi associado a um prejuízo metabólico como resistência à insulina e esteatose hepática (RAICHUR,2014). Ainda nesse sentido, estudos mostraram que as ceramidas de cadeia longa estão associados a processos pró-apoptóticos e as ceramidas de cadeia muito longa parece estar associadas a efeitos benéficos (SISKIND, 2010;GROESCH, 2012). Em nosso estudo, encontramos que a rosiglitazona, de maneira dependente de mTORC1, aumentou as ceramidas de cadeia longa, tidas como prejudiciais, e reduziu as de cadeia muito longas, sugeridas como benéficas, indicando um efeito contraditório aos efeitos benéficos rosiglitazona. Estudos mais detalhados acerca das ações de 
diferentes ceramidas fazem-se necessários a fim de esclarecer as funções relacionadas ao tamanho da cadeia n-acil desses esfingolipídeos.

Esses parâmetros de melhora no metabolismo lipídico promovidos pela rosiglitazona nos levou a analisar as alterações de espécies lipídicas presentes nas amostras de tecido adiposo epididimal. A análise semi-quantitativa do lipidoma do epididimal apontou que $40 \%$ do total de lipídeos correspondem a TAG. Os TAG são formados por três moléculas de ácido graxos ligados à uma molécula de glicerol, com função principal de armazenamento energético sob a forma de gotículas lipídicas, metabolicamente dinâmicas, sofrendo alterações decorrentes dos processos de lipogênese e lipólise (ENGIN,2017). O conteúdo de TAG reduziu nos animais com deleção de mTORC1 (ARapKO) bem como nos animais tratados com rosiglitazona sem a deleção (ARapWT) em comparação com o grupo sem a utilização da droga. Conjuntamente, esses dados de TAG nos mostram que tanto a deleção de mTORC1 quanto o tratamento com rosiglitazona promoveram redução significativa de TAG no tecido, sem efeito aditivo da rosiglitazona sobre a deleção de mTORC1. Além dessa redução, observamos o aumento de diacilglicerol (DAG) na mesma proporção e grupos que observamos a redução de TAG, produto esse resultante da hidrólise de TAG. É importante salientar que o excesso de DAG pode estar relacionado ao aumento na inflamação do tecido (ENGIN,2017) e que talvez esse aumento observado poderia explicar em partes, o perfil inflamatório observado por análise do perfil de leucócitos residentes no tecido adiposo, que não sofreu alterações mediante tratamento com rosiglitazona, dados esses que contrastam com a melhora na sensibilidade à insulina resultante do tratamento com a droga, mostrando ações anti-inflamatórias distintas.

Como já descrito na literatura, o tratamento com rosiglitazona reduz adiposidade visceral (JOHNSON, 2007) que vem a refletir diretamente no conteúdo de TAG do tecido. Tratamento com rosiglitazona em ratos, mostrou que a ativação farmacológica de PPAR $\gamma$ aumenta lipólise no tecido adiposo por aumentar genes lipolíticos (ATGL e MGL) (FESTUCCIA,2006). Além disso, estudo conduzido em camundongos e células 3T3-L1 observou que o tratamento com rosiglitazona aumenta, no tecido adiposo, o conteúdo de RNA mensageiro bem como o conteúdo proteico de ATGL, relacionada à lipólise, resultando no aumento da hidrólise de TAG no tecido adiposo (LIU, 2009). Assim como a rosiglitazona, dados do estudo de Blanchard (2012) 
já citados anteriormente, mostram a importância da mTOR no metabolismo lipídico, bem como no clearance de TAG.

Importante citarmos que não abordamos nesse estudo os mecanismos pelos quais mTORC1 regula PPAR $\gamma$, sendo esse um limitante do mesmo. Porém, nossa hipótese é de que esses mecanismos podem estar ligados a fatores pós-transcricionais, haja visto que não observamos diferença nos níveis de RNA mensageiro de PPAR 1 após deleção de raptor. Entretanto, para excluirmos completamente esta hipótese precisamos também medir os níveis de RNA mensageiro de PPAR 2 , bem como o conteúdo proteico de PPAR $\gamma$. Um outro mecanismo pelo qual mTORC1 pode alterar a atividade transcricional PPAR $\gamma$ seria por meio da modulação de proteínas denominadas de correguladores que interagem e participam do efeitos transcricionais deste receptor. Estudos de imunoprecipitação de PPAR $\gamma$ estão em andamento para testar esta hipótese. 


\section{Conclusão}

Em conjunto, nossos achados indicam que ações importantes da rosiglitazona são mediadas pelo complexo 1 da mTOR, como o aumento da massa do tecido adiposo marrom, aumento nos níveis circulantes de adiponectina, redução de BCAA circulante, aumento de lipídeos mitocondriais (CL e PE), bem como aumento de expressão gênica de importantes genes relacionados ao metabolismo lipídico (CD36, PEPCK).

Por outro lado, efeitos sob a homeostase da glicose são independentes da mTORC1.

A compreensão acerca das ações de rosiglitazona efeito-dependentes de mTORC1 poderão conduzir a novos alvos terapêuticos no tratamento de doenças metabólicas, como a obesidade. 


\section{Referências}

ACHARI, Arunkumar; JAIN, Sushil. Adiponectin, a therapeutic target for obesity, diabetes, and endothelial dysfunction. International journal of molecular sciences, $v$. 18, n. 6, p. 1321, 2017.

ARNER, Erik et al. Adipocyte turnover: relevance to human adipose tissue morphology. Diabetes, v. 59, n. 1, p. 105-109, 2010

BALLESTEROS, Iván et al. Rosiglitazone-induced CD36 up-regulation resolves inflammation by PPA R $\gamma$ and 5-LO-dependent pathways. Journal of leukocyte biology, v. 95, n. 4, p. 587-598, 2014.

BAR-PELED, Liron; SABATINI, David M. Regulation of mTORC1 by amino acids. Trends in cell biology, v. 24, n. 7, p. 400-406, 2014.

BEAUDOIN, Marie-Soleil et al. Rosiglitazone is superior to resveratrol in inducing the expression of glyceroneogenic genes in adipose tissue from obese participants. Applied Physiology, Nutrition, and Metabolism, v. 43, n. 3, p. 307-311, 2017.

BELCHIOR, Thiago et al. Omega-3 fatty acids protect from diet-induced obesity, glucose intolerance, and adipose tissue inflammation through PPAR $\gamma$-dependent and PPAR $\gamma$-independent actions. Molecular nutrition \& food research, v. 59, n. 5, p. 957-967, 2015.

BERG, Anders H.; COMBS, Terry P.; SCHERER, Philipp E. ACRP30/adiponectin: an adipokine regulating glucose and lipid metabolism. Trends in Endocrinology \& Metabolism, v. 13, n. 2, p. 84-89, 2002.

BLANCHARD, Pierre-Gilles et al. Major involvement of mTOR in the PPAR $\gamma$-induced stimulation of adipose tissue lipid uptake and fat accretion. Journal of lipid research, v. 53, n. 6, p. 1117-1125, 2012.

BLANCHARD, Pierre-Gilles et al. PPAR $\gamma$ is a major regulator of branched-chain amino acid blood levels and catabolism in white and brown adipose tissues. Metabolism, v. 89, p. 27-38, 2018. 
CANNON, Barbara; NEDERGAARD, J. A. N. Brown adipose tissue: function and physiological significance. Physiological reviews, v. 84, n. 1, p. 277-359, 2004.

CAI, Huan; DONG, Lily Q.; LIU, Feng. Recent advances in adipose mTOR signaling and function: therapeutic prospects. Trends in pharmacological sciences, v. 37, n. 4, p. 303-317, 2016.

CASTELLANO, Brian M. et al. Lysosomal cholesterol activates mTORC1 via an SLC38A9-Niemann-Pick C1 signaling complex. Science, v. 355, n. 6331, p. 1306$1311,2017$.

CHOI, Songhwa; SNIDER, Ashley J. Sphingolipids in high fat diet and obesity-related diseases. Mediators of inflammation, v. 2015, 2015.

CHIMIN, Patricia et al. Adipocyte mTORC1 deficiency promotes adipose tissue inflammation and NLRP3 inflammasome activation via oxidative stress and de novo ceramide synthesis. Journal of lipid research, v. 58, n. 9, p. 1797-1807, 2017.

CONNELLY, Margery A.; WOLAK-DINSMORE, Justyna; DULLAART, Robin PF. Branched chain amino acids are associated with insulin resistance independent of leptin and adiponectin in subjects with varying degrees of glucose tolerance. Metabolic syndrome and related disorders, v. 15, n. 4, p. 183-186, 2017.

DE VOS, Piet et al. Thiazolidinediones repress ob gene expression in rodents via activation of peroxisome proliferator-activated receptor gamma. The Journal of clinical investigation, v. 98, n. 4, p. 1004-1009, 1996.

DESPRÉS, Jean-Pierre; LEMIEUX, Isabelle. Abdominal obesity and metabolic syndrome. Nature, v. 444, n. 7121, p. 881-887, 2006.

EFEYAN, Alejo; SABATINI, David M. Nutrients and growth factors in mTORC1 activation. Biochemical Society Transactions, v. 41, n. 4, p. 902-905, 2013.

ENGIN, Ayse Basak. What is lipotoxicity?. In: Obesity and Lipotoxicity. Springer, Cham, 2017. p. 197-220. 
EVANS, Ronald M.; BARISH, Grant D.; WANG, Yong-Xu. PPARs and the complex journey to obesity. Nature medicine, v. 10, n. 4, p. 355, 2004.

FAYYAD, Abeer Maher et al. Rosiglitazone Enhances Browning Adipocytes in Association with MAPK and PI3-K Pathways During the Differentiation of Telomerase-Transformed Mesenchymal Stromal Cells into Adipocytes. International journal of molecular sciences, v. 20, n. 7, p. e1618, 2019.

FELIG, Philip et al. Plasma amino acid levels and insulin secretion in obesity. New England Journal of Medicine, v. 281, n. 15, p. 811-816, 1969.

FESTUCCIA, W. T. et al. PPAR $\gamma$ agonism increases rat adipose tissue lipolysis, expression of glyceride lipases, and the response of lipolysis to hormonal control. Diabetologia, v. 49, n. 10, p. 2427-2436, 2006.

FESTUCCIA, William T. et al. Peroxisome proliferator-activated receptor- $\gamma$-mediated positive energy balance in the rat is associated with reduced sympathetic drive to adipose tissues and thyroid status. Endocrinology, v. 149, n. 5, p. 2121-2130, 2008.

FESTUCCIA, William. T; DESHAIES, Yves. Depot specificities of PPARg ligand actions on lipid and glucose metabolism and their implication in PPARg-mediated body fat redistribution. Clinical Lipidology, v. 4, n. 5, p. 633-642, 2009a.

FESTUCCIA, William. T. et al. Depot-specific effects of the PPAR $\gamma$ agonist rosiglitazone on adipose tissue glucose uptake and metabolism. Journal of lipid research, v. 50, n. 6, p. 1185-1194, 2009b.

FESTUCCIA, William $\mathrm{T}$. et al. Basal adrenergic tone is required for maximal stimulation of rat brown adipose tissue UCP1 expression by chronic PPAR- $\gamma$ activation. American Journal of Physiology-Regulatory, Integrative and Comparative Physiology, v. 299, n. 1, p. R159-R167, 2010

FONSECA-ALANIZ, Miriam H. et al. O tecido adiposo como centro regulador do metabolismo. Arq. bras. endocrinol. metab, v. 50, n. 2, p. 216-229, 2006. 
GESTA, Stephane et al. Evidence for a role of developmental genes in the origin of obesity and body fat distribution. Proceedings of the National Academy of Sciences, v. 103, n. 17, p. 6676-6681, 2006.

GLATZ, Jan FC; LUIKEN, Joost JFP. From fat to FAT (CD36/SR-B2): understanding the regulation of cellular fatty acid uptake. Biochimie, v. 136, p. 21-26, 2017.

GILARDI, Federica et al. Systemic PPAR $\gamma$ deletion in mice provokes lipoatrophy, organomegaly, severe type 2 diabetes and metabolic inflexibility. Metabolism, v. 95, p. 8-20, 2019.

GRAY, S. L.; DALLA NORA, E.; VIDAL-PUIG, A. J. Mouse models of PPAR- $\gamma$ deficiency: dissecting PPAR- $\gamma$ 's role in metabolic homoeostasis. Biochemical Society Transactions, v 33, 2005.

GREGOR, Margaret F.; HOTAMISLIGIL, Gökhan S. Inflammatory mechanisms in obesity. Annual review of immunology, v. 29, p. 415-445, 2011.

GROESCH, Sabine; SCHIFFMANN, Susanne; GEISSLINGER, Gerd. Chain lengthspecific properties of ceramides. Progress in lipid research, v. 51, n. 1, p. 50-62, 2012.

GUPTA, Prachi et al. Efficacy and risk profile of anti-diabetic therapies: Conventional vs traditional drugs-A mechanistic revisit to understand their mode of action. Pharmacological research, v. 113, p. 636-674, 2016.

HACZEYNI, F.; BELL-ANDERSON, K. S.; FARRELL, G. C. Causes and mechanisms of adipocyte enlargement and adipose expansion. Obesity reviews, v. 19, n. 3, p. 406-420, 2018.

HANDSCHIN, Christoph; SPIEGELMAN, Bruce M. Peroxisome proliferator-activated receptor $\gamma$ coactivator 1 coactivators, energy homeostasis, and metabolism. Endocrine reviews, v. 27, n. 7, p. 728-735, 2006.

HANNUN, Yusuf A.; OBEID, Lina M. Sphingolipids and their metabolism in physiology and disease. Nature reviews Molecular cell biology, v. 19, n. 3, p. 175, 
HE, Weimin et al. Adipose-specific peroxisome proliferator-activated receptor $\gamma$ knockout causes insulin resistance in fat and liver but not in muscle. Proceedings of the National Academy of Sciences, v. 100, n. 26, p. 15712-15717, 2003.

HOUDE, Vanessa P. et al. Chronic rapamycin treatment causes glucose intolerance and hyperlipidemia by upregulating hepatic gluconeogenesis and impairing lipid deposition in adipose tissue. Diabetes, v. 59, n. 6, p. 1338-1348, 2010.

HUDAK, Carolyn S.; SUL, Hei Sook. Pref-1, a gatekeeper of adipogenesis. Frontiers in endocrinology, v. 4, p. 79, 2013.

IMAI, Takeshi et al. Peroxisome proliferator-activated receptor $\gamma$ is required in mature white and brown adipocytes for their survival in the mouse. Proceedings of the National Academy of Sciences, v. 101, n. 13, p. 4543-4547, 2004

IWAKI, Masanori et al. Induction of adiponectin, a fat-derived antidiabetic and antiatherogenic factor, by nuclear receptors. Diabetes, v. 52, n. 7, p. 1655-1663, 2003.

JIN, Dan et al. Peroxisome proliferator-activated receptor $\gamma$ enhances adiponectin secretion via up-regulating DsbA-L expression. Molecular and cellular endocrinology, v. 411, p. 97-104, 2015

JOHNSON, Julia A. et al. Prolonged decrease of adipocyte size after rosiglitazone treatment in high-and low-fat-fed rats. O besity, v. 15, n. 11, p. 2653-2663, 2007.

KANG, Se-Chan et al. Sphingolipid metabolism and obesity-induced inflammation. Frontiers in endocrinology, v. 4, p. 67, 2013.

KIM, Jae Eun; CHEN, Jie. Regulation of peroxisome proliferator-activated receptor- $\gamma$ activity by mammalian target of rapamycin and amino acids in adipogenesis. Diabetes, v. 53, n. 11, p. 2748-2756, 2004.

$\mathrm{KOH}$, Eun Hee et al. Essential role of mitochondrial function in adiponectin synthesis in adipocytes. Diabetes, v. 56, n. 12, p. 2973-2981, 2007.

LAMMING, Dudley W. et al. Depletion of Rictor, an essential protein component of $\mathrm{m}$ TORC 2, decreases male lifespan. Aging cell, v. 13, n. 5, p. 911-917, 2014. 
LAPLANTE, Mathieu; SABATINI, David M. An emerging role of mTOR in lipid biosynthesis. Current biology, v. 19, n. 22, p. R1046-R1052, 2009.

LAPLANTE, Mathieu et al. PPAR- $\gamma$ Activation Mediates Adipose Depot- Specific Effects on Gene Expression and Lipoprotein Lipase Activity: Mechanisms for Modulation of Postprandial Lipemia and Differential Adipose Accretion. Diabetes, v. 52, n. 2, p. 291-299, 2003.

LAPLANTE, Mathieu et al. Mechanisms of the depot specificity of peroxisome proliferator-activated receptor $\gamma$ action on adipose tissue metabolism. Diabetes, v. 55, n. 10, p. 2771-2778, 2006.

LAPLANTE, Mathieu et al. DEPTOR cell-autonomously promotes adipogenesis, and its expression is associated with obesity. Cell metabolism, v. 16, n. 2, p. 202-212, 2012.

LARSEN, T. M.; TOUBRO, S.; ASTRUP, A. PPARgamma agonists in the treatment of type II diabetes: is increased fatness commensurate with long-term efficacy? International journal of obesity, v. 27, n. 2, p. 147, 2003.

LE BACQUER, Olivier et al. Elevated sensitivity to diet-induced obesity and insulin resistance in mice lacking 4E-BP1 and 4E-BP2. The Journal of clinical investigation, v. 117, n. 2 , p. 387-396, 2007.

LEE, Peter L. et al. Raptor/mTORC1 loss in adipocytes causes progressive lipodystrophy and fatty liver disease. Molecular metabolism, v. 5, n. 6, p. 422-432, 2016.

LEE, Peter L.; JUNG, Su Myung; GUERTIN, David A. The complex roles of mechanistic target of rapamycin in adipocytes and beyond. Trends in Endocrinology \& Metabolism, v. 28, n. 5, p. 319-339, 2017.

LEE, Mi-Jeong et al. Rosiglitazone remodels the lipid droplets and britens human visceral and subcutaneous adipocytes ex vivo. Journal of lipid research, p. jlr. M091173, 2019. 
LI, Qiuyue et al. Role of mTOR signaling in the regulation of high glucose-induced podocyte injury. Experimental and therapeutic medicine, v. 17, n. 4, p. 2495-2502, 2019

LI, Jia et al. Cardiolipin remodeling by ALCAT1 links oxidative stress and mitochondrial dysfunction to obesity. Cell metabolism, v. 12, n. 2, p. 154-165, 2010.

LIAN, Kun et al. Impaired adiponectin signaling contributes to disturbed catabolism of branched-chain amino acids in diabetic mice. Diabetes, v. 64, n. 1, p. 49-59, 2015.

LIU, L.-F. et al. Regulation of adipose triglyceride lipase by rosiglitazone. Diabetes, Obesity and Metabolism, v. 11, n. 2, p. 131-142, 2009

LIU, Weiwei et al. OxLDL-induced IL-1beta secretion promoting foam cells formation was mainly via CD36 mediated ROS production leading to NLRP3 inflammasome activation. Inflammation Research, v. 63, n. 1, p. 33-43, 2014.

LONG, Qinqiang et al. Peroxisome proliferator-activated receptor- $\gamma$ increases adiponectin secretion via transcriptional repression of endoplasmic reticulum chaperone protein ERp44. Endocrinology, v. 151, n. 7, p. 3195-3203, 2010.

LUNDGREN, Magdalena et al. Fat cell enlargement is an independent marker of insulin resistance and _hyperleptinaemia‘. Diabetologia, v. 50, n. 3, p. 625-633, 2007.

MAGDALON, Juliana et al. Constitutive adipocyte mTORC1 activation enhances mitochondrial activity and reduces visceral adiposity in mice. Biochimica et Biophysica Acta (BBA)-Molecular and Cell Biology of Lipids, v. 1861, n. 5, p. 430438, 2016.

MAGDALON, Juliana; FESTUCCIA, William Tadeu. Regulation of adiposity by mTORC1. Einstein (São Paulo), v. 15, n. 4, p. 507-511, 2017.

MATYASH, Vitali et al. Lipid extraction by methyl-tert-butyl ether for high-through put lipidomics. Journal of lipid research, v. 49, n. 5, p. 1137-1146, 2008.

MERLIN, Jon et al. The PPAR $\gamma$ agonist rosiglitazone promotes the induction of brite adipocytes, increasing $\beta$-adrenoceptor-mediated mitochondrial function and glucose uptake. Cellular signalling, v. 42, p. 54-66, 2018. 
MIYAZAKI, Yoshinori et al. Effect of pioglitazone on abdominal fat distribution and insulin sensitivity in type 2 diabetic patients. The Journal of Clinical Endocrinology \& Metabolism, v. 87, n. 6, p. 2784-2791, 2002.

MORAD, Samy AF; CABOT, Myles C. Ceramide-orchestrated signalling in cancer cells. Nature Reviews Cancer, v. 13, n. 1, p. 51, 2013.

OHNO, Haruya et al. PPAR $\gamma$ agonists induce a white-to-brown fat conversion through stabilization of PRDM16 protein. Cell metabolism, v. 15, n. 3, p. 395-404, 2012.

PARADIES, Giuseppe et al. Functional role of cardiolipin in mitochondrial bioenergetics. Biochimica et Biophysica Acta (BBA)-Bioenergetics, v. 1837, n. 4, p. 408-417, 2014.

PASCHOAL, Vivian A. et al. mTORC1 inhibition with rapamycin exacerbates adipose tissue inflammation in obese mice and dissociates macrophage phenotype from function. Immunobiology, v. 222, n. 2, p. 261-271, 2017.

PASCHOAL, Vivian A. et al. Constitutive Activation of the Nutrient Sensor mTORC1 in Myeloid Cells Induced by Tsc1 Deletion Protects Mice from Diet-Induced Obesity. Molecular nutrition \& food research, v. 62, n. 17, p. 1800283,2018

PETROVIC, Natasa et al. Thermogenically competent nonadrenergic recruitment in brown preadipocytes by a PPAR $\gamma$ agonist. American journal of physiologyendocrinology and metabolism, v. 295, n. 2, p. E287-E296, 2008.

POLAK, Pazit et al. Adipose-specific knockout of raptor results in lean mice with enhanced mitochondrial respiration. Cell metabolism, v. 8, n. 5, p. 399-410, 2008.

RAFECAS, I. et al. Plasma amino acids of lean and obese Zucker rats subjected to a cafeteria diet after weaning. Biochemistry international, v. 25, n. 5, p. 797-806, 1991.

RAICHUR, Suryaprakash et al. CerS2 haploinsufficiency inhibits $\beta$-oxidation and confers susceptibility to diet-induced steatohepatitis and insulin resistance. Cell metabolism, v. 20, n. 4, p. 687-695, 2014. 
RICQUIER, Daniel. Uncoupling protein 1 of brown adipocytes, the only uncoupler: a historical perspective. Frontiers in endocrinology, v. 2, p. 85, 2011.

ROSEN, Evan D.; MACDOUGALD, Ormond A. Adipocyte differentiation from the inside out. Nature reviews Molecular cell biology, v. 7, n. 12, p. 885, 2006.

SANCAK, Yasemin et al. Ragulator-Rag complex targets mTORC1 to the lysosomal surface and is necessary for its activation by amino acids. Cell, v. 141, n. 2, p. 290-303, 2010.

SARANTOPOULOS, Christos N. et al. Elucidating the preadipocyte and its role in adipocyte formation: a comprehensive review. Stem Cell Reviews and Reports, v. 14, n. 1, p. 27-42, 2018.

SAXTON, Robert A.; SABATINI, David M. mTOR signaling in growth, metabolism, and disease. Cell, v. 168, n. 6, p. 960-976, 2017.

SEMPLE, Robert K.; CHATTERJEE, V. Krishna K.; O`RAHILLY, Stephen. PPAR $\gamma$ and human metabolic disease. The Journal of clinical investigation, v. 116, n. 3, p. 581-589, 2006.

SCHIEKE, Stefan M. et al. The mammalian target of rapamycin (mTOR) pathway regulates mitochondrial oxygen consumption and oxidative capacity. Journal of Biological Chemistry, v. 281, n. 37, p. 27643-27652, 2006.

SHAN, Tizhong et al. Adipocyte-specific deletion of mTOR inhibits adipose tissue development and causes insulin resistance in mice. Diabetologia, v. 59, n. 9, p. 19952004, 2016.

SHEN, Kuang; CHOE, Abigail; SABATINI, David M. Intersubunit crosstalk in the Rag GTPase heterodimer enables mTORC1 to respond rapidly to amino acid availability. Molecular cell, v. 68, n. 3, p. 552-565. e8, 2017.

SHEN, Kuang et al. Architecture of the human GATOR1 and GATOR1-Rag GTPases complexes. Nature, v. 556, n. 7699, p. 64, 2018. 
SHEN, Kuang et al. Arg-78 of Nprl2 catalyzes GATOR1-stimulated GTP hydrolysis by the Rag GTPases. Journal of Biological Chemistry, v. 294, n. 8, p. 2970-2975, 2019.

SKURK, Thomas et al. Relationship between adipocyte size and adipokine expression and secretion. The Journal of Clinical Endocrinology \& Metabolism, v. 92, n. 3, p. 1023-1033, 2007.

SPIEGELMAN, Tontonoz P. Fat and beyond: the diverse biology of PPARgamma. Annual Review of Biochemistry, v. 77, p. 289-312, 2008.

SPONTON, Carlos Henrique; KAJIMURA, Shingo. Multifaceted roles of beige fat in energy homeostasis beyond UCP1. Endocrinology, v. 159, n. 7, p. 2545-2553, 2018.

SISKIND, Leah J. et al. The BCL-2 protein BAK is required for long-chain ceramide generation during apoptosis. Journal of Biological Che mistry, v. 285, n. 16, p. 11818 11826, 2010.

UM, Sung Hee et al. Absence of S6K1 protects against age-and diet-induced obesity while enhancing insulin sensitivity. Nature, v. 431, n. 7005, p. 200-205, 2004.

WIJEKOON, Enoka P. et al. Amino acid metabolism in the Zucker diabetic fatty rat: effects of insulin resistance and of type 2 diabetes. Canadian journal of physiology and pharmacology, v. 82, n. 7, p. 506-514, 2004.

WILSON-FRITCH, Leanne et al. Mitochondrial biogenesis and remodeling during adipogenesis and in response to the insulin sensitizer rosiglitazone. Molecular and cellular biology, v. 23, n. 3, p. 1085-1094, 2003.

WONG, G. William et al. Molecular, biochemical and functional characterizations of C1q/TNF family members: adipose-tissue-selective expression patterns, regulation by PPAR- $\gamma$ agonist, cysteine-mediated oligomerizations, combinatorial associations and metabolic functions. Biochemical Journal, v. 416, n. 2, p. 161-177, 2008.

World heatlhy Organization. Obesity and overweight. Disponível em: <https://www.who.int/en/news-room/fact-sheets/detail/obesity-and-overweight $>$ acesso em: 24 de abril de 2019, 17:29:00. 
WU, Jun et al. Beige adipocytes are a distinct type of thermogenic fat cell in mouse and human. Cell, v. 150, n. 2, p. 366-376, 2012.

YANG, X.; SMITH, U. Adipose tissue distribution and risk of metabolic disease: does thiazolidinedione-induced adipose tissue redistribution provide a clue to the answer? Diabetologia, v. 50, n. 6, p. 1127-1139, 2007.

ZHANG, Hui H. et al. Insulin stimulates adipogenesis through the Akt-TSC2-mTORC1 $\begin{array}{llllllll}\text { pathway. } & \text { PloS one, v. 4, n. } & \text {, } & \text { p. } 609 .\end{array}$ 
ANEXO 1 


\title{
Adipocyte mTORC1 deficiency promotes adipose tissue inflammation and NLRP3 inflammasome activation via oxidative stress and de novo ceramide synthesiss
}

\author{
Patricia Chimin, ${ }^{1}{ }_{*}, \dagger$ Maynara L. Andrade, ${ }^{1}{ }^{*}$ Thiago Belchior,* Vivian A. Paschoal,* Juliana \\ Magdalon,* Alex S. Yamashita,* Érique Castro,* Angela Castoldi, ${ }^{\$}$ Adriano B. Chaves-Filho,** \\ Marcos Y. Yoshinaga,** Sayuri Miyamoto, ${ }^{* *}$ Niels O. Câmara, ${ }^{\S}$ and William T. Festuccia ${ }^{2}{ }^{*}$ \\ Departments of Physiology and Biophysics* and Immunology, ${ }^{\S}$ Institute of Biomedical Sciences, and \\ Department of Biochemistry, ${ }^{* *}$ Institute of Chemistry, University of Sao Paulo, Sao Paulo, Brazil \\ 05508000; and Department of Physical Education, ${ }^{\dagger}$ Physical Education and Sports Center, Londrina State \\ University, Parana, Brazil 86051-990
}

\begin{abstract}
Mechanistic target of rapamycin complex (mTORC)1 activity is increased in adipose tissue of obese insulin-resistant mice, but its role in the regulation of tissue inflammation is unknown. Herein, we investigated the effects of adipocyte mTORC1 deficiency on adipose tissue inflamma-tion and glucose homeostasis. For this, mice with adipocyte raptor deletion and controls fed a chow or a high-fat diet were evaluated for body mass, adiposity, glucose homeostasis, and adipose tissue inflammation. Despite reducing adiposity, adipocyte mTORC1 deficiency promoted hepatic steatosis, insu-lin resistance, and adipose tissue inflammation (increased infiltration of macrophages, neutrophils, and B lymphocytes; crown-like structure density; TNF- , interleukin (IL)-6, and monocyte chemoattractant protein 1 expression; IL-1 protein content; lipid peroxidation; and de novo ceramide synthe-sis). The anti-oxidant, $N$-acetylcysteine, partially attenuated, whereas treatment with de novo ceramide synthesis inhibitor, myriocin, completely blocked adipose tissue inflammation and nucle otide oligomerization domain-like receptor pyrin domaincontaining 3 (NLRP3)-inflammasome activation, but not hepatic steatosis and insulin resistance induced by adipo-cyte raptor deletion. Rosiglitazone treatment, howe ver, com-pletely abrogated insulin resistance induced by adipocyte raptor deletion. Ifr In conclusion, adipocyte mTORC1 defi-ciency induces adipose tissue inflammation and NLRP3inflammasome activation by promoting oxidative stress and de novo ceramide synthesis. Such adipose tissue inflammation, however, is not an underlying cause of the insulin resis-tance displayed by these mice.-Chimin, P., M. L. Andrade,

T. Belchior, V. A. Paschoal, J. Magdalon, A. S. Yamashita,

É. Castro, A. Castoldi, A. B. Chaves-Filho, M. Y. Yoshinaga,
\end{abstract}

This work was supported by Fundação de Amparo à Pesquisa do Estado de São Paulo Grants 09/15354-7, 10/52191-6, and 15/19530-5 (to W.T.F) and 12/02270-2 (to N.O.C.) and Conselho Nacional de Desenvolvimento Científico $e$ Tecnológico Grants 454226/2014-4 (to P.C.) and 443492/2014-0 (to W.T.F.). Additional support was provided by Fundacão de Amparo à Pesquisa do Estado de São Paulo Fellowships 12/25317-4 and 15/13508-8 (to P.C. and M.L.A., respectively). The authors do not have any potential conflicts of interest relevant to this article.

Manuscript received 22 December 2016 and in revised form 13 June 2017.

Published, JLR Papers in Press, July 5, 2017

DOI https://doi.org/10.1194/jlr.M074518
S. Miyamoto, N. O. Câmara, and W. T. Festuccia. Adipocyte mTORC1 deficiency promotes adipose tissue inflammation and NLRP3 inflammasome activation via oxidative stress and de novo ce ramide synthes is. J. Lipid Res. 2017.58: 1797-1807.

Supplementary key words mechanistic target of rapamycin complex $1 \cdot$ nucleotide oligomerization domain-like receptor pyrin domaincontaining $3 \cdot$ insulin resistance

Chronic low-intensity inflammation is an important link-ing factor between visceral obesity and associated metabolic complications such as insulin resistance (1). Mechanistically, obesity-associated inflammation is triggered through the activation of the canonical toll-like receptor (TLR)4-I B kinase (IKK)-nuclear factor kappa-light-chain-enhancer of activated

Abbreviations: ASC/PyCARD, apoptosis-associated speck-like protein containing a CARD; CASP1, caspase 1; CAT, catalase; CLS, crownlike structure; DEPTOR, DEP domain containing mechanistic target of rapamycin-interacting protein; DUSP6, dual specificity phosphatase 6; FACS, fluorescence-activated cell sorting; G6Pase, glucose 6phosphatase; GPx, glutathione peroxidase; GTT, glucose tolerance test; HFD, high-fat diet; IKK, I B kinase; IL, interleukin; ITT, insulin tolerance test; LPS, lipopolysaccharide; MCP, monocyte chemoattractant protein; MDA, malondialdehyde; mTOR, mechanistic target of rapamycin; mTORC, mechanistic target of rapamycin complex; MYR, myriocin; NAC, $\mathrm{N}$-acetylcysteine; NF B, nuclear factor kappa-light-chain-enhancer of activated B cells; NLRP3, nucleotide oligomerization domain-like receptor pyrin domain-containing 3; PEPCK, phosphoenolpyruvate car-

boxykinase; PI3K, phosphoinositide 3 kinase; PyCARD, PYD and CARD domain containing; RapKO, raptor ${ }^{\text {Lox Lox }}$ adiponectin - -re $^{+/}$mice; RicKO, rictor Lx Lox $_{\text {adiponectin-Gre }}^{+/}$mice; RapWT, raptor ${ }^{\text {Lox Lox }}$ adiponectin-cre
mice; RicKO, rictor ${ }_{\text {Lox Lox }}^{\text {adiponectin-cre }}$ mice; RicWT, rictor adiponectin-cre '; ROS, reactive oxygen species;

RSG, rosiglitazone; S6, p70 ribosomal S6 kinase; SCD1, stearoylCoA de-saturase 1; SMPD, SM phosphodiesterase; SOD, superoxide dismutase; SPTLC, serine palmitoyltransferase long chain base; TLR, toll-like recep-tor; UCP1, uncoupling protein 1.

P. Chimin and M. L. Andrade contributed equally to this work.

2 To whom correspondence should be addressed.

e-mail: william.festuccia@gmail.com

S The online version of this article (available at http://www.jl.org)

contains a supplement. 